University of San Diego

Digital USD

2016

\title{
An Exploration of the Use of Photovoice-Inspired Techniques to Facilitate Narrative Leadership in a Small Group of Middle-Aged Women
}

Michelle M. Zive

University of San Diego

Follow this and additional works at: https://digital.sandiego.edu/dissertations

Part of the Leadership Studies Commons, Organizational Behavior and Theory Commons, and the Women's Studies Commons

\section{Digital USD Citation}

Zive, Michelle M., "An Exploration of the Use of Photovoice-Inspired Techniques to Facilitate Narrative Leadership in a Small Group of Middle-Aged Women" (2016). Dissertations. 67.

https://digital.sandiego.edu/dissertations/67

This Dissertation: Open Access is brought to you for free and open access by the Theses and Dissertations at Digital USD. It has been accepted for inclusion in Dissertations by an authorized administrator of Digital USD. For more information, please contact digital@sandiego.edu. 
AN EXPLORATION OF THE USE OF PHOTOVOICE-INSPIRED TECHNIQUES TO FACILITATE NARRATIVE LEADERSHIP IN A SMALL GROUP OF MIDDLE-AGED WOMEN

\author{
DISSERTATION
}

MICHELLE M. ZIVE

School of Leadership and Education Sciences

University of San Diego

November 30, 2016

Dissertation Committee

Robert Donmoyer, Ph.D.

Mary B. McDonald, Ph.D.

Helen Eckmann, Ph.D. 



\section{UNIVERSITY OF SAN DIEGO \\ SCHOOL OF LEADERSHIP AND EDUCATION SCIENCES}

CANDIDATE'S NAME: Michelle M. Zive

TITLE OF

DISSERTATION:
An Exploration of The Use of Photovoice-Inspired Techniques to Facilitate Narrative Leadership in a Small Group of Middle-Aged Women

APPROVAL:

\begin{tabular}{ll}
\hline Rohert Donnover.dhDll & Chair \\
\hline Mark. B. MKDodhald, $\mathrm{PhD}$ & \\
\hline felen Eckmann, $\mathrm{PhD}$ & \\
\hline
\end{tabular}

DATE: $\quad$ November 30, 2016 


\begin{abstract}
Leadership often is defined as a persuasive relationship. Over the last two decades, narrative leadership has been viewed in the Leadership Studies literature as a source of persuasion. Narrative leaders use stories to impact others in both large-scale political and social movements, as well as in large-scale organizations. Even as this has been happening, the field also has begun to re-conceptualize leadership as a group rather than an individual process, a view of leadership sometimes characterized as shared leadership. There is limited understanding of whether narrative leadership operates in shared leadership situations and a dearth of literature about specific techniques or strategies that foster narrative leadership in small groups.
\end{abstract}

The photovoice strategy encourages group members to take photographs and, then, to use the photographs to prompt storytelling and critical discussion. The purpose of the study was to examine whether photovoice techniques could foster narrative leadership, as well as the conditions the literature indicates are needed for shared leadership to occur within a small group of middle-aged women.

Five women (ages 42-55), plus the researcher who functioned as a participantobserver, took part in three photovoice sessions. Data from videotapes of the sessions, as well as interview and survey data generated before, after, and throughout the process, were analyzed. Analysis techniques included Polkinghorne's narrative-analysis and analysis-of-narrative strategies.

Evidence suggests photovoice techniques changed the thinking of all participants, often in major ways, and, consequently, narrative leadership occurred. The two facilitators also changed their thinking substantially as a result of being involved with the 
group. Though it was nearly impossible to assess whether shared leadership occurred, due to the fact that there was nothing to accomplish other than individual and group learning, the evidence did document that the three conditions the literature suggests are pre-requisites for shared leadership to occur were generated by the photovoice process. The study is significant for a number of reasons, not the least of which is that it documents the utility of using photovoice in small group settings to promote narrative leadership. The study also suggests that photovoice can create conditions considered prerequisites for shared leadership to occur. 
To David, Molly, Kelly, and Jack,

This is for you, this is because of you.

ONWARD! 


\section{Foreword}

As a novelist and memoirist (as well someone with the Irish affinity for storytelling), I have always loved to write, tell, and listen to a great story. This passion is one of the reasons I applied to the Leadership Studies doctoral program at the University of San Diego's School of Leadership and Education Sciences (SOLES). Indeed, over the last four years, I have focused my leadership studies at SOLES on trying to understand the power of narrative in relation to leadership. My education has taken me through a journey of trying to first understand the history of storytelling and, then, its importance for leadership. While taking on the second task, I discovered the concept of narrative leadership.

The narrative leaders described in Gardner and Laskin's (2011), Leading Minds: An Anatomy of Leadership, leaders such as Eleanor Roosevelt, Martin Luther King, Jr., and Margaret Thatcher, were extraordinary, and they were extraordinary, in large part, because of the stories they told and the stories exemplified in the lives they lived. I also quickly concluded that many successful leaders in business-leaders like Cheryl Sandberg, Richard Branson, and Steve Jobs - were narrative leaders. In short, over the past four years I learned if leadership is defined as an influence relationship - a common definition these days - storytelling by and about the heads of large corporations, social movements, and even countries could be a potent source of influence.

Yet, I wondered about the rest of us average people who do not lead social movements, nations, or huge corporations. What about the middle-aged women, like myself, women who, the literature suggests, often feel invisible and voiceless. How can 
they tell their stories? Can they even aspire to exercise narrative leadership occasionally and on a modest scale?

I wondered about other things, as well. I had always been drawn to teamwork and collaboration as a way of transforming small groups, entire organizations, and myself. Consequently, I wondered if storytelling and narrative leadership could be used by members of a group to persuade each other and, perhaps, co-create a collective narrative. To state this question another way: could the concept of narrative leadership be expanded beyond something that individuals undertake in the growing interest of shared leadership, at least in small group settings?

The idea of exploring narrative leadership through storytelling within a nonhierarchical, small group of middle-aged women seemed to be the right intersections of my personal and professional lives, and of theory and practice. Those intersections are the focus of the study that is being proposed here. 


\section{Table of Contents}

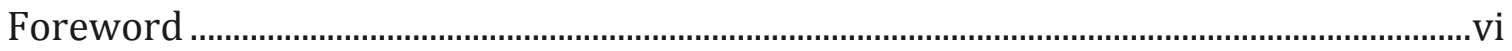

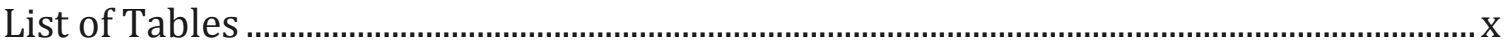

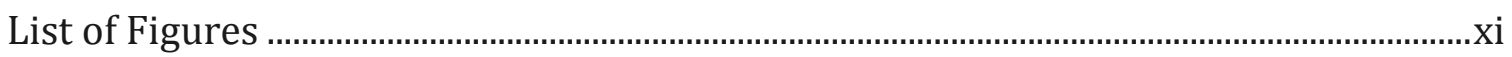

Chapter 1: Introduction, Background, and Statement of Problem ...................................... 1

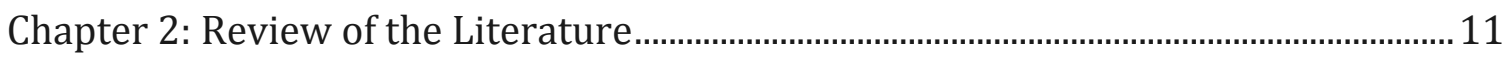

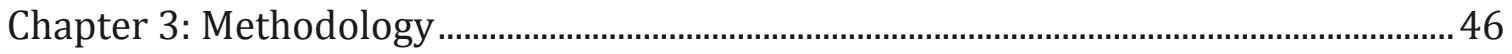

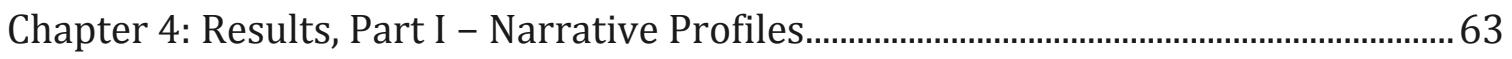

Chapter 5: Results, Part II - Sessions............................................................................ 110

Chapter 6: Results, Part III - Post-Intervention Interviews ......................................... 195

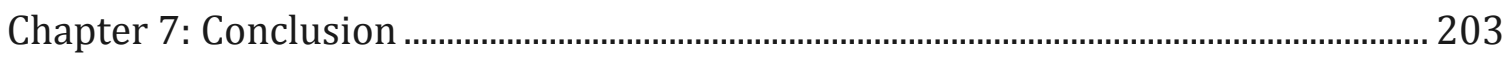

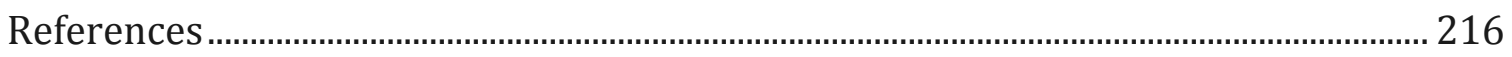

Appendix A: Examples of Timelines............................................................................. 224

Appendix B: Photovoice Sessions Outline ................................................................... 226

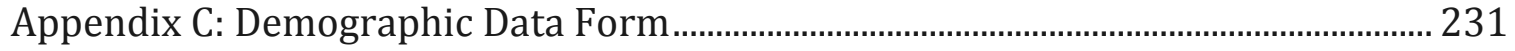

Appendix D: Questions Following Each Photovoice Session........................................ 234

Appendix E: Post-Intervention Interview Questions............................................................ 236

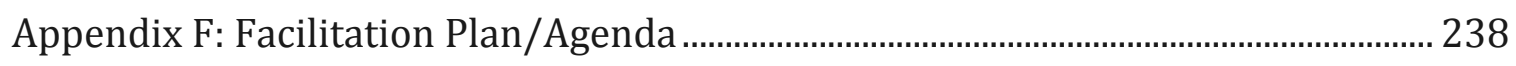




\section{List of Tables}

Table 4.1 Name, Title, and Description of Women Participants

Table 5.1 What worked during Session 1?

Table 5.2 What did not work during Session 1?

Table 5.3 What were the takeaways or what resonated from Session 1?

Table 5.4 What worked during Session 2?

Table 5.5 What did not work during Session 2?

Table 5.6

What were the takeaways or what resonated from Session 2?

Table 6.1

Question: What resonated with you after participating in the project?

Table 6.2

Question: What did you learn about yourself and from the other women as a result of participating in the project?

Table 6.3

Question: What surprised you?

Table 6.4

Question: What happened to you and the other women after participating in this project? 


\section{List of Figures}

Figure 1. In a Train (Cartier-Bresson, 1975)

Figure 2. Rosa's Collage (Rosa, 2016)

Figure 3. Lynne's Collage (Lynne, 2016)

Figure 4. Trixie's Collage (Trixie, 2016)

Figure 5. Meryl's College (Meryl, 2016)

Figure 6. Michelle's Collage (Michelle, 2016)

Figure 7. PrinceFan69's Collage (PrinceFan69, 2016)

Figure 8. $\quad$ Lighten Up (Schreiber, 2014)

Figure 9. Curl (Schreiber, 2014)

Figure 10. As If (Schreiber, 2014)

Figure 11. Rear View (Schreiber, 2014)

Figure 12. Ms. Rose Defies the Odds (Webb, 2014)

Figure 13. Deer Woman (Hughes, 2005)

Figure 14. Emmett, Jessie, and Virginia (Mann, 1992)

Figure 15. Candy Cigarette (Mann, 1992)

Figure 16. Universe (Rosa, 2016)

Figure 17. Being Cool (Rosa, 2016)

Figure 18. $\quad$ Middle-Aged Woman Missing (Michelle, 2016)

Figure 19. Dyeing to Be Young (Michelle, 2016)

Figure 20. $\quad$ Connected (Meryl, 2016)

Figure 21. Life of the Party (Meryl, 2016)

Figure 22. $\quad$ What We See, What We Don't See (PrinceFan69, 2016) 
(List of Figures, cont.)

Figure 23. $\quad$ Middle-Aged Women Walking (PrinceFan69, 2016)

Figure 24. Wild Ride (Lynne, 2016)

Figure 25. Climb the Highest Mountain (Lynne, 2016)

Figure 26. Contemplation (Trixie, 2016)

Figure 27. Juggling Life at a Nexus (Trixie, 2016)

Figure 28. $\quad$ You Are Loved (Trixie, 2016)

Figure 29. Just the Three of Us (Trixie, 2016)

Figure 30. Hero (Meryl, 2016)

Figure 31. $\quad$ At the End of the Day (Meryl, 2016)

Figure 32. $\quad$ Take Me Out to the Ballgame (Lynne, 2016)

Figure 33. We Are Blessed (Lynne, 2016)

Figure 34. What Lies Beneath (PrinceFan69, 2016)

Figure 35. Dancing Queen, Circa 1992 (PrinceFan69, 2016)

Figure 36. Letting Go (Rosa, 2016)

Figure 37. Father's Day (Rosa, 2016)

Figure 38. $\quad$ Peace (Michelle, 2016)

Figure 39. Before and After (Michelle, 2016)

Figure 40. $\quad$ Meryl's Timeline (Meryl, 2016)

Figure 41. Trixie's Timeline (Trixie, 2016) 


\section{Chapter 1: Introduction, Background, and Statement of Problem Introduction and Background}

Humans have been telling stories for tens of thousands of years. The disciplines of evolutionary psychology, neuroscience, and cognitive psychology all support the proposition that language, in general, and storytelling, in particular, evolved as a way to adapt and, ultimately, survive as a species (Darwin, 1859; Dennett, 1991; Gardner \& Laskin, 2011; McBride, 2014). Indeed, storytelling has numerous functions related to survival of the human species including: 1) promoting cooperation among individuals in groups (Boyd, 2009); 2) developing social norms and shared beliefs (prerequisites for establishing social institutions) (Tomasello, Carpenter, Call, Behne, \& Moll, 2005); 3) transmitting culture to subsequent generations (Gardner \& Laskin, 2011; Tomasello et al., 2005); and 4) enhancing high-level cognitive communication which improved humans cooperation and sociality (Tomasello, 2009; Yang, 2013). In short, academic literature reminds us we are storytelling animals with a long history of following the leader who told stories that inspired change in the thoughts, behaviors, and actions of followers. In fact, over the last two decades, the link between storytelling, on the one hand, and leadership, on the other, has received a great deal of attention, especially among scholars and practitioners who define leadership as an influence relationship.

Gardner and Laskin (2011), for example, focused their book, Leading Minds: An Anatomy of Leadership, on the phenomenon of narrative leadership. They defined narrative leaders as "persons who, by word and/or personal example, markedly influence the behaviors, thoughts, and/or feelings of a significant number of their fellow human beings" (p.8). For instance, according to Gardner and Laskin's account, cultural 
anthropologist Margaret Mead used her ethnographies, speeches, and other written works to directly influence the way other anthropologists thought about culture. Additionally, Mead encouraged her colleagues to think differently about how they approached their own studies and presented their writing. She suggested scholars did not have to present findings with the "usual technical language of scholarship with jargon, footnotes, and an overt theoretical framework" (Gardner \& Laskin, 2011, p.69) but she promoted a more literary approach to research reporting. For instance, Mead (1928/2001) wrote in Coming of Age in Samoa:

The life of the day begins at dawn, or if the moon has shown until daylight, the shouts of the young men may be heard before dawn from the hillside. Uneasy in the night, populous with ghosts, they shout lustily to one another as they hasten with their work (p.11).

In short, Mead encouraged her contemporaries to show data and conclusions in plain and accessible (and even in somewhat literary) English. This accessibility translated to the general public where her speech making and writing influenced the views of others throughout the world on such topics as childhood, family life, and society.

Gardner and Laskin (2011) also studied ten other narrative leaders: J. Robert Oppenheimer, Robert Maynard Hutchins, Alfred P. Sloan, Jr., George C. Marshall, Pope John XXIII, Eleanor Roosevelt, Martin Luther King, Jr., Margaret Thatcher, Jean Monnet, and Mahatma Gandhi. Like a number of other scholars who have written about leadership (e.g., Bass, 1996; Bass \& Riggio, 2006; Burns, 1978; Yukl, 2011), Gardner and Laskin defined leadership as an influence relationship, and they demonstrated the eleven leaders they studied influenced others, in large part, by the stories they told. In 
addition, Gardner and Laskin (2011) suggested it was not only the stories these narrative leaders told that impacted people but also these leaders embodiment or exemplification of their narratives through the lives they led. In the case of Margaret Mead, for example, Gardner and Laskin indicated the personal characteristics of the messenger embodied, and, consequently, reinforced the stories the messenger told:

This zestful, energetic and (mostly) sensible American woman could journey around the globe, make keen observations, and share them directly and unsentimentally with other people. Her childhood, her fieldwork, her friends, her travels, her own child, and her own grandchild were all resources on which she could and did draw as she sought to communicate with the spectrum of human beings. Indeed, many of her recommendations emerged from her own life-how to raise children, how to deal with conflict, and so on. And because her life was in many respects representative of the times, such recommendations found responsive ears, particularly among middle-class readers and television viewers (Gardner \& Laskin, 2011, p.78).

According to Google Scholar, Gardner and Laskin's (2011) work on narrative leadership has been cited in more than 1500 articles, which speaks to their contribution to understanding the importance of narrative leaders to large social and political movements. There is, also, other literature that concentrates on the concept of narrative leadership in settings such as business (Danzig, 1999; Fisch, 2014), public service (Ospina \& Dodge, 2005), education administration (Gardiner, Howard, Tenuto, \& Muzaliwa, 2014), and the third sector (Macmillan \& McLaren, 2012). While most of this literature does not emphasize the need for narrative leaders to embody and live the stories 
they tell, this literature is similar to Gardner and Laskin's (2011) book in that it conceptualizes a narrative leader as, more often than not, a single person who influences others. In addition, much of the literature on narrative leadership equates leaders with those who hold positional power in organizations. Consequentially, talk of narrative leadership often perpetuates the dominate discourse that assumes the need for $a$ leader to lead a movement, an organization, or a group of followers.

\section{Statement of the Problem}

An emerging focus on shared leadership. Recently, there has been movement away from equating leadership with the actions of a single individual with formal positional power over others (i.e., followers) (Bryman, Stephens, \& Campo, 1996; Spillane, Halverson, \& Diamond, 1999; Senge, 1997; Yukl, 1999). As organizations, societies, and the world have become more complex, interdependent, and interconnected, at least some leadership research and theories have begun to conceptualize leadership as a process that is more collaborative in nature. In this literature, leadership is a shared activity (Boje, 2006; Burns \& Stalker, 1994; Lawrence \& Lorsch, 1986; Wang, Walman, \& Zhang, 2014). The emerging leadership models conceptualize leadership in terms of a "living systems of relationships" and "practices embedded in a system of interdependencies" (Fletcher \& Kaufer, 2003, p. 21). This vision of leadership emphasizes influence relationships that get played out through interpersonal interactions.

Fletcher and Kaufer (2003) support this paradigm shift from focusing on the characteristics of individual leaders (including the sort of narrative leaders discussed in the majority of the narrative leadership literature) toward a view of leadership practice that emphasizes group-level processes. They characterize the new leadership paradigm 
as shared leadership and contend there are at least three characteristics of the shared leadership model: (a) leadership is distributed and interdependent; (b) leadership is embedded in social interaction; and, (c) leadership is attained through mutual learning.

Bergman, Rentsch, Small, Davenport, and Bergman (2012) have also written about shared leadership. These authors indicated that shared leadership is occurring "when two or more members engage in leadership of the team in an effort to influence and direct fellow members to maximize team effectiveness" (Bergman et al., 2012, p. 18). Both Bergman and coauthors' and Fletcher and Kaufer's (2003) conceptions of shared leadership define leadership as an influence relationship, much as Gardner and Laskin (2011) do in their discussion of narrative leadership. However, rather than associating the concept of leadership with the actions of $a$ leader who influences others, those who have articulated the notion of shared leadership view leadership as a "multidirectional, dynamic, simultaneous, and on-going, and... [as being] characterized by the 'serial emergence' of two or more [group] members as leaders" (Bergman et al., 2012, p. 18).

Three paradoxes. Both the development of shared leadership practices and the empirical study of these practices have been inhibited by three paradoxes or contradictions. The first paradox is that leaders in hierarchal organizations, i.e., so-called "hero CEOs," often are required to create the sorts of flatter, more adaptable organizations in which shared leadership can flourish (Bartunek, Walsh, \& Lacey, 2000; Senge, 1996).

The second paradox focuses on the conflict between leadership rhetoric at the macro and micro levels of an organization. Fletcher and Kaufer (2003), for example, write, 
[Although at the macro level the rhetoric about leadership focuses on teamwork, collaboration, and collective learning, the everyday narratives about leadership and leadership practices — the stories people tell about leadership, the mythical legends that get passed on as exemplars of leadership behavior-often remain stuck in old images of heroic individualism. (p.25)

The third paradox emphasizes that while some organizations espouse the virtues of shared leadership and collaboration, most jobs and careers still emphasize individual achievement (Hall, 2004). Who moves up the corporate ladder and advances in an organization generally has more to do with an individual's accomplishments rather than her or his contributions to a group's accomplishments.

The three paradoxes briefly outlined above often prevent shared leadership from being enacted in organizations, even in organizations that embrace group-centric rhetoric. It should not be surprising, therefore, that it also has been exceedingly difficult to study shared leadership empirically. Consequently, we have virtually no images of what shared leadership looks like even in actual organizations and that the literature does not provide detailed discussions of specific methods that can be used to promote shared leadership. Both these statements apply even to small group situations.

Despite the absence of systematic empirical work on shared leadership, it seems logical that storytelling can play a role in situations in which leadership is (a) distributed and interdependent; (b) embedded in social interaction; and, (c) attained through mutual learning. To date, however, there is no systematically gathered empirical evidence about how to establish a link, or even whether a link exists, between narrative leadership and shared leadership. Consequently, there is a need to explore the relationship between 
narrative and shared leadership and, more specifically, whether specific strategies and techniques oriented toward developing narrative leadership also can function to promote some semblance of shared leadership.

\section{Purpose of the Study/Research Questions}

The purpose of the study is to examine whether a photovoice-inspired technique can be used to promote narrative leadership (i.e., influencing others through the telling of stories) within a small group of middle-aged women. The study explored whether any narrative leadership that was enacted within the group appeared to contribute to the exercise of what the literature calls shared leadership.

Photovoice is based on the principles of participatory action research. In this particular version of participatory action research, group members use photographs and other visual representations of reality (such as collages) to reflect on their concerns and passions related to their community or environment (Simmonds, Roux, \& ter Avest, 2015; Wang \& Burris, 1997). These reflections and the stories generated during the reflection process are shared with other group participants. This sharing is meant to inspire the sort of critical dialogue that transforms the individual storyteller, the collective, and, eventually, the larger community or society (Wang \& Burris, 1997). Another aspect to most photovoice projects is that the critical dialogue is used to develop recommendations to present to key stakeholders in order to advocate for changes. Since this advocacy piece was beyond the scope of the present study, the decision was made to refer to the study as photovoice-inspired. As has already been noted, the photovoiceinspired technique will be used in this study to explore its potential to promote both narrative leadership (i.e., influencing others through storytelling) and shared leadership 
(i.e., leadership that is (a) distributed and interdependent, (b) embedded in social interaction, and (c) attained through mutual learning). The exploration will occur with a small group of women established for the study.

The choice of a group of women in which the study will be undertaken is not accidental. During the early days of the feminist movement, for example, some women participated in small consciousness-raising groups to discuss and share stories about gender-based experiences. This sort of storytelling led some participants to change their view of the world and, also, to social and political activity and change (Tennov, 1973), and there is evidence the women who participated in these groups found the experience both positive and powerful in raising awareness of what it was like to be a women in the late 60 s and early $70 \mathrm{~s}$, and affirming group participants' identities as women (Kravetz, Marecek, \& Finn, 1983; Rosenthal, 1984). Further, it seems axiomatic the women in the consciousness-raising groups influenced the thinking (and often the behavior and actions) of other group members through dialogue and the sharing of stories. Therefore, women's consciousness-raising groups could be seen both as settings in which narrative leadership could be — and, presumably, has been—realized and as venues in which shared leadership through storytelling could be studied.

Of course, women's consciousness-raising groups are less common today than they were during the women's liberation movement. There is a certain irony in this decline, however, because now, more than ever, there are competing narratives about what it is like to be a woman in contemporary society. Therefore, the idea for this study is to bring a group of middle-aged women together, within a context reminiscent of the consciousness-raising groups of the $60 \mathrm{~s}$ and $70 \mathrm{~s}$, to share images and accompanying 
stories. It is presumed this setting could mean opportunities for growth and development — and for exercising narrative leadership — which could be enhanced when different people tell different stories, in this case, stories about the role of gender in middle-aged woman's lives. In summary, this exploration of using a photovoice-inspired technique as a vehicle for promoting narrative leadership, and perhaps shared leadership, was conducted with a contemporary group of middle-aged women who started the group process by viewing gender issues from a variety of perspectives. The study was guided by the following overarching research questions:

1. What evidence, if any, supported or refuted claims that the storytelling engendered by the use of photovoice techniques influenced the thinking, behavior, and/or actions of group members; in other words, was there evidence that photovoice facilitated the exercise of narrative leadership by the individual group members?

2. Did narrative leadership appear to contribute to the development of group characteristics associated with the concept of shared leadership?

\section{Summary of Chapter 1}

While there have been discussions of narrative leadership being exercised by individuals who led nations or large-scale social movements, or by "hero CEO leaders" with positional power in institutional settings such as business, public administration, education, and the third sector, there is a lack of literature about how narrative leadership is enacted in the context of small groups or other types of flat organizations where, in principle, at least, shared leadership gets practiced. It appears as if the leaderless groups that were part of the feminist movement in the 1960s and 70s may have been venues in 
which both narrative leadership and shared leadership, in principle, at least, could have flourished. This study attempted to create a reasonable facsimile of the women consciousness groups of the past and used it to explore the possible contributions of photovoice techniques for promoting narrative and, possibly, also, shared leadership. 


\section{Chapter 2: Review of the Literature}

\section{Introduction}

Chapter 2 includes a review of the relevant literature for the proposed photovoiceinspired study. The purpose of the study is to examine whether a specific photovoiceinspired technique could be used to facilitate the effective implementation of narrative leadership (i.e., influencing others through the telling of stories) within a small group of middle-aged women. In addition, the proposed study will explore whether any narrative leadership that gets enacted through this photovoice strategy facilitates the development of the characteristics that are associated with shared leadership. Therefore, the three bodies of literature reviewed here relate to: 1) the evolution and functions of storytelling; 2) narrative leadership and shared leadership; and, 3) photovoice methodology.

\section{The Evolution and Functions of Storytelling}

The first section of this review focuses on literature about storytelling. More specifically, the goal of this section is to describe and synthesize the literature on (a) the development of storytelling over human evolution, and (b) the functions of stories. Finally, this section links what the literature says about storytelling to the notion of narrative leadership.

Evolution of storytelling. Humans have been telling stories for tens of thousands of years. For example, in The Storytelling Animal: How Stories Make Us Human, Gottschall (2012) wrote,

Tens of thousands of years ago, when the human mind was young and our numbers were few, we were telling one another stories. And now, tens of thousands of years later, when our species teems across the globe, most of us still 
hew strongly to myths about the origins of things, and we still thrill to an astonishing multitude of fictions on pages, on stages, and on screens...We are, as species, addicted to story. Even when the body goes to sleep, the mind stays up all night, telling itself stories. (p. xiii-xiv)

Indeed, the sciences and disciplines of evolution, evolution psychology, neurosciences, and cognitive psychology all point to how humans developed language and storytelling as a way to adapt and, ultimately, survive as a species. Ideas about the development of storytelling found in the literature, ultimately, are based on Darwin's Theory of Evolution, which claims we evolved from simple organisms to more complex creatures over time based on natural selection (Darwin, 1859/2013). Natural selection is the process of random genetic mutations within an organism's genetic code. According to Darwin's theory, beneficial mutations are preserved because they aid in survival and ensure the propagation of the species.

Shackelford and Liddle (2014) postulated that only the process of natural selection could explain the complex design features of the brain. In other words, because of the variety of the human brain's functions, and "the fact that adaptations result from recurrent and specific problems of survival and reproduction, evolutionary psychology posits that our brains consist of a multitude of domain-specific adaptations, each of which solves a unique adaptive problem" (Shackelford \& Liddle, 2014, p. 251). Further, this framework supports the interaction between genetic adaptations and the environment.

Pantomiming was used to communicate amongst our ancestors as way to adapt to and survive in the environment, and preceded language and stories (McBride, 2014). In short, communication was initially these gestures, sounds, facial expressions, and 
imitation (i.e., pantomiming), and developed out of the continual need for family bands to cooperate for survival and reproduction. Indeed, the literature proposes that before language developed stories were pantomimed as an extension of the semantic content of gestures used by apes to communicate (Corballis, 2003; Tomasello, 2009, 2014). Further, the evolution of storytelling through pantomiming was also the origin of storytelling's role in creating shared understanding and intentionality within a group.

McBride (2014) postulated that for our ancestors to evolve from pantomiming to language and storytelling there had to be excursions away from the group to look for food. For instance, when women returned to camp after foraging for the best berries and kill small rodents, they pantomimed stories about the location of the best berries and the nests of small rodents. However, these full-bodied gestures, sounds, and facial expressions took effort and time, so evolving language made communicating stories easier and faster. In addition, verbal stories could be more readily used to train children in the gathering and killing of food, which ultimately led to more food for the family band and an increased likelihood of the survival of the group. According to McBride (2014), "stories were the culmination of natural selection's great search to produce experienced adults without huge waste" (p. 5) of valuable resources.

Goodenough (1990) hypothesized that human language, like other outcomes of the Darwinian two-step, allowed humans to accomplish three things central to survival. First, human language "allowed a more complex, detailed, and accurate representation of the world" (Peters, 1997, p. 478). As previously mentioned, language allowed our ancestors to stop using inefficient and inaccurate gestures, such as pantomimes, and start using language to tell stories in order to adapt to the environment. Stories, such as "there 
is food to hunt beyond this mountain," "run now," or "the river bend twenty steps away is where the best fish are" were used to ensure the family band would survive. Second, language allowed for "human communication," which contributed to cooperation among bands of humans. Goodenough (1990) went further by proposing this communication was the main reason for the natural selection of language. Finally, once language was developed it provided "an information system that becomes part of the experience of each developing human brain, encoding that brain with understandings and values of the current culture" (Peters, 1997, p.478).

The literature regarding the evolution of storytelling, and the human brain, suggests a journey from self-replicating organisms with the primary, non-conscious interest of surviving and self-replicating to, ultimately, the ability of humans to consciously tell stories. Further, the literature suggests the evolution of both language and the nervous system culminated in storytelling being important for the survival of humans (Dennett, 1991; Goodenough, 1990; Peters, 1997). For instance, the ability to use language to communicate efficiently and effectively on topics of food, protection, and reproduction was essential for group members to work together for the survival of the group. In other words, storytelling, and the resulting cooperation, meant communities were able to address, adapt, and survive more complex situations. As human beings evolved in societies, and as a result these societies developed, the stories became more complex. Peters (1997) said stories and scenarios began to be "spun about our human place in the overall scheme of things, goals for human fulfillment, and ways of attaining fulfillment" (Peters, 1997, p. 478). The literature suggests these stories and scenarios became the basis of culture, communities, and institutions. This underscores the 
importance of storytelling, and potentially narrative leadership, to influence others within a cultural context, community, and institutions.

Functions of storytelling. The previous section focused on the evolution of storytelling, and the link between storytelling's development and the simultaneous advancement of the human brain. This synergistic evolution from simple to a more complex mind meant individuals, communities, societies, and institutions also became more complex. Again, as storytelling moved beyond communicating about how to kill large animals for the family band and what plants should be avoided because they were poisonous, we also progressed from understanding the evolution of the brain and storytelling toward the interdisciplinary study of the mind. When the cognitive science lens is used, we begin to understand how information is represented, processed, and transformed into stories. We then appreciate how scholars have suggested storytelling has led to culture, community, and institutions such as the origin of religion and religious institutions. The following section investigates the literature on the functions of storytelling including: cooperation, communication, and culture, as well as other functions important to narrative leadership. Understanding the important ways stories and storytelling can influence people's thoughts, behaviors, and actions can help us appreciate how stories are used by effective narrative leaders.

Cooperation. As previously stated, storytelling is a natural selected trait for how humans have adapted and survived in a complex environment. Further, sharing stories with the family band meant the beginning of cooperation and sociality of humans (Boyd, 2009). In other words, this sociality, or the tendency to which individuals associate together, was the beginning of formalized groups, communities, and societies. 
While evolution has helped explain how storytelling led to cooperation, and this sociality led to the development of societies through natural selection, Darwin and others could not explain in a biological context how cooperation and altruism trumped selfishness (i.e., survival of the fittest) (Darwin, 1859). In the insect world, for instance, ants and bees have a generous queen who reproduces all offspring while the workers are sterile; yet, this altruism does not translate to humans. There is no survival or reproduction guarantee when a selfless a person draws attention to him/herself when fighting off a predator for the good of the group any more than there are any such guarantees for a selfish person who chooses to leave the group behind in order to protect him/herself. In a strict Darwinian proposition, over generations the selflessness or selfishness genes would overtake and dominate within the population. Instead, biologists propose selfish genes have not dominated the human race because of naïve group selectionism, meaning "individuals could easily evolve to act for the good of their group or their species" (Boyd, 2009, p.52).

The human paradox of group selectionism, one in which Darwin understood but could not explain with his strict genetic accounting, was addressed by other biologists as well as evolutionary psychologists. All struggled to find theories, such as Hamilton's inclusive fitness theory, Dawkins' selfish gene theory, and John Maynard Smith's evolutionary game theory, to explain group selectionism (Hamilton, 1964; Dawkins, 2006; Smith, 1982). However, these scholars and others have come to understand the need for a multilevel selection theory which at its core means selfishness - getting a benefit without paying a full share of the cost—pays in the short term, but in the long run "cooperation can yield more, enabling a group to achieve more than the sum of what its 
members can achieve individually, whether that be building hives or dams, for bees or beavers, or hunting large prey, for hyenas or humans, and thereby to outcompete other groups" (Boyd, 2009, p.52). Tomasello and others (2005) agreed saying it is "shared intentionality," or the cooperation of humans to participate with others in shared activities with mutual goals and intentions, which is the critical difference between human cognition and other species.

Evolutionary psychologists propose storytelling developed as an important way to motivate cooperation, and this shared intentionality (Boyd, 2009). In addition, stories arose as a result of the intense need for social monitoring within groups. People have a strong interest in "social information, whether in the form of gossip —indirect but real and relevant social information-or fiction---admittedly invented and heightened version of the behaviors we naturally monitor" (Boyd, 2009, p. 64). In fact, the egalitarianism of the modern hunter-gatherer groups were preserved by gossip, such as sharing stories of those pursuing status and by cautionary tales warning against violating group norms which promoted equality (Boehm, 2000). For instance, religion is infused with stories "with unseen agents who can monitor our behavior and administer punishment or reward" (Boyd, 2009, p.64). The literature suggests these religious narratives are a powerful approach to motivating and socially monitoring cooperative behavior. Stories, both fiction and nonfiction, can strengthen, consolidate, and communicate norms, Boyd (2009) said:

$[\mathrm{P}]$ roviding us with memorable and shared models of cooperation that stir our social emotions, our desire to associate with altruists (like Dr. Seuss's Horton), 
and our desire to disassociate from cheats and freeloaders (like the suitors whom the Odyssey repudiates and Odysseus routs). (p.64)

These stories of pro- and anti-social characters and their actions, which are shared and identifiable across societies, can define and communicate shared standards, and ensure everyone in the group has the same understanding of these stories and standards, and the value of shared intentionality.

This section presented literature on the acknowledged benefits of cooperation and shared intentionality, as well as how cooperation impacted the survival of small groups and led to the establishment of entire societies with shared cultures.

Communication. As previously mentioned, human cooperative communication evolved originally from gesturing and pantomiming, then from shared intentionality, social monitoring, and cooperation (Tomasello, 2009). Consequently, the research suggests our distant ancestors were likely confronted with "strong selection pressure for verbal communication out of an inborn need for social grooming and social affiliation" (Yang, 2013, p. 142). Yet, despite the research and our evolutionary history suggesting we are storytelling animals, the rational world paradigm has been the modus operandi in understanding human communication since the days of Aristotle, the first to argue that science, facts, and logic should be used to discuss and debate a decision. Thus, the rational world paradigm is a scientific or philosophical tactic where facts and evidence are used to defend a hypothesis and has been the reigning paradigm for over 2000 years, especially in research, academia, and by many professionals.

In 1984, Walter Fisher proposed a theory of communication called the narrative paradigm as an alternative to the rational world paradigm. Fisher said, "Many different 
root metaphors have been put forth to represent the essential nature of human beings: homo faber, homo economous, homo politicus, homo sociologicus, 'psychological man,' 'ecclesiastical man,' homo sapiens, and of course, rational man. I now propose homo narrans to be added to the list" (Fisher, 1984, p. 7). Fisher supported the narrative paradigm by proposing that all meaningful communication is the linking of events (i.e., narrative). Further, decisions are made based on whether a story resonates with our values and beliefs. Fisher (1984) said, "Humans as rhetorical beings are as much valuing as they are reasoning animals and in the conception of good reasons as those elements that provide warrants for accepting or adhering to the advice fostered by any form of communication that can be considered rhetorical"' (p. 1).

Fisher did not discount the rational world paradigm, instead he suggested, "In truth, however, the narrative paradigm, like other paradigms in the human sciences, does not so much deny what has gone before it [rational world paradigm] as it subsumes it" (Fisher, 1984, p. 3). He suggested the rational world paradigm could be seen as one way to tell the story "of how persons reason together in certain settings" (Fisher, 1984, p. 3). To better understand the narrative paradigm we need to understand the rational world framework. Fisher (1984) wrote:

[T]he rational world paradigm presupposes that: (1) humans are essentially rational beings; (2) the paradigmatic mode of human decision-making and communication is argument-clear-cut inferential (implicative) structures; (3) the conduct of argument ruled by the dictates of situations-legal, scientific, legislative, public, and so on; (4) rationality is determined by subject matter knowledge, argumentative ability and skill in employing the rules of advocacy in 
given fields; and, (5) the world is a set of logical puzzles which can be resolved through appropriate analysis and application of reason conceived as an argumentative construct. (p.4)

Fisher maintained in order for rational and logical arguments to be effective in swaying others they must take the narrative form, which is the basis of narrative leadership. Like the rational world paradigm, the narrative paradigm has presuppositions including:

1. We are storytellers;

2. The primary way we make decisions and communicate is by using "good reasons" which vary depending on the situation;

3. Good reasons are influenced by our particular culture, history, biography, and character;

4. Our reasoning, or good/moral reasons, is based on what constitutes a coherent story, narrative probability and the fidelity of the story, or the rationality of a story; and,

5. The world is a set of stories from which we choose.

Fisher claimed using formal logic, expertise, and facts - the way people argue when using the rational world paradigm—requires specialized training and cognizance. However, people are taught from infancy how to evaluate the world using narrative. In essence, through stories we are able to communicate across cultures, genders, ethnicities, socio-economic status, and ideologies. Fisher (1984) says this is because narratives are universally intelligible and "the operative principle of narrative rationality is identification rather than deliberation" (p.9). 
Related to Fisher's narrative paradigm is Bormann's symbolic convergence theory of communication (Bormann, 1985). This theory posits "the appearance of a group consciousness, with its implied shared emotions, motives, and meanings, not in terms of individual daydreams and scripts but rather in terms of socially shared narrations or fantasies" (Bormann, 1985, p. 128). Symbolic convergence is considered a general social theory of communication in which theories "deal with tendencies in human communication events that cannot be ignored or rescinded by the participants" (Bormann, 1985, p. 129), and transcend historical boundaries and are trans-cultural. These general theories are equivalent to natural science theories that explain expansive classes of events. Therefore, the symbolic convergence communication theory is a general theory because it explains the development and use of distinct communication theories, in this case communicative theories related to homo narrans (i.e., storytelling animals).

Symbolic convergence theory is comprised of three parts. First is the "discovery and arrangement of recurring communicative forms and patterns that indicate the evolution and presence of a shared group consciousness" (Bormann, 1985, p. 129). The second part consists of an explanation of the "dynamic tendencies within communication systems that explain why group consciousnesses arise, continue, decline, and disappear and the effects such group consciousnesses have in terms of meanings, motives, and communication within the group" (Bormann, 1985, p. 129). In other words, the fundamental communicative process is the dynamic of individuals sharing group fantasies. The final part of the theory consists of the reasons why and when people share the fantasies they do. Within the context of the symbolic convergence theory, Bormann (1985) defines fantasy as "the creative and imaginative shared interpretation of events 
that fulfills a group psychological or rhetorical need" (p.130). Rhetorical fantasies result when a group of people share creative and imagined stories to account for their experiences, hopes and fears. These fantasies are sometimes fictions full of imaginary characters; however, more often, they are narratives that have been actually experienced by members of the group and are recounted in works of history, in the news media, or in other groups' and communities' folklore (Bormann, 1985). When the shared group fantasies generate a merging of appropriate feelings amongst the group members, then the fundamental communicative dynamic of the theory has been realized (Bormann, 1985). For example, when an audience of a play or movie feels empathy for a leading character, this emotional investment leads to involvement in the story (i.e., the plot). This shared fantasy of experientially sharing the same emotions, fostering shared heroes and villains, celebrating particular actions as commendable, and understanding some part of their collective experience in the same way is referred to as "symbolic convergence" (Bormann, 1985).

Bormann (1985) claimed that symbolic convergence occurred in a group when a number of the people have shared a group consciousness. Bormann (1985) theorized "the result of sharing dramatizing messages is a group fantasy; the content of the dramatizing message that sparks the chain of reactions and feelings is called a fantasy theme" (Bormann, 1985, p. 131). When a group of people shares a collection of fantasy themes and types, then the participants may integrate them into a "coherent rhetorical vision of some aspect of their social reality" (Bormann, 1985, p. 133). Rhetorical visions, which are frequently integrated by the sharing of fantasy themes and types (i.e., dramatizing message containing a master analogy), are normally chronicled by a key word, slogan, or 
label. Examples include "the Cold War," "the Tea Party," and "One Day at A Time" (Ford, 1989). In essence, symbolic convergence theory "creates a symbolic climate and culture that allows people to achieve empathic communion as well as 'meeting of the minds"” (Bormann, 1985, p.134).

Like Fisher's narrative paradigm, the symbolic convergence theory accounts for human communication related to homo narrans. Ultimately, symbolic convergence theory presumes we are social storytellers who have the ability to share fantasies, and to ultimately create group consciousness and build social realities.

Social evolution and cultural transmission. As mentioned before, historically the assumption was the evolution of the brain was driven by the need to survive and reproduce as a species, for humans to solve ecological and survival problems. For instance, there is research supporting brain sizes of prey and their predators simultaneously increased across the Paleogene and Neogene periods, with increases in the prey's brain being later followed by increases in the predator's brain size (Jerison, 1973). This information assumes human beings intellectual abilities are directly related with the production and use of tools. However, Byrne and Whiten (1997) suggested primates differed from non-primates essentially in the complexity of social skills instead of their survival skills. This suggestion generated a new way of thinking about the social brain and traditional ecological/technological hypotheses. The question was no longer whether or not ecology influenced behavior, but instead "whether ecological/survival problems are solved explicitly by individuals acting on their own or by individuals effecting social (e.g., cooperative) solutions to these problems" (Dunbar, 2003, p.164). The social brain hypothesis has been tested by correlating appropriate indices of social 
complexity and suitable indices of brain volume, principally the neocortex which is responsible for higher functions such as sensory perception, conscious thought, and language, and is the most recently evolved part of the brain.

There is evidence advanced social cognition is crucial to the emergence of culture (Gardner \& Laskin, 2011; Tomasello et al., 2005). In other words, human cooperative communication, or human social cognition, was only possible "when our distant ancestors had developed a system of shared meaning and values for the community" (Yang, 2013, p. 143), which then led to culture. Stories, in addition to other symbolic mechanisms such as rituals, appear to be essential as "cultural vehicles" for sharing and communicating those values, concepts, and practices which enhanced the chance of survival of the group (Yang, 2013). It appears storytelling enactments within a community were important to the survival and endurance of cultural values and norms.

In summary, the literature supports that language, storytelling, and culture were naturally selected for the survival of humans (Dunbar, 2003; McBride, 2014; Peters, 1997). McBride (2014) further noted "that elementary learned and selected 'cultures' evolved first within and created primitive animal societies, were later enhanced enormously within family life, especially in troops, and exploded with storytelling" (p. 7). In fact, the first important human culture to develop was a highly functioning experiential culture because of the gains made through storytelling, flourishing as a result of moving away from miming and pantomiming toward the use of language. McBride (2014) posited culture evolved and expanded because of the ability of groups of humans to transmit learned information through storytelling and teaching. 


\section{Narrative Leadership and Shared Leadership}

While there are many definitions of leadership, for this study leadership is defined in the context of an influence relationship. Many scholars have defined leadership using this construct (e.g., Bass, 1996; Bass \& Riggio, 2006; Burns, 1978; Hollander, 1978; Yukl, 2011). For instance, Hollander (1978), a distinguished professor in psychology, said, "Leadership is a process of influence between a leader and those who are followers" (p.1). Narrative leadership has also been regarded as an influence relationship in large part by the stories told by a leader to influence the thoughts, behaviors, and actions of others. Examples in the narrative leadership scholarship include those narrative leaders who have effectively told and, according to Gardner and Laskin (2011), embodied innovative and visionary stories that influenced many others to participate in large national social and political movements, such as Margaret Mead, J. Robert Oppenheimer, and Mahatma Gandhi. Other scholars have studied narrative leadership in organizational settings such as business (Danzig, 1999; Fisch, 2014), public service (Ospina \& Dodge, 2005), education administration (Gardiner et al., 2014), and the third sector (Macmillan $\&$ McLaren, 2012). The narrative leadership in the organizational, management, and business literature is summarized by leadership researcher Stodgill (1950) stating, "Leadership may be considered as the process (act) of influencing the activities of an organized group in its efforts toward goal setting and goal achievement" (p 3).

The literature suggests that regardless of whether the narrative leader leads social/political movements or organizations, they have an important factor in common: narrative leadership is usually enacted by a single leader with some kind of informal or formal authority who uses stories to influence others (i.e., followers). This focus of an 
individual leader to motivate people to cooperate with each other to accomplish goals, objectives, and great things (Kouzes \& Posner, 2007) has been the focus of leadership studies for the latter part of the twentieth century (Bass, 2008). Yet, as organizations, societies, and the world have become more complex, interdependent, and globalized, leadership research and theories have turned away from those leadership models focusing on individual leaders. Rather, there is interest in studying other leadership theories and models that are more collaborative in nature, (Boje, 2006; Burns \& Stalker, 1994; Lawrence \& Lorsch, 1986; Wang, Waldman, \& Zhang, 2014), such as shared leadership.

Shared leadership is defined as occurring "when two or more members engage in leadership of the team in an effort to influence and direct fellow members to maximize team effectiveness" (Bergman et al., 2012, p. 18). As with other definitions of leadership, particularly narrative leadership, there is an element of influence when implementing shared leadership. However, rather than being a leader who influences others, shared leadership, as in narrative leadership, is "multidirectional, dynamic, simultaneous, and on-going, and it is characterized by the 'serial emergence' of two or more members as leaders" (Bergman et al., 2012, p. 18).

The following section focuses on: 1) narrative leadership literature including linking the literature on the evolution of storytelling and the functions of stories to narrative leadership; 2) shared leadership and its potential relationship with storytelling and narrative leadership; and, 3) the gaps in the literature which address the opportunities for the proposed study.

Narrative leadership. As mentioned above, the idea of leadership can be found in our primate history. Prior to the advent of language, the animal leader was usually the 
strongest and most aggressive male. In fact, it seems humans have inherited primates' "organized in hierarchies with clear dominance relationships amongst its members" (Gardner \& Laskin, 2011, p.22). Primates have the ability to identify individuals from their species at a young age, contest other members for ranking within the hierarchy, and ultimately accept specific dominant or submissive relationships. For example, using the Darwinian lens of evolution, the dominance processes are most prominent in males living in the savannah, where there is first the rough play of childhood and then later fights for control of the group, protection of offspring, and control over the desirable females who can reproduce (Dobzhansky, 1962). In addition to inheriting hierarchies, humans have also inherited the proclivity to imitate, which again supports that pantomiming was the precursor to communicating through language and storytelling (Corballis, 2003; McBride, 2014; Tomasello, 2014). Imitation is usually unidirectional meaning the higher-status primates' actions (i.e., leaders' actions) are imitated by the lower primates in the hierarchy (i.e., followers). These two inheritable traits from primates translate fundamentally into an appreciation for leadership. As a result, we expect a leaderfollower social structure and struggles for positions of power within a hierarchy, as well as we tend to assess our position within the context of various hierarchies we found ourselves in (Gardner \& Laskin, 2011).

Yet, while there is evidence there is a biological aspect to leadership, most of the nature and processes of leadership occurs in the human mind, or in human minds since leadership occurs equally between the mind of the leader and the minds of the followers (Gardner \& Laskin, 2011; Little, 1985). To support this claim, Gardner and Laskin said we need to understand "first, of the ways in which leaders of different types achieve 
varying degrees of success in characterizing and resolving important life issues in their own minds, and, of how, in parallel or in turn, they attempt to alter the minds of their various audiences to effect desired changes" (Gardner \& Laskin, 2011, p.15). Thus, we can better understand the relationship between narrative leaders and their followers by moving toward an interdisciplinary study of the mind and moving away from studying leadership within discreet disciplines of biology where leadership is understood in context of evolution, or behavior where the leader's overt actions are the focus, or psychoanalysis where the leader's personality and motivations are of interest, or cognitive psychology where attention is on how ideas or thoughts develop and "how they are stored, accessed, combined, remembered, and (all too often) rearranged or distorted by the operations of the human mental apparatus" (Gardner \& Laskin, 2011, p.15).

The development of narrative leadership, in a lot of ways, follows the same trajectory as the evolution of storytelling. For instance, in the beginning, a leader of a tribe told stories of where the best hunting was, what plants were poisonous, how to make tools to defend the tribe, and so on. As humans evolved, the stories leaders told evolved, too. Therefore, in contemporary society, effective narrative leaders often share stories that appeal to our human social cognition of complex social skills and culture (Gardner \& Laskin, 2011; Tomasello et al., 2005; Yang, 2013). For instance, according to Fisher's narrative paradigm (1984), narrative leaders need to tell stories to be successful since all meaningful conversation is the linking of events (i.e., narrative) within a particular context. If the leader tells a coherent story, which Fisher defined as the narrative probability and fidelity of the story, to a group of followers, this narrative has the potential to promote cooperation and shared intentionality in others (Boyd, 2009). 
Narrative leaders. Howard Gardner, a developmental psychologist who was the lead author on a book entitled Leading Minds: An Anatomy of Leadership (2011), claimed the kind of narrative leadership in his book is best described by emphasizing the relationship between a leader's mind and followers' minds, once again emphasizing the theory that all leadership happens between the leader's and others' minds. Gardner (2011), and his contributor Emma Laskin, posited effective narrative leaders did not just tell coherent and compelling stories but related their stories because simply using words to communicate is only one way to present a story. For instance, effective narrative leaders are those "who, by word and/or personal example, markedly influence the behaviors, thoughts, and/or feelings of a significant number of their fellow human beings" (Gardner \& Laskin, 2011, p.8). Indeed, narrative leaders have mastered ways of communicating stories by relating stories through the "ability to deploy, understand, and even create whole ensembles of symbols and symbol systems" (Gardner \& Laskin, 2011, p.36), such as innate language, gestural language, and other symbolic systems such as music, picturing, and numeracy. Bormann's (1985) symbolic convergence theory supports this claim by arguing it is, in this case, the narrative leader's ability to change group consciousness (i.e., followers), "with its implied shared emotions, motives, and meanings, not in terms of individual daydreams and scripts but rather in terms of socially shared narrations or fantasies" (p. 128).

It is important to not only understand this relationship between narrative leaders' and followers' minds through storytelling (i.e., the cognitive aspect), but to also acknowledge these relationships happen within a cultural context. This is supported by the literature emphasizing the importance of storytelling to culture (Gardner \& Laskin, 
2011; Peters, 1997; Tomasello et al., 2005; Yang, 2013). After all, we are cultural creatures (i.e., we have grown up in societies, and subsequent cultural institutions, formed over thousands of years by our ancestors). Gardner and Laskin (2011) explained, "I view leadership as a process that occurs within the minds of individuals who live in a culture - a process that entails the capacities to create stories, to understand and evaluate these stories, and to appreciate the struggle among stories" (Gardner and Laskin, 2011, p.21).

Gardner and Laskin (2011) studied eleven individuals from different countries and social backgrounds with different training and vocations who exemplified narrative leadership by relating stories to a wide variety of people within the cultural context. They included: Margaret Mead, J. Robert Oppenheimer, Robert Maynard Hutchins, Alfred P. Sloan, Jr., George C. Marshall, Pope John XXIII, Eleanor Roosevelt, Martin Luther King, Jr., Margaret Thatcher, Jean Monnet, and Mahatma Gandhi. According to Gardner, these leaders created a new story, one not known by most individuals, and effectively related the story to not just those followers in a specific domain or discipline but influenced individuals throughout the greater society.

While Gardner and Laskin's book (2011) provides one theoretical framework and supporting examples of narrative leadership, a substantial amount of the narrative leadership literature can be found in leadership journals, such as International Journal of Leadership in Education and Leadership Quarterly, business journals such as Journal of Business Ethics, and other management and organizational journals, such as Leadership and Organization Development Journal and Academy of Management Review. Further, narrative leadership can be found in a variety of organizations such as business (Danzig, 
1999; Fisch, 2014), public service (Ospina \& Dodge, 2005), education administration (Gardiner et al., 2014), and the third sector (Macmillan \& McLaren, 2012).

There are some key differences between Gardner's definition and examples of narrative leadership, and those found in the aforementioned journals. First, Gardner claimed that the narrative leaders he studied not only told stories to influence and inspire others, but they embodied and related these stories by the lives they led. This embodiment is not necessarily the case with narrative leaders found in organizations. For instance, Steve Jobs the cofounder of Apple, Inc., was considered a narrative leader because "Jobs' job is story. He knows his devotees can't just be customers-he needs apostles for his products who tell his story as their own and move I forward" (Wainwright, 2013). These stories translated beyond the Apple organization into the world. However, it appears these were stories told to inspire people to believe in Apple and to make products that, alternatively, support the stories ultimately to sell Apple products. Further, the stories Jobs' told did not necessarily mean he embodied these stories outside the Apple organization, as was suggested by those narrative leaders found in Gardner and Laskin's book (2011). More importantly, there is a different context when studying narrative leaders who lead organizations versus those who lead large national social and political movements. Organizational narrative leaders often use stories for communication and sense making, and these stories are essential for employees in constructing and making meaning of the organization (Auvinen, Aaltio, \& Blomqvist, 2013).

Regardless of the theoretical framework or the context of narrative leadership, all narrative leaders focus on storytelling to influence others. Indeed, those managers, CEOs, 
and others who are identified as charismatic leaders are often the best speakers and storytellers, and as such they tend to be the best leaders to lead the respective organization (Auvinen, Aaltio, \& Blomqvist, 2013). When it comes to organizations, narrative leaders use stories to effect employees to advance organizational change (Denning, 2005; Parkin, 2004), to develop leadership skills (Denning, 2011), and as a tool for narrative patterning in organizations through storytelling (i.e., best practices) (Snowden, 2001).

Narrative leadership model. Most research on narrative leadership focuses on the traditional way leadership has been studied; it is the person who tells stories who is the leader. Examples include famous narrative leaders who embodied their stories like Mahatma Gandhi, Margaret Thatcher, or Pope John XXIII (Gardner and Laskin, 2011), as well as more contemporary organizational narrative leaders such as Steve Jobs, Cheryl Sandberg, and Richard Branson (Wainwright, 2013). However, the Great Man theory of leadership, which in the case of an organization is the hero CEO or other formal leader of organizational victory and a central figure in its realization (Auvinen, Aaltio, \& Blomqvist, 2013; Bass, 2008; Peters, 1990) is no longer the predominant model. This means narrative leadership studies of theory and research are moving away from $a$ leader telling stories to impact other's thoughts, behaviors, and actions, to narrative leadership as a discourse (Auvinen, Aaltio, \& Blomqvist, 2013; Boje, 2006; Parry \& Hansen, 2007). In other words, we can begin to understand "stories in relation to leadership, distinguishing them from the notion of 'leader as person' to understand 'leadership as discourse' in the creation and representation of visions" (Auvinen, Aaltio, \& Blomqvist, 2013, p. 4). 
Parry and Hansen (2007) went as far as to propose it is the leader's story that leads people in the organization -- not the leader. Therefore, it is then stories that are the leaders. Since the 1980s, scholarship about organizational culture has focused on interactional and social processes (i.e., discourse) leading to the knowledge that organizations have "norms, beliefs, self-certainties and stories as essential parts of their existence (Auvinen, Aaltio, \& Blomqvist, 2013, p. 1). Therefore, this narrative approach to leadership emphasizes "discursive interaction and a socially constructed reality, where storytelling is the preferred method of sense making and currency in human relationships" (Auvinen, Aaltio, \& Blomqvist, 2013, p. 6). As Lawrence and Pirson (2015) stated, "Our understanding of leadership can be no better than our understanding of what motivates human behavior, because leadership is all about relationships with others" (p. 383).

In theory, narrative leadership can diminish the hierarchical relationship between leader and follower since communication takes place one-on-one (Auvinen, Aaltio, \& Blomqvist, 2013). Indeed, scholars support the need to reduce the number of hierarchal levels in order to create less distance between people thereby allowing for better bonding and fostering the kind of trust associated with face-to-face relations (Burns \& Stalker, 1994; Lawrence \& Lorsch, 1986). In addition, less hierarchy also promotes higher levels of comprehension since it is postulated more decisions are delegated to employees of lower rank. In turn, if more decisions are made at a group level, including those at the lowest rank, it is suggested every employee will then be required to activate his or her drive to comprehend the decisions, beliefs, and stories (Driscoll \& McKee, 2007). 
While scholarship supports narrative leadership models that emphasize discourse, the sharing of stories, and decisions made within leaderless groups, the practice of narrative leadership is often quite different than these narrative leadership models presented in the literature. Boje (2006), who wrote an essay on the pitfalls of storytelling advice and practice presented in narrative leadership books, said "The assumption is that more complex treatments of story-in-context are just not marketable to the practicing management audience; I disagree, because the more complex approaches get closer to the people's lived experience in organizations" (p. 222). Further, as mentioned above, there is the concept that narrative leadership diminishes the hierarchal distance between the organizational leader and followers where the relationship is considered dyadic, natural, and an innocent process, such as talking and chatting. However, often this relationship is unequal with organizational leaders feeling they can use their power ultimately experiencing more satisfaction with the discourse than those with less power (Dunbar, 2003). Finally, leadership theories have proposed effective leadership as less of a topdown, leader-centric process, and more of a follower-centric process through which certain understandings of leadership, such as sense-making, vision, and decision-making from lower organizational levels, like work groups, who have the potential to share leadership (Wang, Walman, \& Zhang (2014). Yet, it is understood this is rarely seen in practice.

Regardless of the profound interest in narrative leadership, such as with management consultants and leadership scholars (Boje, 2006), narrative leadership remains under-researched (Boje \& Rhodes, 2006). Therefore, there is the opportunity to study how narrative leadership could be practiced in a small group of women who share 
stories about what it is like to be middle-aged in contemporary society. Additionally, there is a need to investigate how sharing these kinds of stories within a group could potentially influence others' thoughts, behaviors, and actions (i.e., narrative leadership), and how these practices could move from a leader-centric process to one of shared leadership by focusing on a group-centric process. Therefore, there is an opportunity to explore how the potential narrative leadership could lead to shared leadership, a model of leadership which focuses on social interactions and interpersonal relationships within a group (Wang, Walman, \& Zhang, 2014) to encourage the serial emergence of two or more group members as leaders (Bergman, et al., 2012). By giving members participating in a non-hierarchal, leaderless group the opportunity to practice narrative leadership, will this allow shared leadership to be realized?

Shared leadership. Like other definitions of leadership there is a component of influence with shared leadership. However, rather than there being $a$ leader who influences others/followers, shared leadership is "multidirectional, dynamic, simultaneous, and on-going, and it is characterized by the 'serial emergence' of two or more members as leaders" (Bergman et al., 2012, p. 18). Much of the shared leadership research has been conducted in organizational settings. Pearce and Conger (2003), the editors of Shared Leadership: Reframing the Hows and Whys of Leadership, defined shared leadership as an opportunity for a group of individuals to participate in a dynamic, interactive, and influential process in which the aim is to lead one another to effectively achieve group or organizational goals or both. Regardless of the context, the literature sees shared leadership 
[A]s a potentially important complement to traditional, singular forms of leadership, the key distinction between shared and traditional, vertical leadership is a 'simultaneous, ongoing, mutual influential process' that involves 'peer, lateral, upward or downward influences of team members,' while the latter involves only 'a downward influence on subordinates by an appointed or elected leader' (Wang, Walman, \& Zhang, 2014, p. 182).

Fletcher and Kaufer (2003) describe the shared leadership model as one where: (a) leadership is distributed and interdependent; (b) leadership is embedded in social interaction; and, (c) leadership is attained through mutual learning. Like other emergent models of leadership, shared leadership focuses on "living systems of relationships" and "practices embedded in a system of interdependencies" (Fletcher \& Kaufer, 2003, p. 21), and this kind of leadership emphasizes influence relationships that get played out through interpersonal interactions much like what was proposed by scholars in the narrative leadership literature.

As noted above the literature supports these emergent leadership models meaning a paradigm shift away from focusing on the characteristics of individual leaders (including the aforementioned narrative leaders), toward a view of leadership practice that emphasizes group-level processes. Often visionary leadership has been hypothesized as a downward, hierarchical, or vertical process (Bass, 1985); however, there is data to suggest vision creation can and should generally be more a practice of a collaboration of multiple individuals (Wang, Walman, \& Zhang, 2014).

Yet, despite the interest in the development of shared leadership practices and the empirical study of these practices, three paradoxes or contradictions have been offered as 
to why shared leadership scholarship has been repressed. The first paradox is leaders in hierarchal organizations, i.e., so-called "hero CEOs," are often required to create the sorts of flatter, more adaptable organizations in which shared leadership can flourish

(Bartunek, Walsh, \& Lacey, 2000; Senge, 1997).

The second paradox involves the conflict between leadership rhetoric at the macro level of organizations, on the one hand, and micro-level rhetoric, on the other. Fletcher and Kaufer (2003) noted, for example, that

[A]lthough at the macro level the rhetoric about leadership focuses on teamwork, collaboration, and collective learning, the everyday narratives about leadership and leadership practices — the stories people tell about leadership, the mythical legends that get passed on as exemplars of leadership behavior-often remain stuck in old images of heroic individualism (p.25).

The hero issue can be seen in the narrative leadership literature as well, whereby it is often $a$ leader who tells stories to inspire others (i.e., heroic individualism), like Martin Luther King, Jr.

The third paradox emphasizes that while some organizations espouse the virtues of shared leadership and collaboration, most jobs and careers still emphasize individual achievement (Hall, 2004). Who moves up the corporate ladder and advances in a person's career, in general, has more to do with an individual's accomplishments rather than her or his contributions to a group's accomplishments. This preference for an individual leader to inspire, influence, and motivate others is not isolated to businesses and corporations but can be seen in politics (i.e., President of the United States), the academy (i.e., Chairs, Deans, Provosts), and the third sector (i.e., Executive Directors). 
These three paradoxes briefly outlined above often prevent shared leadership from being enacted in organizations, even in organizations embracing shared leadership rhetoric. As such it should not be surprising that it also has been exceedingly difficult to empirically study shared leadership in small group settings. Consequently, we have virtually no images of what shared leadership looks like in actual organizations through small group situations, such as working groups, and essentially no methods to recommend to facilitate the exercise of shared leadership in small group settings. Despite the absence of systematic empirical work on shared leadership, the narrative leadership literature suggests that sharing stories and communicating visions within a group can lead to leadership that is distributed and interdependent, embedded in social interaction such as discourse, dialogue, and chatting, and is accomplished between mutual learning amongst the participants of the group.

Yet, like narrative leadership, shared leadership remains under-researched and poorly understood (Pearce \& Conger, 2003). To date there is no systematically gathered empirical evidence that establishes a link, or even whether a link exists, between narrative leadership and shared leadership. Consequently, there is also an absence of knowledge about strategies that could be employed to promote effective narrative leadership to potentially achieve shared leadership characteristics. This study suggests Photovoice-inspired methodology is one means to empirically study the link between narrative and shared leadership.

\section{Photovoice}

Photovoice methodology is based on the principles of participatory action research where group members use photographs, and other visuals such as collages, to 
reflect about their concerns and passions related to their community or environment (Simmonds, Roux, \& ter Avest, 2015; Wang \& Burris, 1997). These reflections and stories are shared with the other participants to inspire critical dialogue in order to transform the individual, the collective, and sometimes to a larger extent the community or society (Wang \& Burris, 1997). Photovoice projects usually involve individualswith limited power because of ethnicity, socio-economic status, gender, sexuality, health status, or other circumstances which create disparities such as immigration — to capture and present images of the environment and experiences to share with others (Fawcett, Schultz, Holt, Collie-Akers, Watson-Thompson, 2013). Typically, there is another aspect of photovoice involving group identification of recommendations through the critical dialogue, then advocating for these recommendations with policymakers and other stakeholders. This advocacy piece is not part of the current study.

Wang and Burris (1997) wrote a seminal photovoice article about how the process combines the work of Paulo Freire's idea of "critical consciousness" as a deep understanding of how society, politics, and power relationships affect an individual's situation; feminist theory and its focuses on the significance of voice and agency; and documentary photos with the potential to bring about social change. Freire $(1973 / 2000)$ proposed the teacher and the learner co-create knowledge. This pedagogical approach challenges the traditional "power dynamics of education from a dialectical approach as a simple transfer of knowledge to an egalitarian approach that created knowledge through communal introspection" (Carlson, Engebretson \& Chamberlain, 2006, p. 837). According to Freire (1970/2000, 1973/2000), the communal introspection process, referred to as dialogue, and his approach is the basis to many public health models of 
social change including photovoice. This communal introspection through visual cues such as photographs and sharing the accompanying stories prompting dialogue appears to be important aspects of realizing narrative and shared leadership.

Photovoice methodology was developed as part of the movement away from academics and researchers developing the research question, methodology, analyses plan, and the interpretation of the data to methodologies, like photovoice, where the participants and facilitators co-create knowledge. Indeed, these community-based participatory research methods emphasize the collaboration between the community, the academy, and other stakeholders to not only address disparities but also to affect social change (Minkler \& Wallerstein, 2003; Wallerstein, Yen \& Syme, 2011). Yet, in a review of 37 unduplicated photovoice projects from peer-reviewed journals, Catalani and Minkler (2010) found evidence that implementation methods did not use the group to its fullest potential by preventing the distribution and sharing of the decision-making power. Hergenrather and others (2009) found similar results in their review of photovoice projects. In addition, both Catalina and Minkler (2010) and Hergenrather, Rhodes, Cowan, Bardhoshi, and Pula (2009) found that the majority of photovoice projects focused on community-based interventions, such as rebuilding the community, promoting community health, and improving the quality of life, and on theories of social change that target individual behavior (Potvin, Gendron, Bilodeau, \& Chabot, 2005). In fact, most photovoice researchers have used community change theories "inadequate to account for the specificity of causal mechanisms and mediating relationships" (Carlson, Engebretson, \& Chamberlain, 2006, p. 837). Further, Sanon, Evans-Agnew, and Boutain (2014) review of photovoice projects focused on whether or not there was a social justice impact 
as a result of these endeavors, instead of concentrating on those aforementioned projects which targeted individual behavior (i.e., personal agency). Sanon and others (2014) suggested like Carlson and associates (2006) that photovoice facilitators and projects should be guided by justice-oriented methodologies as opposed to community-change theories found throughout the photovoice literature. This social justice approach considers the community participants' existence/reality (ontology) and is transparent about the epistemology used to acquire knowledge (methodology), which subsequently shapes the research method. After reviewing 30 photovoice studies with this social justice lens, it was determined that all of the studies reported raising awareness around "making burdens and benefits more apparent with attention to relationships of power" (Sanon, Evans-Agnew, \& Boutain, 2014, p. 214). Eleven of the 30 studies provided an immediate action or reaction "to address acute and emergent issues that are symptoms of oppression or power imbalances which result in vulnerability" (Sanon, Evans-Agnew, \& Boutain, 2014, p. 214).

The photovoice process has been used to create and foster human agency amongst the participants. Human agency is the belief one can act independently and make choices by changing one's own cognitive beliefs, especially personal efficacy (Bandura, 1997). Perceived self-efficacy is crucial in the ways humans behave, but so is how "its impact on other determinants such as goals and aspirations, outcome expectations, affective proclivities, and perception of impediments and opportunities in the social environment" (Bandura, 2000,pg. 75). The preponderance of the literature on human agency has focused on personal agency; yet, there are two other forms such as proxy and collective agency, which can happen as a result of the photovoice process as well (Bandura, 2000). 
Proxy agency is not a focus of this research, but is defined as eliciting control over social structures, systems, and institutions through others with expertise, influence, and/or power to act on behalf of them to get the desired outcomes (Bandura, 2000). Collective agency is the idea that many of the photovoice outcomes sought can only be achieved through collective power and working interdependently (Bandura, 2000). Collective agency is reminiscent of the principles of shared leadership, and similar to shared leadership, there is limited literature addressing collective agency in photovoice projects.

Related to personal and collective human agency is the idea that the most substantial way to make collective changes and community improvements is to move the individual from the lowest level of consciousness (magical level) through the second level (naïve level of consciousness) to the highest level of consciousness (Freire, 1970/2000, 1973/2002). For example, an individual who moves from feeling "trapped by assumptions of inherent inferiority and lived within a culture of silent acceptance of the status quo" to the second level where there is a perception and interpretation of individuals that "the social situation is sound but corrupt," and instead of analyzing this injustice they "exhibit behaviors of horizontal violence" by blaming peers for the social reality in favor of the highest level of consciousness which involves becoming aware of "their own responsibility for choices that either maintain or change that reality" (Carlson, Engebretson, \& Chamberlain, 2006, p. 837). The literature supports the idea that the individual and the group need to be impacted in order to make and sustain the changes in the individual, the collective, and throughout the community (Carlson, Engebretson, \& Chamberlain, 2006). 
Based on this review of literature, there is evidence the photovoice technique could potentially support narrative leadership by the participants in a group sharing photographs and other visuals and accompanying stories. In fact, Gardner and Laskin (2011) identified how embodying a story was an effective way narrative leaders successfully communicate and influence others. Examples include Gandhi nakedly coming face-to-face with his enemies or Martin Luther King, Jr. standing determinedly behind prison bars. These communicate symbolically and visually the embodiment of the leader's virtues. However, these visual representations are powerful because these individuals are recognizable, and their causes and stories are understood. In other words, "since the story has already been assimilated [by the followers], an illustration of it suffices" (Gardner and Laskin, 2011, p.38). While the images taken and shared amongst the proposed group of women will not necessarily include self-portraits, nor are they iconic, the aforementioned example speaks to the power of photographs and how they can influence others.

In summary, the photovoice philosophy supports emergent leadership models to be potentially realized. There are a number of photovoice concepts that are linked to narrative leadership including the sharing of images and the associated stories, as well as the communal introspection and critical dialogue, all of which have the potential to impact the thoughts, behaviors, and actions of the others participating in the photovoice group. In addition, there is the concept that the photovoice technique can create equitable and co-creating relationships where power and leadership is shared. It seems reasonable that if narrative leadership is seen using photovoice, there is a likelihood that shared leadership can be realized by observing leadership that is distributed and interdependent, 
embedded in social interaction, and is attained through mutual learning (i.e. co-created) (Fletcher \& Kaufer, 2003).

\section{Summary of Literature Review}

The literature reflects that humans have a long and important history involving storytelling including how our storytelling past has been crucial in our development as a society. Further, the literature emphasizes a link between storytelling and leadership (i.e., narrative leadership) that goes back thousands of years and remains relevant today. Narrative leadership is the model of connecting storytelling, the functions of stories such as promoting cooperation, and leadership (i.e., influencing others thoughts, behaviors, and/or actions through stories). While research shows narrative leaders have been important in leading large social and political movements, as well as corporations, nonprofits, government agencies, etc., the issue is the literature focuses on $a$ single leader, who often has either formal or informal power, who communicates stories to influence others (i.e., followers) (Bass, 2008). Yet, recently there has been a move away from leadership theories and approaches that envision effective leadership as top-down, hierarchical, and leader-centric toward a more follower-centric, flat organizational, interactional and social process, such as shared leadership (Wang, Walman, \& Zhang, 2014). Shared leadership has been defined as "multidirectional, dynamic, simultaneous, and on-going, and it is characterized by the 'serial emergence' of two or more members as leaders" in a group (Bergman et al, 2012, p. 18).

Despite the literature supporting the importance of storytelling, no literature could be found which studied the combination of narrative leadership and using storytelling within a non-hierarchal and leaderless group, such as the consciousness-raising groups of 
the $60 \mathrm{~s}$ and $70 \mathrm{~s}$. There also appears to be an absence of possible methodological tactics and strategies to enact narrative leadership, and perhaps shared leadership. It appears the photovoice process, or a photovoice-inspired process, of sharing photographs and other visuals with corresponding stories has the potential to effectively influence others to the degree that shared leadership is enacted and, therefore, empirically studied. 


\section{Chapter 3: Methodology}

This chapter describes the methodology used to pursue answers to this study's research questions. The chapter begins with a review of the gaps in the literature that helped to identify the purpose of the study and the overarching research questions. Then, the research design is explained using a chronological timeline. The final sections focus on the limitations of the study, including the researcher's (my) positionality, and the potential significance of the study.

\section{Purpose of the Study/Research Question}

Based on the review of literature, the following gaps and opportunities were identified. First, most of the discussion on narrative leadership focuses on $a$ leader who tells and embodies stories to inspire people in order to lead nations or large-scale social movements (Gardner \& Laskin, 2011), or on "hero leaders" with positional power in institutional settings such as business (Danzig, 1999; Fisch, 2014), public service (Ospina \& Dodge, 2005), education administration (Gardiner et al., 2013), and the third sector (Macmillan \& McLaren, 2012). There appears to be a lack of literature about how narrative leadership is enacted in the context of small groups or other types of flat organizations where, in principle at least, shared leadership gets practiced.

Second, the literature supports the claim that women have historically gathered to share stories and influence others in "leaderless" small groups, such as the consciousnessraising groups during the women's liberation movement of the 1960s and 1970s. It appears these sorts of venues offer an opportunity to study both shared leadership, in general, and the role of storytelling in exercising leadership when leadership is defined as an influence relationship. 
Third, the literature supports the claim that shared leadership, which is based on interpersonal interactions, is found more often in groups of women than in groups of men (Miller, Jordan, Kaplan, Stiver, \& Surrey, 1997) or mixed groups of men and women (Spillane, Halverson, \& Diamond, 1999). Consequently, women's groups without a designated leader appear to be venues in which to explore both narrative and shared leadership.

Finally, photovoice-inspired techniques have been identified as a strategy that encourages the sharing of stories using photographs and other visuals within a small group setting to transform the participating individuals and the collective. However, there seems to be a lack of literature exploring whether these techniques can be used as a tool to promote narrative leadership and, if it can, whether narrative leadership in small leaderless group settings can contribute to creating the conditions associated with shared leadership.

The purpose of this study, therefore, was to examine whether a photovoiceinspired technique can be used to facilitate the effective implementation of narrative leadership (i.e., influencing others through the telling of stories) within a small group of middle-aged women. Leadership, in this case, is being defined as an influence relationship and the study will attempt to discover whether the storytelling prompted by photovoice techniques altered the thinking, and possibly the behavior and actions, of members of the group. In addition, the study explored whether any narrative leadership that gets enacted through photovoice facilitates the development of group characteristics that are associated with shared leadership. These characteristics include leadership that is 
(a) distributed and interdependent, (b) embedded in social interaction, and, (c) attained through mutual learning.

Initially, at least, the study was guided by the following overarching research questions:

1. What evidence, if any, supported or refuted claims that the storytelling engendered by the use of photovoice techniques influenced the thinking, behavior, and/or actions of group members; in other words, was there evidence that the photovoice techniques facilitated the exercise of narrative leadership by the individual group members?

2. Did narrative leadership appear to contribute to the development of group characteristics associated with the concept of shared leadership?

\section{The Study Design Timeline}

Below is the proposed study's chronological timeline to explore the guiding research questions. The various methods to be used are discussed in the context of the different components in this timeline.

First step: participant selection. The first step of the study is to recruit the participants for the photovoice project. The general strategy of participant selection is based on Kristin Luker's book, Salsa Dancing into the Social Sciences (2008). Luker (2008) recommends researchers interested in exploring a phenomenon should not create a sample of participants based on representativeness, but rather the sample should be constructed based on "data outcroppings_-places where you have good reason, either from previous theory or logic or personal experience, to think there will be a lot of what it is you want to study" (p. 161). 
Selection criteria. For this study, the participant selection criteria focused on recruiting middle-aged women, women close to the age of the researcher and an age with which I hold particular scholarly interest (Zive 2011, 2014), with potentially differing views and stories to tell based on a variety of socio-demographic variables. Evidence suggests middle-age, defined in the United States as ages 40 to 64, is a time in which women are marked by certain emotional, physical, and societal issues (CDC, 2013; Phillips, Robin, Nugent, \& Idler, 2010; Zive 2011, 2014). From this it can be reasoned middle-aged women likely have a wide-range of experiences from which they can pull information for a study focused on the potential impact of narrative leadership. In addition, if the methodological purpose of this study is to explore the enactment of narrative leadership, women sharing middle age as a characteristic may have comparable historical references growing up in a similar time period with greater potentiality for comfort and familiarity thereby building the necessary the trust to share stories, particularly personal stories, within a small group setting. Finally, I am a middle-aged woman who has the experience anecdotally of "disappearing" and marginalization. This seems to be a cultural, social, and personal phenomenon of middle-aged women. However, this phenomenon is not exclusive to this demographic. That is to say, this is not the only group that is made to feel invisible because of the lack of voice, narratives, and role models in popular culture that can influence the personal and social spheres as well. Yet, because I am a middle-aged woman this is the focus of this research. The hope is if photovoice techniques can inspire narrative leadership for middle-aged women, then perhaps this methodology can you be used for other groups as well. 
However, if the middle-aged women all potentially shared similar stories based on their experience, it is likely there would be little evidence of narrative leadership within this group (i.e., the shared stories will not influence thinking, behavior, and/or actions of the participants since they had similar views at the outset). Therefore, additional criteria were used to recruit middle-aged women likely to have differing identities based on ethnicity, socio-economic status, religious affiliation, sexual orientation, marital status, having children or not, and/or occupation/position. Differing identities lead to the sharing of different stories of their experiences as middle-aged women in contemporary American society, and further these shared stories (and the varying images associated with them) ultimately influenced participant and group thinking, behavior, and/or potentially their actions.

Sampling techniques. Five middle-aged women were recruited for the study. The small group literature supports the claim that groups comprised of between three to eight members are more productive and developmentally advanced than groups of nine or more participants (Wheelan, 2009). Sampling methods for this study included purposeful (Creswell, Klassen, Plano Clark, \& Smith, 2011) and snowball (Faugier \& Sargeant, 1997) techniques. These recruiting techniques have been successful when recruiting middle-aged women for previous studies (Zive 2011, 2014).

Purposeful sampling techniques were used first to recruit three to four middleaged women. Specifically, I reached out to middle-aged women acquaintances of mine via email, telephone, and social media to inviting them to participate in the study. Once contact was made, I used a standardized script explaining the purpose of the study and the criteria used to recruit participants. My acquaintances were informed of the likely 
benefits of participation. The recruitment protocol asked each participant, "What are your thoughts and feelings, if any, about being a middle-aged woman?," to gauge potential variance in the narratives. To further ensure variance of ethnicity, socioeconomic status, religious affiliation, sexual orientation, marital status, children or not, and/or occupation/position, as well as potential differences in the way the women felt about being a middle-aged woman, snowball sampling was used to recruit the remaining six participants. Specifically, this involved asking acquaintances from the purposeful sampling to provide names and contact information of middle-aged women with varying identities, and possibly different narratives of what it is like to be a middle-aged woman, not yet represented in the group.

Pre-session interview. In order to get a "life history" of each of the women, I interviewed each woman in a one-on-one interview. First, each participant was asked to draft a timeline of those significant events in her life that contributed to "the woman she is today." For an example see Appendix A. The timeline guided the interview in order to get more details. I drafted a timeline and narrative as well. Once the narratives were completed, I emailed the respective narrative to each of the women to verify the information (i.e., member check).

Second step: photovoice-inspired group process. The photovoice group met in at my home, which was deemed a central, safe, and comfortable place. The group of women met three times over three consecutive Mondays in the late afternoon/early evening. Appetizers and wine were served. Each meeting lasted approximately 120 minutes and was videotaped. Because my role was as a participant/observer, with an emphasis on participant, I hired two professional facilitators to oversee the process. The 
main facilitator assisted with the drafting of the facilitation agenda for the three sessions (Appendix B) and was responsible for ensuring all deliverables were met (i.e., signed consent forms, explanation of the homework, evaluation questions were completed by the participants, etc.), and acted as timekeeper. The second facilitator, a photographer and educator familiar with photographic storytelling, facilitated the discussion of our photographs and visuals. I viewed each videotaped session a non-participant observer which permitted me to take more detailed field notes and review session action multiple times, if necessary. I felt I was able to stand outside of the action within which I was a part in order to analyze my influences on the group and its interactions, both positive and negative, if any.

First session. During the first session, the participants were introduced to the potential contribution of storytelling and the photovoice process that was used to promote storytelling in the group. During this first session, there was an opportunity to practice storytelling within the group, as well as an opportunity to construct a collage that was used to highlight the link between stories and visuals. Each woman was encouraged to share her individual stories and collages with the group. Once each individual shared, the group was asked to reflect on and discuss the following questions:

1. What did you hear when you listened to the stories? Saw the collages?

2. How did you feel?

3. Were there any common themes? Different themes?

4. What resonated with you?

Other questions arose during the discussion. Following these discussion exercises of sharing stories and making collages, as well as the ensuing discussion, it was apparent 
very different stories and reactions were presented related to identity, power, agency, and voice as presented in the photovoice literature (Carlson, Engebretson \& Chamberlain, 2006; Freire, 1973, 2000; Wang \& Burris, 1997).

Next, participants were instructed how to tell stories about being a middle-aged woman in today's society. The women were asked to take photos over the next week about what it is like to be a middle-aged woman in today's society. Each woman was then asked to email me their top two photos to be enlarged to 8 "x10" to be shared at the next session.

To obtain some immediate feedback regarding the first session, each woman was asked to write her answers to three questions: (1) What worked during the session?; (2) What did not work?; and (3) What, if anything, are you taking away from the session? The participants' written accounts were collected.

I took notes throughout the session, although because I was an active participant notes were taken minimally so as not to distract the group. Between the first and second session, I followed up with the women to ask for further feedback regarding the first session, and inquire about the progress of their picture-taking processes and/or choosing photos from their "gallery."

Second session. Before the second session, I presented the group with 8"x10" enlargements of the top two favorite photographs for each woman. All the photos were displayed on a large, waist-high table allowing the women to walk around and study them. Each woman was asked to present the group with her selected photos and accompanying stories. Afterward, the photos and stories were displayed around the room 
so the women could continue walk around and spend more time viewing the images and stories. After the presentations, the group will be asked the following questions:

1. What did you hear when listening to the stories and seeing the photos regarding what it is like to be a middle-aged women?

2. What were the common narratives, or themes, across the presentations, if any, you saw or heard?

3. How are the stories related, understood, misunderstood?

4. What were the unique stories, if any, being told?

5. What could be some counter narratives to the photos and stories being told?

6. How do these stories relate and interact with other stories, especially contradictory stories which have been indoctrinated into the consciousness of the participating women?

Finally, the group reviewed and discussed the themes and stories shared in the session. The "homework" was then assigned. Each woman was to take photographs within the next week in their own private spaces and frequented public spaces which reflected the stories and themes which resonated with them as middle-aged women. By the end of the week (before the third session on a Monday), they were asked to email me their two favorite photos they took in their respective private and frequented public spaces.

After the discussion, the women were again asked to write their responses to the three session feedback questions: what worked, what did not, and what will be taken away from the session. The responses were collected. I took notes throughout the session. 
Third session. Again at the beginning of the session, I presented the group with 8"x10" enlargements of the top two favorite photographs for each woman. The same process was followed as outlined in the second session, including asking the six questions mentioned above.

The photographs and stories are intended to engage the group in critical reflection and dialogue/discussion directed to understand whether or not there was a change in individual and/or group thinking about what is like to be a middle-aged woman in contemporary society. Following the critical dialogue, I facilitated a group discussion speculating on the group's future (i.e., whether there is interest in the group continuing, sharing the photographs and stories, publishing the research, etc.).

At the end of the third session, the women were again asked to write their responses to the three session feedback questions: what worked, what did not, and what will be taken away from the session. I took notes throughout the session.

The data collected. The qualitative data collected during the three sessions included: the videotapes, as well as the photographs taken and stories told by the participants. In addition, the participants provided written and open-ended feedback after each session (i.e., the three questions). In addition, I contacted each of the women after the first and second sessions to obtain any additional feedback regarding the session and/or the process.

Third step: post-intervention data collection. Within two weeks after the completion of the third session, I conducted either a brief follow-up phone call or a faceto-face interview with each of the participating women, based on the preference of each woman. Prior to each interview, the women were emailed a draft of their narrative 
profile for their review. In addition, open-ended inquiries were made regarding the group process such as:

1. Now that you have had time to reflect on the experience, tell me what kinds of things (e.g., stories, images, the process, etc.) stayed with you as a result of participating in this project?

2. What did you learn about yourself? What did you learn from the other women about being a middle-aged women you did not know before this process?

3. What surprised you?

4. What do you think happened to you and the other women as a result of being part of the group?

5. What happened, if anything, in terms of your ability to tell your story and find your voice?

6. How, if at all, did your thinking change as a result of participating in photovoice sessions?

Fourth step: data analysis. Analysis of narrative and narrative analysis were used to analyze the qualitative data. According to Polkinghorne (1995), when engaging in narrative analysis “the researcher's task is to configure the data elements into a story that unites and gives meaning to the data as contributors to a goal or purpose" (p. 15). In other words, the researcher is required to "develop or discover a plot" that shows the relationship among the data components "as parts of an unfolding temporal development culminating in the denouement" (Polkinghorne, 1995, p. 15). While narrative analysis synthesizes data into a cohesive story, analysis of narrative evaluates "the data to identify particulars as instances or general notions or concepts" (Polkinghorne, 1995, p. 13). 
Analysis of narrative "requires a database consisting of several stories [rather than a single story]" (Polkinghorne, 1995, p. 13), and this allows the emergence of themes across the stories (Lincoln \& Guba, 1985).

Chapter 4 analysis processes. First, the women's individual interviews were examined using both Polkinghorne's (1995) narrative analysis to construct each woman's history and his analysis of narrative strategy to conduct a cross-case analysis (See Chapter 4 for the results of both of these analyses). For this research, each woman's constructed timeline (See Appendix A for an example) was used to identify those significant events in her life that contributed to making her the [middle-aged] woman she is today. The results of the narrative analysis (i.e., the woman's narrative profile in Chapter 4) allowed me and the reader to understand the diversity among the women based on their respective histories (or, it might be more appropriate to say herstories). Analysis of narrative, on the other hand, was used to examine the six women's histories to identify the diverse and similar experiences, events, and actions the women had through the course of their lives. Initially, in vivo coding was employed. This type of coding, which is also considered "literal coding" and "inductive coding," refers to "a word or phrase from the actual language found in the qualitative data record" (Saldaña, 2013, p. 91). The primary goal of in vivo coding is to devise the facilitator's interpretations of terms "that participants use in their everyday lives, rather than in terms derived from the academic disciplines or professional practices" (Stringer, 1999, p. 91). The in vivo coding strategy seems especially appropriate to use in a study employing the photovoice technique because this methodology emphasizes elevating a photovoice participant's voice (Wang \& Burris, 1997). 
In the second cycle of coding of the narrative profiles, focused coding was used to find the most frequent or significant codes and themes that surfaced during in vivo coding. The emphasis in this second round of coding is on identifying "the most salient categories" in the body of data and "requires decisions about which initial codes make the most analytic sense" (Charmaz, 2006, p. 46, 57).

Chapter 5 analysis process. For Chapter 5 (Sessions), narrative analysis was used to understand the "plot" of the three intervention sessions. Polkinghorne (1995) wrote: As the plot begins to take form, the events and happenings that are critical to the story's denouement become apparent. The emerging plot informs the researcher about which items from the gathered data should be included in the final storied account. Not all data elements will be needed for telling of the story. Elements which do not contradict the plot, but which are not pertinent to its development, do not become part of the research result, the storied narrative (p. 16).

Saldaña (2013) noted that narrative analysis is especially "appropriate for exploring intrapersonal and interpersonal participant experiences and actions to understand the human condition through story which is justified in and of itself as a legitimate way of knowing” (p. 132).

Chapter 6 analysis process. Analysis of narrative was used to answer the study's two research questions: 1) Did the photographs and accompanying stories produced by the photovoice process lead to a change in thinking, behavior, and/or actions of the participating women; in other words, is there evidence that some form of informal narrative leadership occurred?; and 2) If any narrative leadership occurred, is there also evidence of the conditions necessary for shared leadership to occur (i.e., was leadership 
(a) distributed and interdependent; (b) embedded in social interaction; and (c) attained through mutual learning). Specifically, qualitative data from the five post-intervention interviews of the participants, as well as the two facilitators, were used to conduct analysis of narrative to determine whether or not the thinking of the women had changed. Post-intervention questions focused on determining whether the women had been influenced by participating in the project and included those ideas or experiences which resonated with each of the women, what they learned from the other women, what surprised them, and how each of them were influenced and their thoughts about how they thought the other women were impacted by participating in the project.

For the second research question, analysis of narrative was used to answer whether the conditions for shared leadership was evident. The analyzed qualitative data were from the three sessions (See Chapter 5) including the transcription of the videotapes from the three sessions, as well as the visuals (i.e., collages and photographs) and the accompanying stories; the written and open-ended feedback after each session; and, the additional feedback from the interviews between sessions 1 and 2 and then again between 2 and 3 . These data were used to identify the themes of shared leadership where leadership is distributed and independent, embedded in social interaction, and attained through mutual learning.

Ensuring trustworthiness. After the data collection, analyses, and interpretation of findings, the next phase of the study focused on procedures ensuring the trustworthiness of study findings. Member checking was used to ensure the interpretation of the data and the findings were accurately portrayed based on each of the participant's review. I sent an email draft of the results section to each of the women. 
Depending on each of the women's preference, I then met face-to-face or via telephone to conduct a follow-up interview to ensure the accuracy of the results. In addition to the member checking, I asked: (1) In general, is this interpretation accurate?, and (2) Does this correctly portray the way you think the process and resulting categories and themes occurred? The visual data and stories told by all the participants, as well as the postinterviews with each of the participants were used to triangulate the data.

\section{Limitations and Significance}

Limitations. The following limitations are brought forward for consideration:

1. Positionality - Researcher positionality as a middle-aged woman may be a limitation. I have a concentrated interest understanding the impacts of gender and age on leadership, voice, agency, etc., which potentially could influence the results of this study.

2. Generalizability - It is understood the small participant size of this study does not lend itself to understanding populations. However, as mentioned before, this is an exploratory study to understand how storytelling can be used to understand narrative and shared leadership. It has been suggested that women have a history of practicing storytelling as a means to influence the thoughts, behaviors, and actions of other women in the consciousness-raising groups of the 1960s and 1970s. This is an attempt to see if narrative leadership (and perhaps shared leadership) can be resurrected today.

3. Dosage of the intervention - It is acknowledged that there are three photovoice sessions. It is unknown whether there is sufficient time and interaction to identify whether narrative and/or shared leadership will be experienced within the group. 
However, it is anticipated that the qualitative data collection and analyses will allow the exploration of whether themes and concepts connected with the methodology (i.e., photovoice) suggest the group experienced narrative or shared leadership.

4. Lack of product, objective or goal - There is no identified product, objective, and/or goal related to the outcome of this study. Most literature related to both narrative and shared leadership involve some kind of outcome. Because of fact that the group of women will not have an outcome per se, it could be difficult to identify whether narrative and/or shared leadership is realized. However, the research design (i.e., the post-session questions, field notes, and videotapes) was developed in such a way to be sensitive to being able to "observe" whether narrative and/or shared leadership were actually enacted.

Significance. This study will be among the first to explore whether a photovoiceinspired technique can be used to promote narrative leadership within a small group, and whether any narrative leadership that gets enacted facilitates or inhibits shared leadership among the group members. As such, it will make several contributions to the field including: (a) adding to the scant literature on whether photovoice, which has been a successful tactic in transforming participants, the collective, and the larger community (Wang \& Burris, 1997); and (b) effectively inspiring and influencing a small group of women through the shared stories and accompanying photographs. Thus, this study's results have potential implications in organizations seeking to implement narrative leadership and a storytelling culture in a non-hierarchal, leaderless context, such as working groups. As mentioned before, there is an interest in studying leadership theories 
and models that are more collaborative in nature (Boje, 2006; Burns \& Stalker, 1994;

Lawrence \& Lorsch, 1986; Lawrence \& Pirson, 2015; Wang, Walman, \& Zhang, 2014), such as shared leadership. This study contributes to whether or not a photovoice-inspired technique supports narrative leadership, and in turn, whether the enacted narrative leadership is shared by more than one of the participants (i.e., shared leadership). 


\section{Chapter 4: Results, Part I - Narrative Profiles}

This chapter on Narrative Profiles, is the first of three of the research findings chapters; Chapter 5 presents the group session findings, and Chapter 6 highlights the post-intervention results. Below each of the six participants' narratives are presented. Briefly, since the methodology is covered in Chapter 3, I interviewed each of the women prior to the sessions. The purpose of the interviews was to ensure, and understand, the diversity of the group. Equality of positional power was created by the fact that all the participants were middle-aged women. However, if the question of whether sharing photos and stories could influence the participants' thinking, behaviors, and/or actions (i.e., narrative leadership), it was important there be diversity amongst the women to explore this.

I met with each of the women at a location of their choice, with the exception of Lynne whom I spoke to over the phone. Meryl came to my house, both PrinceFan69 and Rosa met me at a different wine cafés, and I interviewed Trixie at her home. Each woman decided whether or not she wanted a pseudonym or agreed to the use of her real name; three decided to use an alias and three did not. When I met with the women, they were asked to create a timeline of those significant events that "made her the woman she is today" (Appendix B). The timeline was used to guide each woman's interview, which then informed the narrative profile.

It is worth noting that the created timelines were as different as the women themselves. For instance, Meryl, Rosa, and I created chronological timelines starting at our births to the present day, whereas Trixie spoke about her current lack of purpose because her adult sons had moved out of the house. Both PrinceFan69 and Lynne 
highlighted important events throughout their lives life they felt defined the women they are today. The differences in our timelines meant differences in their life stories, and ultimately differences between the women we are. Table 1 provides the names and descriptions of the participants, and will aid the reader in identifying the women in the subsequent chapters.

Table 4.1

Name, Title, and Description of Women Participants

\begin{tabular}{lll}
\hline \multicolumn{1}{c}{ Name } & \multicolumn{1}{c}{ Title } & \multicolumn{1}{c}{ Description } \\
Meryl & Public Servant & White, gay, 42-years-old, single \\
Rosa & Immigrant & $\begin{array}{l}\text { Mexican, married, 42-years-old, } \\
\text { two children }\end{array}$ \\
PrinceFan69 & Biracial Artist & $\begin{array}{l}\text { White/black, gay, 46-years-old, } \\
\text { two children }\end{array}$ \\
Trixie & Empty Nester & $\begin{array}{l}\text { White, married, 52-years-old, } \\
\text { two grown boys }\end{array}$ \\
Lynne & African-American Christian & $\begin{array}{l}\text { Black, married, 55-years-old, } \\
\text { two grown children }\end{array}$ \\
& Active Participant Observer & $\begin{array}{l}\text { White, married, 52-years-old, } \\
\text { three children }\end{array}$ \\
& &
\end{tabular}

\section{Meryl, The Public Servant}

Meryl is a 42-year-old white woman holding a master's degree. Currently, she is not working and is not looking for a job. Meryl is single, gay, and has never been married. She considers herself spiritual but not committed to a particular faith. 
Lost time. Meryl was born March 14, 1974, in Long Beach, California. She has a brother who is three years older. Previous to Meryl's mother marrying her father, at her mom had a baby girl at 18 years of age and gave her up for adoption. When Meryl was 5-years-old, her mother had an affair and left the family for a period of time to live with the other man.

Looking back, I was terrified. I have a fear of abandonment. But you want to know what's weird? I didn't realize my mom had left us until I was 18. I asked my brother, and he told me she had. To this day, we don't talk about it.

After that conversation with her brother, she began to remember things like her dad's parents moving in to help take care of her and her brother for the six months her mom was gone. Meryl explains, "Now my mom is always apologizing for that time. I tell her things happen. She was young. When she returned, she was, she is, a great mom."

Looking at her completed timeline, Meryl noted there was a huge gap between the ages of 5 and 21. This surprised her. She had never considered this "lost time" in her life. When asked about it, she admitted there were a number of traumatic events over this period of time besides her mother leaving the family. For instance, Meryl was very sick in kindergarten and first grade. She had strep throat five to eight times a year. "I didn't start school until the middle of second grade," Meryl said. "Then I go to school and I'm bullied. They used to kick in the door of my bathroom stall." She laughed when she described one of the reasons for the bullying; her father was a barber for over 40 years, and he gave her a Dorothy Hamill haircut. "I didn’t look like Dorothy Hamill," she said. "I looked like a little boy." Another reason for her bullying was she was painfully shy. Because she started school in second grade instead of kindergarten, this led to social 
anxiety (something she struggles with today). She confessed to peeing her pants in school and wetting her bed until she was 12-years-old.

Once Meryl got to high school, she was in the popular "A" group; however, according to Meryl, there were always conflicts with her girlfriends at school. She found herself possessive of her relationships with her friends, and yet she didn't understand why. It seemed as soon as she got close with her girlfriends something would happen. She kept asking her mom, "What's wrong with me?" When she was a junior in high school, the class was asked to do a presentation on who was one of their greatest influences. For Meryl it was Debbie Gibson. "I loved her," Meryl said. "And I nailed the presentation. I even wore one of Debbie's concert t-shirts." After the presentation, a girl confronted Meryl by accusing her of being a lesbian. Meryl denied it. But in 1996, Ellen DeGeneres came out in Time Magazine with the headline, "I am gay." This was Meryl's watershed moment when she realized she was gay, too. While Meryl identified with Ellen, her dad who was a conservative (he listened to Rush Limbaugh), republican, and Italian-Catholic told Meryl, "Ellen will never see the face of God because she is gay." Meryl said, "My dad's comment struck me, and stuck with me."

A year later Ellen was on Oprah introducing Anne Heche as her girlfriend. Meryl realized, “THAT'S ME.” Soon after, at the age of 23, she came out to her therapist who asked if Meryl had read any books about being gay, or if she knew anyone who was gay. Meryl states, "I'd been raised in a conservative home. And, at the time I was a second grade teacher, so I didn't know anyone who was gay. I just didn't hang out in those circles." Her therapist told her to go on to AOL message boards to connect with others like her. That was where she met Whitney, her first girlfriend, who was 12 years older 
and living in San Diego. Before moving down to San Diego to be with Whitney, she came out to her parents.

Looking back when I was younger, I wore my hair in a mullet. I told my barber dad that I wanted it short and spiky in the front and longer in the back," she said. "Plus I dressed like a tomboy. I wore t-shirts and jeans all the time. Really, how could they not know?

When pressed about this issue, Meryl admitted her outside knew before her inside or before she was willing to admit she was gay. When she came out to her mom, she described the scene like "a very Taster's Choice Coffee commercial moment." Meryl and her mother were on the beach where she told her. "My mom was disappointed," she said, "But she understood." Her mom told Meryl she had to tell her dad. "It was the hardest thing in the world to do," Meryl said. "Needless to say, he didn't take the news well." According to Meryl, he was VERY disappointed. Meryl stopped the story stating: But I want to tell you something. Six months later, my family was at my grandmother's house. I was in her bedroom, in the dark, whispering on my cell phone to Whitney about my plans to drive that night from Long Beach to San Diego to go see her. All at once, my dad came into the room and turned on the light. I got off the phone, and he gave me a huge embracing hug. I knew what he was saying 'no daughter/child of mine is going to be in the dark, whispering on the phone, ashamed about who she is.' He didn't say a word but this conservative-Rush-Limbaugh-listening dad was connecting to me, his daughter, in a way that I knew I was loved unconditionally. 
Finding herself, finding her career. Growing up, Meryl was a big dreamer. She wanted to be a writer. In college, she discovered screenwriting and wanted to be a screenwriter. During this time, she wrote two screenplays. Meryl said, "I spent ten hours a day writing these screenplays, getting lost." One of them got read. She was told she was good writer, especially her dialogue, but she was told, "to go get more life experience."

After she graduated from college — she was the first in her family to graduateshe became a second grade teacher. She taught for two years before she decided to move to San Diego to be with Whitney. They bought a house together, and Meryl contemplated about going back to teaching. "I didn't want to teach. I didn't want to be in a classroom all day long doing the same thing," Meryl said. "I wanted to be outside. I wanted my days to be different but I wanted stability." Therefore, she decided to apply to be a police officer. She had saved $\$ 13,000$ from teaching, and on the day she had $\$ 20$ to her name, she received notifications from both the La Mesa and San Diego Police Departments that she'd been accepted into the academy. She went with LMPD "because it felt like family." Meryl laughs:

When they called my dad for a reference, the interviewer said to my dad 'we are concerned about Meryl because she is so short and petite.' My dad said, 'You don't know my daughter.' Seriously, I didn’t know I was short or petite. My parents had always told me I could do anything, and I believed them.

Meryl recalled a time when she wanted to be a singer and her dad — who was always supportive while her mom was more conservative — signed her up for singing lessons. Meryl was the one who realized she could not carry a tune, but her parents let her figure 
it out. Her parents' philosophy was “it doesn't matter how far you fall, pick yourself back up and do it again." When she became involved in San Diego's gay community, it made her sad to hear the stories of all the people who had been rejected by their parents and family because of the fact they were gay.

Meryl was confident when she joined the LMPD because of the way she had been raised. She found she was good at what she did, despite the fact that Meryl found the academy artificial

...by trying to give us realistic scenarios, but until you are out on the street it really can't prepare you. I could find the bad guy. I would get a call, go to the location, and be behind the car of the perpetrator.

She never thought about being a female in her day-to-day job at the police department made up of mostly men. "I thought of the guys I worked with as my peers," Meryl said. Yet, she was harassed for her entire fifteen-year career, including experiencing her sergeant put his hands down her shirt and a male boss bully her for her last five years. "I scored for the number one spot for the sergeant position twice but I was passed over for a man." Because she "maintained her poise and integrity," she became the first female in LMPD history to become Lieutenant and was positioned to become the Chief of the department. However, this would never be realized. In 2014, she was put on administrative leave when a sexual discrimination lawsuit had been brought up against her. One of the women dispatchers accused Meryl of sexual harassment. When asked why a woman was accused and found guilty of sexual harassment when the department has had other instances of sexual harassment by men to 
women, in typical Meryl fashion she shrugged and laughed, "I don’t know. The men are having affairs. There are dogs involved, and I get falsely busted for sexual harassment."

The next phase.

I look at this whole mess as a blessing," Meryl said. "Yeah, this wasn't the way I had planned things. But then I realized I had been spending many days on my couch where I was talking to someone [God], and saying things like there has to be more to life than this.

She had given up one position as an elementary school teacher for another. "I was making a disgustingly good income, and yet here I was miserable." She realized she was not political and, therefore, not interested in playing the political game. Meryl chose not to pursue a lawsuit against City of La Mesa and the LMPD for unlawful termination. She moved on because she knew every time there had been a shakeup in her life something extraordinary happened.

Meryl's friends have encouraged her to pick herself up and find a new career, like writing about her funny experiences on Match.com. Meryl is in no hurry to find another career. She wants to spend her time being kind and laughing.

I have had my fill of anxiety and depression. I take medication, but I make a conscious choice to be light, and enjoy what I'm doing. I think this is age related. I refuse to be a victim. Being happy is a choice.

She has surrounded herself with women from the gym who are supportive. Meryl said, "We don’t gossip. We care. We move each other forward." She acknowledges that she still has male friends. In fact, she still has a lot of male friends from the LMPD. Yet, it is Meryl's women friends, her support network, which she leans on the most. 
Meryl has a tattoo on her wrist, which translated from Latin reads, "Peace and Goodness." She got this to remind her at LMPD meetings to" bite her tongue" rather than saying something like her boss was a hypocrite. But now, at this stage in her life, it is a reminder that life is about balance.

During this time in my life, I admire those of us who follow through not like how we are in our 20s. Be passionate about what you do, whatever that is. This is our last call. Listen, I have slept the best I have in a long time. I live in a RV with my dogs. It's quiet. I am settled. I continue to be scared because of the insecurity, but I am excited because I have a support system.

\section{Rosa, the Immigrant}

Rosa is a 42-year-old Latina holding master's degree and is married with a daughter (age 11) and son (age 7). She works in public health at a local university. She is Roman Catholic.

An immigrant's American dream. Rosa was born in a rural town in south central Mexico on April 18, 1974. Las Animas (The Ghost) is in the province of Zacatecas, and had a population of less than 800 when Rosa was born. Rosa recounted they didn't have electricity and they had to get water from a well.

My father was a learned man, although he only had a high school degree. He read all the time, and wrote books about religion and politics. He wanted to be a lawyer, but his family couldn't afford it. That's why he always pushed me and my brother to get our education.

Her father had health conditions including epilepsy, allergies, and neurological problems caused by an accident. These health concerns, and the fact her father wanted more for his 
children, such as a better education, meant he tended to be reserved with the townspeople.

When Rosa was four, her uncle, who had been part of the Bracero Binational Immigration Program, helped her dad immigrate legally into the United States. Bracero means "manual laborer" or "one who works using his arms," and the program was a series of laws and diplomatic agreements that began on August 4, 1942, as part of the agreement signed by the U.S. for the Mexican Farm Labor Agreement with Mexico. The program brought Mexicans to the U.S. to work (usually in the fields), and in return they earned U.S. citizenship. Although her dad hated agriculture, he knew the value and importance of becoming a U.S. citizen. He thought his aspirations of becoming a lawyer could be realized. Rosa's dad ended up working at a store similar to Home Depot, while her mom, brother, and she waited back in Las Animas. Rosa explains,

I don't remember much about my childhood. Really anything. I know I have selective memory. I had mixed feelings about my hometown. It was full of machismos. Men told women what to do. There was abuse. My hometown showed me the injustices of women compared to men. While my dad had a high school degree, my mom only had a sixth grade education.

As learned and progressive as Rosa's dad was, she had many rules and restrictions. She could never wear pants. Rosa wasn't allowed to socialize, and therefore she had very few friends - girls or boys. Rosa said, "My dad was so strict. He ruled the house, my mom, me, and my brother." This was true even during the year or so her dad was in the U.S. seeking citizenship and the rest of the family was back in Las Animas. Throughout Rosa's childhood, her dad's strictness was hard; however, looking back Rosa 
said, "I realize now my dad was so strict because he was protective of me. He was also very loving, and had a tremendous faith in God, which he inspired all his family members and others around him to have faith."

At age five, Rosa's mother drove Rosa and her brother to the U.S. to stay. They were undocumented while her father had gotten his U.S. citizenship. This was 1980, and they moved to Norwalk, California. For a time, because of their undocumented status, they stayed with someone before they could be reunited with her father. "This is another time I don't remember much about," Rosa said. Referring to the isolation she felt in her hometown, and now again in the U.S., she exclaims, "Once again we were isolated." When Rosa was in kindergarten, her dad had an accident. There are not a lot of details since little was shared with her.

My dad never talked about the accident. Never. We never talked about it. All I know is he fell from a two-story apartment building. He had to go to the hospital. I remember my brother and I lived in the hospital with my dad because my mom had to stay with him. We slept and ate there. During this time, there were many "angels" in the family's lives. There was a priest who would give them food every weekend. They would get food from food banks, and "there were kind people at the hospital who allowed my brother and I to eat in the hospital's cafeteria.

After Rosa's father was discharged from the hospital, he could not longer work and went on disability. The family moved back to Las Animas so her dad could take care of his aging parents. Back in their hometown, her dad became a spiritual counselor. 
There were always people in their house. "Even though my dad didn't really associate with the people. He had a calling to help people on their spiritual journey."

Once back in Las Animas, Rosa's father pushed education more than ever. Rosa states,

He was the one who made me a feminist. He wanted me to have an education and not be a typical Mexican woman who cooks, cleans, and has babies. It's one of the reasons I don't know how to cook because my dad never wanted me to learn how or allowed me in the kitchen.

Rosa recounted she was "the smartest girl" in her class, actually the most intelligent in her class. When she went to other cities throughout Mexico, such as Zacatecas, Aguascalientes, and Guadalajara for academic competitions, she won. Because Las Animas was so small, she attended middle school via the television. The family was about to move to Guadalajara to seek a good education when her dad's brother-in-law passed away unexpectedly. Rosa's aunt, her dad's sister, and her six kids lived in Tijuana. Instead of moving to Guadalajara, they moved to Tijuana so her dad could take care of the family.

Yet, her father had an alternative motive. Her dad sought legal U.S. resident status for Rosa and her brother so they could cross the U.S.-Mexico border to go to high school in the U.S. (Rosa received her U.S. Citizenship when she was in graduate school at UCSD.) By this time, at age 16, Rosa was a senior in high school. She crossed the border every day to attend high school in San Diego. 
I didn't speak English. I was put in the ESL courses. By the end of my senior year, I could say numbers and colors in English, and that was it. We ended up living the American Dream, such as going to school in the U.S. of A.

This dream wasn't realized without a price to pay. She wasn't allowed to socialize; only allowed to cross the border, go to school, come back home and do homework.

I didn't wear the same clothes that everyone else wore. I wore different clothes, more conservative, than the other girls. I felt ugly. I didn't even go to my prom. I did go to Grad Night. My dad allowed it but told me to be home by 10 p.m. I didn't know what Grad Night was, but there I was at Disneyland and it was 9 p.m. I started to cry. I knew my dad was going to be angry, and I was scared. I couldn't do anything to get back home.

When she returned home after midnight, her dad slapped her in the face. This is only one story where her dad had disciplined her in this way.

Her dad expected her to go to the university right out of high school, despite the fact that she only knew colors and numbers in English. Her high school counselor helped her write a college essay for UC San Diego. She did not get accepted but went to community college instead. It took her three more attempts before she got into UCSD. She credits affirmative action and the Transfer Admission Guarantee program for getting her in the university.

Rosa wanted to be a lawyer. It was partly because it had been her dad's dream, and she knew he would be proud of her if she became a lawyer. However, the other part was growing up she had not heard of any other choices other than a lawyer, doctor, or engineer. 
I remember my first class was U.S. Constitution. I read the big, thick textbook by using a translational calculator and dictionary. I was so scared. I knew for the first time in my life I was going to get an F, and I knew this would bring shame and embarrassment to my father.

She contemplated suicide. Rosa said, “This wasn't the first time, I had thought a lot about suicide in high school."

She went to her dad to tell her she could not "do" college. He told her she could. This didn't motivate her. Rosa thought about running away, but she did not have anywhere to go. She did not know anyone in the U.S., and she had not been back to Las Animas since her family had moved to Tijuana to take care of her aunt's family. Without another choice, she sat down again with her English translation calculator and dictionary to help write every word of the midterm essay. She said, "When I got the paper back, I got a C-. It wasn't an F, and that's when I knew I could do it."

Rosa ended up adding Spanish Literature to her political science major. She explains, "I wanted to connect to minorities like me. I felt lost and different on the UCSD campus. I had no support system. It was a culture shock.” Spanish literature opened her eyes to social justice, politics, and history. This awakening is similar to what happened for her in her current job "where public health can be applied to anything in life."

Upon graduation from UCSD, her first job was at the Center for U.S.-Mexican Studies where her brother worked.

This is where I learned more about social injustice, and my cultural history. I also saw how my culture, the culture of Mexico, the hierarchy and patriarchy was 
overt. I was disappointed to see how men from different Latin American countries treated women, and how women treated other women in the political field. I was running away from a machismo hometown to see regardless of education and social status, machismo men were part of our Latin culture. Rosa stated that this was another experience that propelled her to work in public health in order to fight injustices and to help those who live in communities with the largest health disparities.

Living in two worlds. Around this time her dad was diagnosed with pancreatic cancer, and he was told he had three months to live. Her father sold his property in Tijuana and Las Animas to fund his cancer treatment in Mexico, which used alternative medicine therapies and was extremely expensive. While her father was being treated for cancer, Rosa went back to UCSD to get her master of arts in Spanish Literature, which she received when she was 25 .

Looking back, I feel bad. I think I threw myself into getting my master's degree because I didn't want to deal with my dad dying. I also know I was angry at him for dying and he was so accepting. Here he was in agony, and he would pray and smile. I didn't understand how he could be so spiritual during this time.

While sick with cancer, Rosa's father asked her to forgive him for how strict he had been during her childhood and adolescence. She conceded that she found it difficult to resolve her confusing feelings about her father, and admitted she never cried over her dad's death until three years later. When asked if she ever rebelled against her father, she admits she never did, though she explains her brother did. "It might be the reason I was my dad's favorite," Rosa said. This may indicate the cultural expectations of a daughter 
honoring the patriarch of the family regardless of whether or not he might be wrong. She did share that the more she was educated in the U.S., the more she felt a cultural tension between the two cultures she lived in.

Over the two years of her dad's illness, Rosa was awed by her father's spiritual transformation. During his battle with pancreatic cancer, he became even more than ever committed to God and his spiritual transformation. "When my dad was sick and before he died, sixteen priests visited him. They would sit and discuss God and death and heaven and forgiveness." Because her father no longer had money and he had U.S. medical insurance, he spent his last two weeks at UC San Diego Medical Center. At his hospital bedside before he passed, there were over 50 family members, including "my tias, tios, cousins, siblings, nieces and nephews." The U.S./Mexico Consulate, the place where Rosa had once worked, gave permission for this gathering to happen in the hospital room. "Most people think this is a sad time," Rosa said. "It wasn't for us and my dad. It was such a loving moment."

Searching for identity, searching for balance. Rosa thought no one would marry her because she felt ugly. "So if I was never going to marry, because no one wanted me," Rosa said adding, "And then, I would never be a mom." She, also, did not want to be like her mom and the other women from her hometown who were not educated and were expected to marry, have children, and then take care of the house. Therefore, she concentrated on her education and career.

Before her father's death, he predicted Rosa "would marry a blue-eyed, blondhaired man, have two beautiful children, and a happy and loving marriage." She didn't place much merit in her dad's words since, up to this time, she had only dated Mexican 
men. However, her father was not the only person who told Rosa, "I'd fall in love with a white guy." Andres was her college friend's best friend, but she'd never met him before until they ended up in a graduate class at UCSD together where Andres helped teach the class.

He is part Mexican [his mom is Mexican], smart, and a friend. Even though I'd only dated three other boys in my life [and her dad didn't like any of them], I had a spiritual and physical connection with Andres. I knew he was different.

In 2001, Rosa married Andres. In 2004, she became a mom for the first time with her daughter, Sofia. Rosa said, "This was so important because I never wanted to be a mom, and here I was with a beautiful girl.” Five years later they had their son, James.

When James was three, he nearly drowned. Rosa explains, I was at work, and Andres had taken the kids to our community pool. Andres was in the pool with the kids, when his phone rang. He took it, and he got distracted with the conversation. The next thing he knew Sofia was yelling about James sinking to the bottom of the pool.

Andres jumped in the pool, and pulled James out to the side where he started CPR. He told Sofia to call 911. The ambulance took James to Rady's Children’s Hospital. James survived, but Rosa feels a great deal of guilt. She feels strongly she should have been there. She feels if only she had been at the pool, none of this would have happened. She wonders if she cared more about her career than her child.

Rosa finds herself at a crossroads at this point in her life. She has fought against the cultural patriarchy. She has tried to come to terms with her dad's mixed messages of getting an education and career, and not becoming "another woman who is married with 
children." Andres supports "her feminist ideals" of working and earning a paycheck, and “he cooks more than I do." However, after James's near drowning and both of her children's health issues (James and Sofia have severe allergies and other health problems), Rosa wants to "just be a mom and open a daycare." When Rosa tells her friends and family about this idea, they all agree such a suggestion "it's ridiculous." Rosa feels she must continue to find ways for balance between the push and pull of two cultures, and her multiple roles she has in her life.

Finding peace and meaning. Rosa states, "I have now forgiven my dad in my heart. I've reconciled my relationship. Religion gives me peace." She attends Catholic Church every Sunday. In addition, Rosa has discovered Hugh Ross, an astronomer, who dedicates his work to demonstrating that science and biblical faith are allies rather than enemies. Ross's perspectives speak to Rosa with her deep religious beliefs and her commitment to science.

Rosa realizes she has not mentioned her mom.

I think it's because I don't want to end up like her. Don't get me wrong. She is an amazing, giving person. She is a saint. She is studying theology — this woman with a sixth grade education - to be a deacon.

However, Rosa understands it is her dad's voice which has been louder to her. "My dad told me to go to school, take karate classes, speak up but be respectful and loving. And yet my mom did none of these things." Rosa realizes there is something to be said for the way her mom lives her life. Rosa explains,

She has a real connection to God. And I now know how brave my mom was considering the time we crossed the border illegally to be with my dad. And then 
when my dad fell and spent all that time in the hospital. She didn't speak English, and she did her best with my brother and me, and my dad. She lives a very contented life.

It seems middle age has been a time of tension and reconciliation for Rosa. Since she's turned 40, she refuses to talk about her age. "I have been depressed," she said. “There is job insecurity, and I feel like I'm trying to give the best to my kids, but it is hard to balance work and home." She admits she has a mixture of feelings.

I have a good husband who is a loving dad to our kids. Andres is loving to my mom, and my brother's kids. I have a great job that allows me to be a mom and available to my children, but it's still so hard.

She also realizes other changes since she approached middle age.

For over five years, I've been trying to lose the last 10 pounds of 'baby weight'. And, I notice my face has aged. Recently, a clerk called me señora. I told him I AM NOT A SEÑORA. Another time someone called me 40, and I was only 36. This exploration of Rosa's life has been both reflective and difficult for her.

No one has ever asked me about my story, and so I've been talking to my cousins and other family members about our history. One of my cousins asked me why I never go to back to my hometown. My cousins shame us about how we don't embrace Las Animas. They say how lovely the people are, how beautiful the land is. But my dad never took us camping. We never hiked in the hills or explored. If someone asked me to choose whether I am American or Mexican, I would tell them I am both. I love my Mexican culture, but I am so grateful for this country 
and the opportunities it has given all my family to have a better life. This country has given me so much.

\section{PrinceFan69, the Biracial Artist}

PrinceFan69 is a 46-year-old, biracial (white and black) woman with a master's degree. She has a daughter (age 22) and a son (age 12) and is currently in a domestic partnership with a woman. She is a self-employed writer but is looking for a full-time job. Although she was raised Christian, she is now agnostic and devoted to science.

One nation under God. PrinceFan69's first vivid memory was of her baby brother's circumcision when she was six-years-old. She remembers walking into the room and "seeing blood smeared all around the room." She added, "I don't think there really was blood all over. Maybe I saw a drop of blood, but I do remember the screaming coming from my brother." She said, "What have you done to my brother?" She wondered how anyone could do this to a small baby, or anyone. She wondered what that kind of pain and trauma can do to a boy, and then promised, "If I ever had a son, I would NOT get him circumcised."

Growing up, PrinceFan69 had severe asthma and was often hospitalized when while in elementary school. She took prednisone for her asthma, which, at the age of 13 or 14, caused prednisone-induced diabetes. "I remember going to the theater, and not being able to see the movie," she said. "I had all the classic signs of diabetes, including drinking too much water, peeing constantly, vision changes." Finally, her mom called the doctor and said PrinceFan69 had blurry vision. The doctor told her mom PrinceFan69 probably had gotten mascara in her eyes. "Really?," PrinceFan69 said. 
"Not only was that doctor wrong, but he was a perv. I didn't realize until I stopped going to this pediatrician that not every doctor rubs his crotch on your knee."

She recalled that during her childhood there was parental violence, and soon after a particular violent episode her parents divorced. Her dad went to jail for nonpayment of child support. After telling me this, she quickly added, "But I want to be clear, there were good times. My dad was a storyteller, and loved storytelling. We used to listen to my dad's old radio shows and records. We loved Bill Cosby." The reference to Cosby had a postscript: Because of recent news about Cosby being a serial rapist, PrinceFan69 declared, "I'm done. It's all tainted."

PrinceFan69's family also had a strong commitment to civil rights. On the piano in their living room sat a framed photo of Martin Luther King, Jr. "My dad marched at Selma, and both my parents marched on Washington, DC," she said. "This stays with me, racial and social justice." What hasn't stayed with her is religion.

Both of my grandfathers were Methodist ministers. My aunt was a Quaker minister, and her grandson is a Catholic monk. My dad wanted to be ordained a Lutheran minister but they refused to allow this since my dad was divorced. Her father spent years petitioning the church to allow his ordination. (Her dad was very litigious and used the court system to harass her mother through legal arguments about custody and child support).

PrinceFan69 indicated she was aware of the patriarchal sexism, magical thinking, and gender biases of religion from a young age. She remembered how she and her brother used to roll their eyes when the minister gave his sermon. The only thing that the church did was "turn me into a feminist and onto wine. I love me some good old blood 
of Christ." The final incident that turned her away from Christianity was her mother's death from breast cancer. She indicated she is now devoted to science.

The breast-cancer diagnosis occurred when PrinceFan69 was 17. With her older sister already out of the house, PrinceFan69 took care of her mom. "I was either at work or school, and when I wasn't doing those two things I was cooking, doing laundry, grocery shopping, doing errands, and taking my brother to and from school," she said. The only reprieve was when her mom's friends would come and help when she was going through chemo.

During the years when her mom was in remission, PrinceFan69 got her own apartment. In December 1989, her mother passed away at the age of 48 .

If there is an afterlife that Christians told me about, if there is a heaven, my mom would have returned to me in my dreams, or in other ways. You know, she never has, and, more than that, every time I have a dream about my mom, it is negative. When asked why she thinks it is that her mom comes to her in only bad dreams, she talks about her father's passing.

I had my issues with my dad. But when he was dying a few years ago, my sister, my brother, and I sat around his deathbed and said goodbye. We cried, we talked, and we had a lovely moment. It was the way 'we' should say goodbye to our parents.

Yet, with her mother, she has unresolved feelings about her passing.

She [her mom] had just come to the realization she had been sexually abused as a young child, along with two of her sisters, by a family member. She was pissed, and she didn't want to die and leave us behind. I was her caretaker, and I was a 
selfish teenager. There is a lot of guilt about this time for me, [guilt related to the fact] that I wasn't able to be a better help to her.

With liberty and justice for all. As a senior in high school, PrinceFan69 went on an Outward Bound outdoor education experience. For this senior seminar, she and 25 classmates went to Big Bend National Park in Texas for three weeks. She said, "I learned about hunger. We learned how to work together and divvy up seven almonds because our food had gone bad. I learned what poverty feels like." During a three-day "solo" mission (fasting and alone), the counselors spaced PrinceFan69 and the other students throughout a gulley. She couldn't see anyone. They didn't have a tent. She slept on the ground. She spent her days writing in her journal "because there was nothing else to do." During this time, PrinceFan69 was the only one who had food, including crackers and fruit cocktail she had brought from home. "Because I had just gone through two years with prednisone-induced diabetes," she said, "I wasn't going to risk going into a diabetic coma from low blood sugar." For PrinceFan69, this trip to Big Bend National Park in Texas was a gift. "To this day," she noted, I am thankful for hot water, for food in the cupboard, for flushing toilets. I have such gratitude."

Travelling around the world has also given PrinceFan69 a better world perspective. PrinceFan69's obsession with traveling and seeing the world was fueled by her mother's family. Everyone on her mother's side has traveled extensively; they had studied, lived or worked overseas. (They call the family's desire to travel "the bug," PrinceFan69 told me.) Her aunt was a missionary in India for a number of years; her mother taught English in Turkey. Her maternal grandparents started and ran a tour company, travelling the world with vacationers for many years. They went to over 140 
countries "and took pride in being the first family to travel the Pan American highway in the late '40s." For PrinceFan69, world travel began at the age of 12 when she went to the UK with her grandmother and aunt. All the grandchildren were given a trip anywhere of their choosing at this age. At 17, PrinceFan69 took a trip to Amsterdam with her mother and brother to visit her sister who was studying abroad. When she was 18 , she lived in England for six months, and at age 19 she went back to England and took a trip to Greece. Decades later, she applied for and received an artist's residency in Romania. PrinceFan69's travel overseas gave her, in her words,

...a much broader perspective on what I have and what I lack, my role in the world and my rights and privileges as an American and where those rights and privileges fall on an international scale of well-being as a woman, a mixed person, an LGBTQ person, an educated person, and so on.

She added, "I think travel gives people a much needed sense of human perspective and develops independence, empathy, and awareness."

(Re)writing herstory. PrinceFan69's brother's multiple suicide attempts were given a prominent place when she was completing her timeline as part of her research interview. "I felt obligated and responsible to take care of him during the time my mom was ill and after her death," she said. "So, instead of going to college when everyone else did at 18 or19, I moved to San Francisco to get a job." She couldn't find one, so she started stripping. She said,

You know, last month I did a panel for Association of Writers \& Writing Programs. I had to get up there and introduce myself. I hadn't written anything 
down, and I noticed that the other panelists had a long bio typed out. I started to panic. Then I got up there and said, 'When I lived in SF, I was a sex worker.'

She indicated there are a number of reasons she shared this information for the first time publicly. One is that she is middle-aged, and she isn't apologizing or feeling shame for what she needed to do to make a living. The second reason is her feeling regarding how unfair and unjust it is to "make more money as a 20-year-old 'exotic dancer' simply because I have a female body than I do now with all my education, my MFA, the books I've published, and my life experience."

PrinceFan69 has always been artistic. She credits her Montessori preschool experience with beginning this creative journey.

I believe Montessori set a foundation of inquisitiveness, problem-solving, and self-directed work that has served me well in the pursuit of my goals. Its pedagogical theories and methods have resurfaced in my own teaching as I begin to develop Narrative Structure Modeling for writers and educators in the creative writing classroom. Incorporating hands-on work, the arts, and creative and technical initiative, NSM has revealed itself to hold many of the lessons I learned through Montessori.

Further, PrinceFan69 also said her dreams and dream work has been instrumental in the way she has lived her life. She recognized giving birth and being a mom to her daughter and son has been a life-altering event that has encouraged her to pursue her goals of being creative and living an authentic life. As a result, PrinceFan69 has published two novels, one in 2009 and the other in 2011, along with many short stories, poems, and essays. In 
2012, she went back to school to get her MFA. Next, she plans to apply to be admitted to a doctoral program in literature.

While PrinceFan69 said middle-aged has been a creative period with the publication of her novels and getting her MFA, it has also been challenging. "I have had severe anxiety all my life," she said. "I'm sure it was my asthma, my health, my hospitalizations, and my family life which contributed to the anxiety. It was profound." When her first book was about to be published, she noted, "I thought what do I do when I fly and have to meet with people about my book? What happens when I have to give an interview and talk about my book?" Her anxiety was debilitating, but she realized she had to do something because her dream of publishing was happening. She takes Prozac, which helps her overcome her social anxiety and panic attacks, but "more than that," she noted, "it helped me to live." Right around the time she was getting her MFA, her marriage ended and she started a new relationship.

When PrinceFan69 was asked about her thoughts and feelings about being a middle-aged woman, the first thing she said was, "I feel socially invisible." However, for her being invisible isn't negative.

For the first time, I am not looked at. I am not looked at for my body, for the way I look. I feel powerful. I am empowered. I am past the point of social expectations. I know myself well, and like the way I feel. I don't need permission to act or dress a certain way. I don't care.

She then added,

A couple of months ago, I had a scare about calcifications in my breasts. Since my mom died of breast cancer, I thought if I have to get a double mastectomy 
what kind of tattoo would I get across the front of my chest. I don't need my

breasts anymore, so what kind of creative statement can I make?

PrinceFan69 summed up her attitude about being a middle aged woman as follows:

"Middle aged means a place to wrestle with, address and think about the ideas, issues, and stories that I have had all my life and how these create meaning through my writing."

\section{Trixie, the Empty Nester}

Trixie is a 52-year-old, white, married, heterosexual, homemaker with sons, who she wanted labeled as Thing \#1 (age 25) and Thing \#2 (ages 23) in her profile. She is Roman Catholic and has some college education.

Looking backward, going forward. While Trixie completed her timeline, much like the other participants did by starting it chronologically with birth to present day, the task was executed with much more contemplation and reflection for the present day compared to the others. Trixie acknowledged part of the reason she has become more introspective in recent years is because she has more time. When asked about this time in her life, Trixie responded, "Getting old sucks, but it's better than the alternative," adding: I know it's cliché to say that. I really am enjoying this time because of the empty nest. For a quarter of a decade, I have only known what it was like to be a fulltime, stay-at-home mom. That's about half of my life.

Being a wife and mother fulfilled Trixie for all those years. She was kept busy by being a room mom at her sons' elementary school, the quintessential soccer mom throughout Thing \#2's illustrious and long soccer "career," and being "Mama" to many of her sons' friends. Being married and raising her sons might have been the first time in Trixie's life she felt she had a purpose. Ask her about her purpose today, as an empty 
nester, and she will tell you, "I STILL DON'T HAVE ONE." This question of purpose comes up often with her. However, she also mentions how much she likes her life now with her husband, and how both of her sons have graduated from college, live in Northern California, and have a long-term relationships with girlfriends. "I want to enjoy this time in my life," Trixie said. "I know the older we get the less time we all have." Trixie is all too familiar with this fact. In 2009, she lost her mother to Alzheimer's, and, seven months later, she lost her dad in the midst of a messy situation Trixie refers to as “outlaws" taking advantage of her dad. ${ }^{1}$ In 2013, her father-in-law passed away from cancer. "I know mortality is a fact, and I don't want to be immortal or anything, but..." Trixie paused for a moment before completing her thought.

I get it. In your 20s and 30s, you strive. You build and build and build and move forward, and then you hit the top and then it's all downhill from here. I've had to deal with both of my parents dying, and my father-in-law. They all had completely different scenarios, yet the result is the same, isn't it?

Going backward, looking forward. Trixie never wanted children, she noted, “Because I saw how hard my mom worked to raise four kids. I didn't want to do this on my own the way my mom did, and now how my sister was." If Trixie were to ever have a family, she wanted one that wasn't blended. Growing up, she had a half-sister and two half-brothers. Trixie's hope was to be married with a husband who would help her raise their children together.

\footnotetext{
1 'Outlaws' is the name Trixie gives her fathers' sister-in-law and her grown son and daughter who took advantage of Trixie's father's failing health and death.
} 
"My mom started working when I was five, and worked all her life," Trixie said. "My sister raised me." Trixie's father corroborates this story. Her sister, who is eight years older, made Trixie dinner, went grocery shopping, and took care of her while her mom worked. "I think my mom was trying to find herself, and maybe escape from her four kids," Trixie said. "I don't know what my mom was running from. She was the one who created her life." Then Trixie caught herself and presented a more charitable picture of her mother:

I have often judged my mom for the decisions she made, the men she married and those she didn't, and the three kids she had, and then me. But then I think, as I have grown older her decisions become clearer. She didn't abort me. She could have. Instead she made the hard choice of keeping me. Throughout her life, she made hard choices for someone else's benefit. I get this now.

Trixie has a complicated relationship with her sister. Trixie is aware of how maternal her sister was to her growing up. In fact, her sister is mentioned as the inspiration behind the second significant event on Trixie's timeline (after Trixie's birth on November 16, 1963, in El Cajon, California). When her sister was 12 and Trixie was 3, her sister made two matching dresses for Trixie and her to model in a fashion show at her sister's middle school. “

Being up on the stage with my sister in matching dresses was a special event for me; I felt special. But that was almost 50 years ago. I'm a grown woman with two adult sons. I think [my husband] and I have done pretty well, and yet my sister still treats me like a child. 
One constant in Trixie's life is her athleticism. From 1970 to 1978, she played softball, football, and basketball. Today, she plays soccer on four different teams, and she also does CrossFit, a high intensity strength and conditioning program. The soccer is special to her because of the connection she has to Thing \#2's soccer career. Thing \#1's passion is surfing, and Trixie wants to learn how to surf.

Why do my sons get to have all the fun? I raised those boys, took them to soccer practice, made them dinner, helped them with their homework, and with [my husband] provided them with opportunities to go to college, while they continued to go surfing and play soccer. It's my turn now.

Another constant in Trixie's life is her marriage to her husband. At the age of 21, after being suspended from UC Davis for academic failure and not marrying her high school boyfriend of five years, she met her husband where they both worked. They dated for a few years and married in 1987. "I also became a Catholic," she added. Her husband was raised Catholic, and one of her husband's neighbors gave her information about becoming a Catholic. She stated, “I remember this time in my life. I didn't have any patience. I considered everyone idiots. I looked around, and the nicest, most genuine people were Catholics. Loving means living with grace." This conversion to Catholicism was easy for Trixie, since she had been introduced to Christianity when she was eight. Her daycare provider used to take all of the kids to youth groups, summer programs, and Sunday services. She said, "It has always felt natural and comfortable praying to and believing in the Holy Trinity."

When Trixie and her husband had their first son in 1991, Trixie noted, "I retired from my accounting job. I was getting a promotion and more money, but after my eight 
weeks of maternity leave I wasn't about to turn my son over to someone else.” She added,

My husband never forced me to be a stay home, but he voiced his opinion that, if he had the choice, he would like me to stay home with the kids just like his mom did. And since my mom didn't, and my dad wasn't really around, this made the most sense for my family.

She also pointed out that her mom was 35 and her dad was 41 when she was born. "They seemed so old when I was growing up, and, since they were older than my friends' parents, they would pass sooner. I wanted to be around for my sons."

Many of the family decisions Trixie and her husband made were based on how they were raised by their respective parents. Trixie was raised in a blended family with her half-brothers and half-sister being significantly older than she was, with a working mom and an absent father. Her parents got divorced in 1988, a year after Trixie got married. Her husband was raised with his five brothers and sisters by a stay-at-home mom and a dentist father in a Catholic home where they stayed married until his father passed in 2013 .

Thing \#2 was born in 1992.

He was a very difficult child. He needed a lot of attention, and I gave it to him at the expense of our first son. If I could go back and change anything it would be that I would be more in tune with what was going on with my first son. Looking back now with my experience and education, I think he felt ignored because I was putting so much energy into our second son. He was resentful of his younger 
brother. He was obedient, and kept his feelings, including his dislike for me, inside.

Trixie noted that there is an irony here: "When I was pregnant with Thing \#1, I wrote a diary for him. I prayed he wouldn't hate me the way I hated my mom. And this is exactly what happened; he ended up hating me.” This is a new revelation for Trixie. While the boys were younger, Trixie felt she was "an all in mother and homemaker." When Thing \#2 was six, Trixie became a soccer mom:

My younger son was a gifted soccer player," she said. "I would continue to be a soccer mom even when he went off to college. For five years, I followed him around the countryside and drove to northern California a lot to watch him play.

Last year was her son's last season playing soccer, and this has left a void in Trixie's life. Thing \#2's college soccer career gave Trixie a purpose, and a connection with her youngest son. Also, she credits this time going up to northern California as being the time she was able to establish an adult relationship with her oldest son. However, now that there is no longer soccer in her son's life, Trixie is forced to rethink her purpose for her life.

Circle of life. In 2002, Trixie was diagnosed with breast cancer and went through a double mastectomy, radiation, and chemotherapy. "I've been cancer-free for over fourteen years, but I still get tested once a year," she says. Since the diagnosis of Trixie's cancer, she has had a number of additional transitions and challenging events in her life. In 2004, her mom was diagnosed with Alzheimer's.

My sister and I had always thought she had mental issues, but this was finally a verification. In some ways Alzheimer's was a blessing. My mom forgot how 
unhappy she was. She seemed to be always searching...searching for purpose, searching for happiness. Happiness is a choice. Love is a choice, and it seemed in her later years Alzheimer's made these choices for her.

Because her sister lives in Texas, and one brother lives in Las Vegas and the other is homeless, Trixie was left to care for her mom over the years of her illness. In 2005, Eddy, the family's beloved family Boston terrier, had to be put down. "I never want to make another life ending decision again," Trixie says. Trixie's mom died in 2009.

Seven months after her mom's death, her dad passed. He had suffered a number of strokes, which left him mentally incapacitated. His seventh wife, the love of his life whom he married after divorcing Trixie's mom, had died in August 2005. In 2010, her dad became sick. Seeing an opportunity, his deceased's wife's sister, son, and daughter took advantage of her dad. They stole money, had him co-sign papers for cars, property, and businesses. "Worse [than that]," Trixie claimed, "They poisoned me to him. They told him lies about how I was trying to control him and his money. They said that was all that mattered to me," Trixie acknowledges the irony here stating, "When my dad died, they stole jewelry and other property, and they took me to court to refute his will." Realizing it was going to cost her too much money to go to trial, Trixie decided to settle out of court. "I am trying to let go of my resentment and extreme dislike for the outlaws," she said. "I know they will have the ultimate judge when they pass from this earth." In 2013, Trixie's father-in-law died of cancer.

Like many of us, Trixie's middle-aged years have been a period of loss and transitions. For instance, in 2011 both her sons were off at college, and by 2015 both had graduated and now live in Northern California. The empty nest makes Trixie mostly 
happy. She and her husband have more time for each other. In 1996, when she was in her early thirties, she reconnected with her girlfriends from her high school days. For over twenty years, some of these friends and Trixie go to dinner once a month, and on weekend trips at least once a year.

Today, at 52, Trixie is reflective. She has learned that love and happiness are choices, and "that God (or the Holy Spirit), whatever you want to call it, leads my life." She added, "Having your heart open to the truth is important, and if you're open to learning, you will." Yet, despite reconnecting with old friends, living a mostly contented life with her husband, and having an open heart, she is haunted by not finding her purpose.

I think I'm afraid of finding purpose at this stage of my life," she said. "If my purpose is substantial, a higher purpose, like advocating for the elderly in the way I did for my mom and dad, it might not be fun. I have control where I'm at. I'm not suffering where I am.

She doesn't want things to be difficult, and stability is important to her since "while growing up my life was in flux." There is tension in this time in her life between finding another purpose now that her sons are out of the house and enjoying the rest of her years because she's earned it. "When is it my turn?" she asks. "Isn't this my time to be a fuck up?"

\section{Lynne, the African-American Christian}

Lynne is an African-American Christian who was born on October 9, 1960. She has a master's degree and is currently an executive for a nonprofit organization. She is married with a daughter, Joshlyn (age 31), and a son, Jeremiah (age 21). 
Death and rebirth. The first event Lynne noted on her timeline was the murder of her brother in 1982. He was 21; she was 22. The following year, she took her son from a previous relationship, Jason, to visit her brother's grave and place flowers at the site. She was unable to find the headstone. David, a groundskeeper at the cemetery, who would turn out to be her future husband, asked if he could help her locate the site. It turns out David knew Lynne's brother, who was very popular. Lynne and David dated for a year and then became engaged. Right before they married, Lynne got a call from her fiancée. "He wanted me to drive him to the ER," she said. "This was the first time I found out his kidneys were failing."

Despite his serious health problems, Lynne and David married. She was 24; he was 27. Jason was 18 -months-old at the time. For almost seven years of their marriage, David was on dialysis three times a week.

We both worked full-time. After work, I would pick him up and drop him off at the dialysis facility for his $3 \frac{1}{2}$ hour dialysis treatment. Then I would go home to make dinner, do homework with the kids [which, by now, included their daughter who was born in 1985], and then go back to the hospital to pick up my husband. When asked how she did it, Lynne said, "God's grace. [This is a common motto of Lynne's.] I took my vows seriously. I was a wife, mother, and employee. Whenever I had things that needed to be done, I got them done."

In 1991, her husband had a successful kidney transplant. The donor was 19years-old. 
My husband gave a new life to this boy who had lost his. Once again God blessed us. There have been no complications. No rejections. My husband was a model patient. He ate the right things, and listened to the doctors.

The whole family adapted to David's diet. To this day, they have maintained (for the most part) the same healthy renal diet of low sodium, low potassium, and low phosphorus that they began eating immediately after David's transplant.

In 1995, once she knew her husband was healthy, Lynne enlisted in the Navy Reserves. She figured this was her opportunity to serve her country by working one weekend a month, and two weeks out of the year. Still, she was 35 at the time and had a newly healthy husband, a 14-year-old son, a 10-year-old daughter, and a newborn son. Lynne explained why she decided to join with such responsibilities:

I'd always wanted to the join the military since I was in high school. However, I allowed family to talk me out of it, because they said things like 'you know people are going to tell you what to do,' and 'you will have to get up early in the mornings.' My response had always been, 'Yeah, you're right.'

Lynne conceded she wasn't so much talked out of enlisting. Rather, she didn't have the confidence at 17 to make decisions "for my future." So she waited until she had the wisdom and confidence to join, and, according to Lynne, it was worth the wait. "I'd always wanted to travel and get my education," she said. "I traveled to Hawaii for three years, then Italy, and Japan the following years."

In 2003, when Lynne was 42, her first son, Jason, passed away from Deep Vein Thrombosis (DVT). He was a 6'9", 290 pounds, and an apparently "healthy football player." Jason had injured his ankle playing football. Everyone agreed it was probably 
just a sprain. Jason went to Kaiser Medical Center because he had congestion and was having difficulty breathing. At the time, the ER was dealing with a lot of people because it was flu season. "So they treated Jason for congestion, as if it was the flu," Lynne said. "It turns out, if they would have taken blood, they would have realized he had a blood clot lodged in his lungs." Although it seemed like it was days later, a couple of weeks went by before Jason passed.

We had an autopsy so we could understand how a healthy young man could pass so suddenly. That's when we found out he had DVT. Of course, after his passing we saw all sorts of information and television commercials about DVT.

Much like she had handled her husband's health issues, Lynne picked herself up. "I knew I couldn’t mourn, or go to that dark place," she said. "I had a family to take care of." When she was pregnant with her youngest son, Jeremiah, she said, "Lord, what do you have in mind for me?" Jeremiah would be 10 years younger than her daughter, Joshlyn, and 14 years younger than Jason. She questioned what He had in store for her. Now she knows. "Jeremiah looks and acts identical to Jason, like his older brother. He's 6'7", and athletic like Jason," she said. "Since there isn't a day I don't think about Jason, I have an opportunity to see Jason through Jeremiah."

Moving on. Even though Lynne had two more years to serve in the reserves, her heart was not in it after Jason's death. In 2004, Lynne received her Bachelor of Science in Computer Science and Information Technology from the University of Phoenix. Lynne said, "I was into computers, and I'm glad I understand computers and how to use them. My uncle, my mom's brother, graduated from college in computer science. He was the oldest sibling. I wanted to be like him." 
Before her brother was murdered, before she had Jason, before she met and married David, Lynne had a chance to go to fashion merchandising school in Los Angeles.

I was accepted in the school of Fashion Merchandising and Design in Los Angeles. When my mother and I went to visit the school, she asked me where I was going to live. I shrugged my shoulders. I had no idea. I was only 17 . So, I put college on hold until I was older and my kids were older, and my husband was healthy.

In 2008, Lynne received her master's degree from Ashford in Organizational Management. "I became very involved in nonprofit organizations. I've worked for organizations focused on teen pregnancy, child and youth like Head Start," Lynne explained. Lynne has also worked as a civilian government contractor stating, "My first terrorist experience was when I served on active duty during 9-11. I worked with a fourstar general as a public affairs officer and Executive Assistant. It was great money. If I'm honest, I miss the money." Lynne appreciates the controlled world of the government and the armed services. For almost two decades, she appreciates that there was direction and money and resources. Currently, Lynne is the Director of Missions and FreshStart discipleship at her church. Lynne acknowledges that in the nonprofit world, "we are always pinching pennies and trying to produce a good product. We are always trying to work and help those who need us the most on a shoestring budget. "

Lynne is committed to doing good on behalf of others, but states, I'm ready for a change, a transition, a transformation. This time in my life, I want to separate my work life from my spiritual life. I've thought about getting my 
Ph.D. Being a student means my success is my measurement, and not anyone else's.

During her midlife, Lynne said, "I look back, and even now, I want to be a role model for my kids. I never wanted to think they were a hindrance. I want to be the best I can be.” Lynne reflects, "Throughout my life, I turned lemons into lemonade. And if you don't take a risk, you're not living."

\section{Michelle, the Researcher and Active Participant Observer}

I am a 52-year-old, white married woman with a master's degree, and seeking my doctorate. I have two daughters (age 23 and 27), and a son (age 13). I am a principal investigator on many large health-related projects at University of California, San Diego. Although I was raised Catholic, I consider myself spiritual but not committed to any particular faith.

My father's daughter. I was born on October 3, 1963, in Pensacola, Florida. My parents married on December 22, 1962. My mom was 19 and my dad was 22 when they married. The reason they got married so young (and, also, so soon after they met) is because my dad was being relocated to Florida to be trained as an officer and pilot in the Navy. Essentially, my mom was pregnant with me their first nine months of marriage. Consequently, in a lot of ways, I grew up along with my parents. Quite literally, I have been part of their marriage for their 53 plus married years together.

When my mom was pregnant with me, my dad was partying a lot (a euphemism for drinking too much — my dad had been an alcoholic without seeking treatment until I was eighteen). Years later I asked my mother, "Why did you stay?" My mom answers, "What was I going to do? I was twenty, Catholic, married, and 3000 miles away from 
home. I didn't really have a choice." This lack-of-choice scenario is a common refrain not only in my mom's life but also in the lives of other women of her generation.

Fourteen months after me, my sister was born. My mom recalls this time as both lonely and wonderful. My dad was gone for months at a time, but my mother had the other officers' wives to keep her company.

After my dad's requisite four years, he got out of the Navy. We moved back to San Diego, where both of my parents were raised and my mom was born. My brother was born on New Year's Eve of 1968. There is family folklore of my dad insisting my mom have my brother before January 1, 1969, for tax purposes.

There are stories I could tell about mothering my mom and taking care of my brother and sister. I choose not to. It is important to know, however, I confronted my dad more than once about his drinking, especially when we lived in Pacific Beach (PB) from 1967 to 1976. During this time, there were beautiful hippie women who baked zucchini cake (What? A vegetable in a cake?), spun pottery, and loved art. This was the time of free love and peace, nakedness, and communes. Dad associated himself with all sorts of people: a couple from Ethiopia who wore colorful robes, the man who walked with a beautifully carved cane; a nudist commune in Valley Center; and, a Hare Krishna temple. We also took family field trips to Horton Plaza in downtown San Diego when it was full of veterans, the homeless, and hookers. For me, these experiences were both magical and frightening.

At an early age, maybe eight or nine, I realized I was living a different life than those around me. While the adults were living the life of the sixties by partying, smoking pot, drinking, and listening to Led Zeppelin, Eagles, Crosby, Stills, Nash \& Young, and 
Cat Stevens, I hid in my room waiting until everyone who had come to visit for the evening (or longer) went home. These were days of staying in bed with migraine headaches, and stomachaches. Norman, my white cat with a green eye and blue eye, was my best friend.

In PB, Mr. Bernard lived down the street. Every day he wore his casual Navy retired uniform, although he had been out of the Navy for decades. He had a wife and two grown daughters in their 40s or 50s. The neighborhood kids called the wife a witch because she had dyed black hair, and we had to leave Mr. Bernard's house whenever she came home. Years later, decades really, we kids didn't realize she was the one who protected us from him. When there was a mass exodus from the neighborhood, the explanation was that Mr. Bernard had a record as a pedophile.

In 1976, my family moved to Alpine. While living in PB, my dad had worked as a carpenter for a bar in Hillcrest on Fifth Avenue. The owner of the bar couldn't pay my dad, and he was foreclosing on his house in Alpine. Therefore, the owner traded my dad's pay for easy access into buying the home. Google Maps says Alpine is only 34 miles away from Pacific Beach (PB), but it could have been 3400 miles. At the time, in the late 70s, the town had one stoplight, no sidewalks, and one grocery store. But there were other differences: life was slower, quieter, and, more boring than PB. For me, Alpine was so unusual it was painful. Or, maybe it was me who felt odd and unusual since this is the way the other kids made me feel. I spent sixth grade leaning against a wall watching the other kids play during recess and lunch. At home, I'd escape to my room and read. When I went to high school "in town" (i.e., in the larger city of El Cajon), I hung out with the popular group, although I remained an outsider because I 
lived in Alpine. I threw myself into academics, went to high school dances, and spent many weekends in El Cajon with various friends so I didn't have to go back home to Alpine.

After graduating from high school in 1981, I met my first husband, Bill, at my first fraternity party, my first weekend at SDSU. Bill was attentive, good-looking, funny (so funny), and available, and, now, looking back, perhaps safe. I knew he would never leave me and never have drinking or career problems like my dad. Indeed, throughout our relationship and marriage, Bill never did have these issues. He was paternal in a lot of ways, buying me my first brand new car, before we were even engaged, and supporting me through graduate school after we married. Bill financially supported me in ways my father never did. Yet, Bill ended up being just as emotionally unavailable as my dad.

Breaking apart, breaking free. Bill and I married in 1985. In 1989, I became a mom to Molly, my first true love. Being a mom, being a good mom, has been a huge identity and purpose for me. In 1992, I had Kelly. When Kelly was around two and Molly almost five, I had a breakdown. I was going on a business trip to New Orleans, and I prayed I would break a leg, requiring that I cancel the trip, or that one of the girls would get sick enough to keep me home. Neither of these things happened; instead I lost 10 pounds in a week before the trip to New Orleans. I flew to the Big Easy for the business trip with a lot of help from Xanax and vodka. I was a mess; I only left the hotel room when it was absolutely necessary for trainings with the other three research sites involved in the large NIH project we were undertaking. 
When I returned to San Diego, there was a crack in the illusory "perfect" life I had been complicit in creating with Bill. What did I have to complain about? We owned a house, we had two dependable cars, food on the table, and two lovely and healthy girls. Yet, I continued to live a lonely and scared life. I sunk deep into depression and anxiety. I kept up the façade as long as I could. On the outside I maintained my roles as a wife, mother, employee, etc. But, this ended on December 16, 1996. On that date, Molly became very ill during a second-grade fieldtrip to Old Town. Because I have written a novel and a memoir about it, I will not spend a lot of time rehashing the experience. Four days after she became ill on the fieldtrip, I took her to our family physician. He took one look at her, and said, "Drive her to Children's Hospital." There, she was immediately admitted, and after an ultrasound, blood work, and other diagnostic tests, we were told she had a ruptured appendix.

Bill was on a business trip in Philadelphia, so I called my mom to pick up Kelly and my aunt sat with me during Molly's surgery. For seven days, I stayed in the hospital while they pumped Molly full of antibiotics to prevent sepsis. During that week, I took a hard look at my life and assessed what was important. We could have lost Molly; she could have died from "how bad" (a quote the surgeon said numerous times) the cleanup was from the ruptured appendix. So, on December 16, 1996, I realized I had to start letting go of the story of the perfect family, which included a sober husband and father to our children, a house in the suburbs, two cars, and a yearly family vacation in Hawaii.

In 1997, Bill and I officially separated. I struggled with embracing a new identity of being a separated working woman with two young daughters. I was surrounded by heterosexual, married couples, where the man worked and the women stayed home (or 
worked only part-time) in order to pick up children from school. Often these women dropped off their children at school in the mornings dressed in their white tennis clothes to make their 9:15 tennis game. These women volunteered as room moms and served on the PTA board. I was no longer part of this tribe, although I now realize I never was.

Changing the narrative. When I separated from Bill, I was in my early 30s. For the first time in my life, I stopped for a moment and reflected upon my life thus far. I took an inventory, of sorts. I was a good mom. I had moved up in my career at UCSD. Yet, were these the only two roles I was destined to play? At this point in my life, I would have been okay with playing only these roles since there was some security in clearly knowing who I was rather than aspiring to do things I had not already done (and knew I could do well).

In 1999, I became involved with David, a co-worker at UCSD. For ten years, he had been my friend who listened and a man who cared. I wasn't looking for love, since I was content to be Molly and Kelly's mom and had a fulfilling career that I continued to grow in, but I found a very special love with David. On our first "date," David said to me, "You are the most together woman I know." I did not question his judgment or how he had experienced me. I knew David is a man of a few words, and what he said is his truth.

In 2002, David and I married. Because David was such a wonderful man and great stepdad to Molly and Kelly (even before we were married), I said I would be willing to get pregnant before I turned 40. Jack was born in 2003. I thought I'd have a baby, and "put baby in the corner." Jack, however, was not going to be put in the corner and ignored. 
Today, more than ever, I question my thinking. Had I not learned anything from my experience over my four decades of life? Ultimately, I know I'm responsible for achieving the life I want, the life I lead. And, yet, I had relied on others, my dad, Bill, and David to make this come true. This is not to discount the village needed to achieve my vision, the life I want, but I know I must be the captain of my ship. I needed to step up, lead my journey, and stop playing the victim.

A postscript. In my early 40s, I found myself talking to a number of women in their 50s who said when you get to be their age you become invisible. What? No way, I thought. Maybe if you stop wearing beige and sitting in the corner, you'd stop being invisible. What if you put yourself out there, wear red lipstick, and own your power? So in my mid-40s, after Molly had graduated from UCSD, Kelly was on her way to UC Santa Barbara, and Jack had conquered the first four years of elementary school, I decided to go back to school. It was my turn. Plus, I wanted to get out of my corner. I had a wonderful life, a wonderful family, and a good job. Yet, I yearned to push myself, to continue to grow and learn. In 2012, I began the doctoral program at the University of San Diego in the School of Leadership and Education Sciences' (SOLES) program in Leadership Studies.

\section{Analysis of Narratives}

Analysis of narrative was used to examine the six women's histories to identify the diverse and similar experiences, events, and actions the women have had through the course of their lives. Table 1 provides the names, titles, and description of the six participants. Based on this information, there are differences in ethnicity, marital status, 
sexuality, and whether or not they had children, and if they did the varied ages of the children.

Both in vivo and focused coding were conducted in order to delve deeper into the participants' narrative profiles to identify both diverse and similar experiences, events, and actions among the women. First, based on in vivo coding there were diverse experiences where only one woman had the experience. Examples included coming out, immigration and living in two cultures (i.e., bicultural), the passing of both parents (mother from Alzheimer's and father from stroke), the role of a stay-at-home mom, and the loss of a child. Second, focused coding was used to find the most frequent or significant codes or themes using the in vivo data. Some of the themes included: experiencing at least one traumatic event (i.e., divorce, death of a parent, violence, etc.); being educated (five out of six women have a graduate degree); being sexually harassed or abused; focusing on a higher purpose or spirituality; serving others or caretakers; and, the importance of being a mother (only Meryl did not have children).

\section{Conclusion}

The narrative profiles highlight both the diversity and the similarity of the participants. When the women were recruited, there appeared to be only two common variables among the women: gender and age. Indeed, many other demographic variables, such as race, sexuality, religion, career, etc. and life experiences were varied. As mentioned before, this diversity in life experiences and identities are important when researching narrative leadership. In other words, it is proposed that only with diversity can we "see" how photos and accompanying stories impact the participating woman's thoughts, behaviors, and/or actions (i.e., narrative leadership). However, the analysis of 
narrative also showed the women had similar life experiences, which helps with sharing empathy.

Chapter 5 presents the results from the three intervention sessions, and Chapter 6 focuses on the findings from the post-intervention interviews. 


\section{Chapter 5: Results, Part II - Sessions}

The design of the study entailed creating a diverse group of middle-aged women who participated in three photovoice-inspired sessions. In Chapter 4, the narratives about each of the participants supported the fact that the six women (including myself) were diverse based on such things as ethnicity, religious beliefs, and sexuality. This chapter describes what happened during the sessions that were part of the photovoice-inspired process.

The three, two-hour sessions were held at my house. Food and beverages, including wine, were offered at each session. The sessions were conducted in the main room of my house around a large dining room table. The six participants sat in a Ushape, and the two facilitators (Avonlie, the lead facilitator, and Hilary, the photographer/educator) sat at the head of the table with their backs to the video camera.

For Session 1, the basic agenda was as follows: welcome/introductions; introduction to images and the stories they tell; create and share a personal collage; introduction to women photo essayists; and instruction for "homework" and evaluation of the session. Both Session 2 and Session 3 followed the same agenda which was for each woman to share the two enlarged photos they had taken and brought to the meeting, followed by a group discussion about what stories and themes were being told by the images. When the discussion ended, the photographer explain what story she had intended to tell with the photos. Once all six women had shared, we had a discussion about common themes and stories.

\section{Session 1}


Preliminary activities. Once the women were settled with food and drink, Avonlie (the facilitator) welcomed the group. She then turned it over to me to explain the project. Among other things, I welcomed and thanked them for participating. I had told each of them individually what the purpose of the project was, but I told them as a group that the purpose was "to see if sharing photos and other images, as well as the accompanying stories, can influence our thoughts, behaviors, and actions." I did not mention the word "narrative leadership" because I did not want them to be confused with the language. Further, I emphasized this was "an exploratory" project and that there was no outcome or product per se, but "I was interested in this process." Before they signed the consent forms, I described the consent form process and highlighted important topics such as confidentiality and the voluntary nature of the project.

Next, I asked if there were any questions the participants had. As it turned out, they had no questions at this point, though, at the end of this session, they wanted to be sure the photos they would take prior to the next session and bring to that session met my expectations. I assured them that I did not have expectations, that this was an exploratory process, and that we would work with whatever they produced. (At the start of the second session, Lynn reiterated the latter point when she noted, "We are the project.)

Finally, the participants, including Trixie, Rosa, Lynne, PrinceFan69, Meryl, and me, as well as Avonlie and Hilary, introduced themselves. During their selfintroductions, all expressed excitement and curiosity about what would happen in the project. 


\section{Introduction to photovoice and photo essay.}

Hilary: "As I mentioned I have a photography and education background.

I have a tendency to work with students at a much younger age, usually elementary school students. But I welcome this opportunity to work with you all today. I'm really excited.

What have you learned about photovoice, or has anyone in the room ever heard that term before? “

With the exception of Trixie who knew a little from my interaction with her, no one else was familiar with the notions of photovoice or photo essay.

Hilary: "So, photovoice is a process of telling stories and taking action through photography as a medium. Photography is a piece of the visual, how we are visually sharing with each other. The really important part of photovoice is the discussion with each other, and storytelling really brings forth those ideas we get from the images. “There's another part too, and that's action, but for today we are really focusing on visual storytelling and how we can share these with each other.

"Whenever I think about visual storytelling, I think about the saying, I'm sure everyone has heard it before, 'A picture is worth a thousand words.' When I look at a picture, I tend to think of a thousand words or one word. Photos can affect us in different ways. What I think is so important about photos is that we can interpret images in different ways, right? We bring our own 
experiences, our vision, our past, anything, every time we see a photograph.

"To illustrate this point, I brought some photographs with me today to share with you. I'm going to share the photo, and then I'm going to ask you a couple of questions about the photos. I just want you to answer honestly and immediately. I also encourage you that if you connect with what someone else has said, I encourage you to connect with that and continue to build on what they are saying."

Hilary: "Here's the first photograph. I want you think about one word that describes this photo. What is the story that is being told by this photo? “

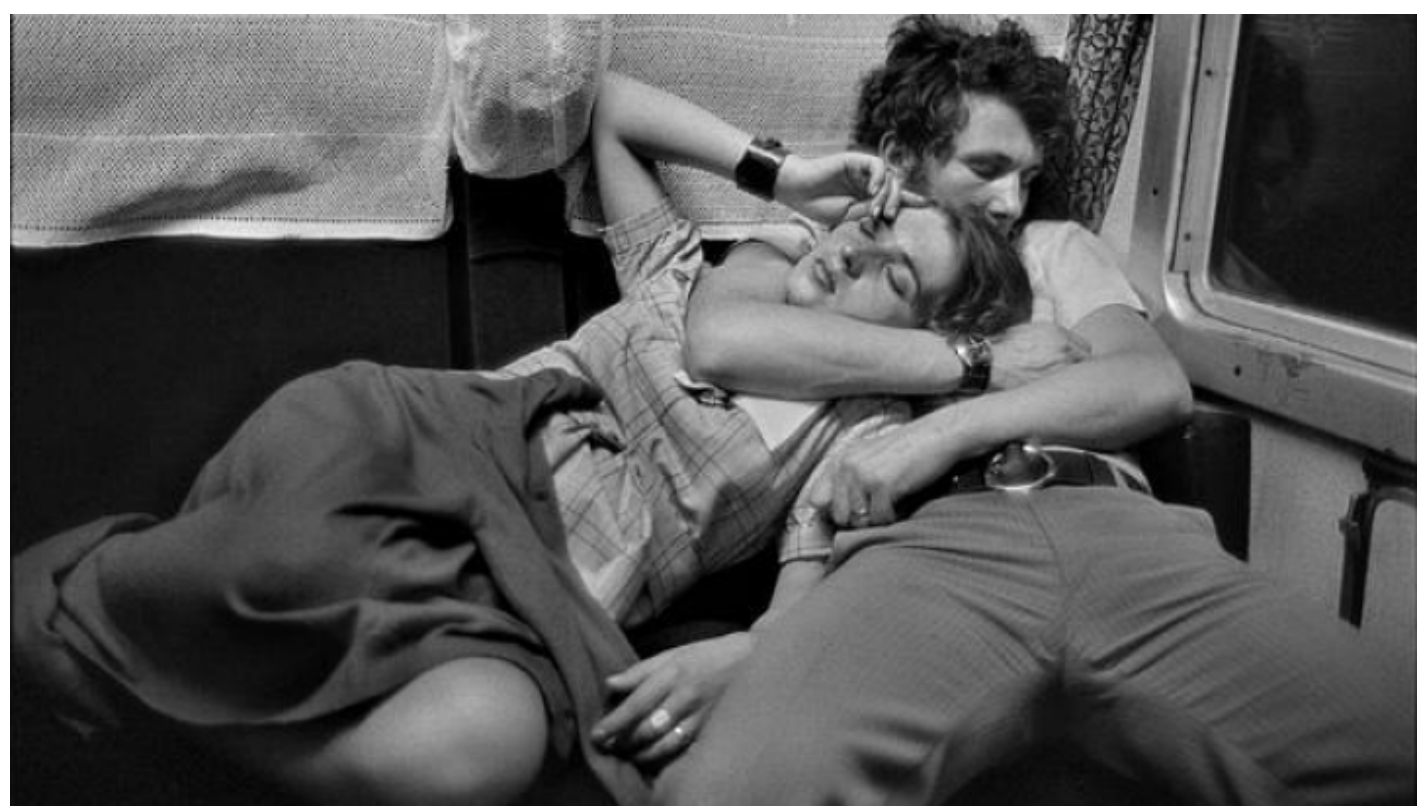

Figure 1. In a Train (Cartier-Bresson, 1975). 
Michelle: "Exhausted."

Lynne: “That's what went through my mind, exhausted. Relieved, comfort."

Avonlie: "Passion."

Trixie: "Romance."

PrinceFan69: "Possession."

Meryl: "Control."

Hilary: "And what did you see in the image that gave you those kinds of words? Who said comfort?"

Lynne: "I did. They're embracing [she demonstrates with her hands] so I see them relaxing. They're in a relaxed state."

Hilary: "So you see this in their body language?"

Lynne: “The fact that he's not sitting up and looking around. He's kind of lost within himself. There's some kind of comfort in that."

Hilary: “The fact he’s not sitting up. There's something about his posture." Any other thoughts about why you chose a certain word?"

Trixie: "I chose "romance," because to connect and touch like that seems intimate to me."

Hilary: "Probably not strangers on a train in this kind of pose."

Trixie: "Oh, I hope not. I thought it was a bus...."

Hilary: "So traveling. There is some intimacy and comfort that we notice in the way they hold each other. So their mannerisms and their 
body language tells us that story [of romance, intimacy, and comfort]. Any other thoughts about this image?"

Rosa: "Violence or controlling. My first word about the image was of exhaustion, but then I thought about controlling

[PrinceFan69 had the same words].

Rosa: "The way he has his arm around her neck.

[Rosa demonstrates].

Rosa: "I would never feel comfortable."

Michelle: "Meryl you said something about control."

Meryl: “He's embracing her around her neck, and she doesn't look comfortable. That makes me uncomfortable."

[Rosa's and Meryl's body language indicate both of them feel uncomfortable.]

Meryl: "I feel claustrophobic."

PrinceFan69: "And the way his arm is framing her head."

[PrinceFan69 demonstrates how awkward the woman in the photo appears.]

Trixie: "She does seem a little distraught."

[This is a change from Trixie's original thoughts of "romance" and "intimacy."]

Hilary: "You notice the angling of bodies and how they're coming together. One subject's body is more relaxed and in one state, and she is a little more uncomfortable."

[Hilary demonstrates.]

Hilary: "There's a conflict." 
There was more dialogue around the table regarding the photograph of the couple, and how an image tells a story through setting and background, style of clothes, body position and posture, and using black and white film as opposed to color. PrinceFan69 commented that the photo seemed "timeless," and "since the photo is in black and white, or it could be in the 50s. You can't really tell where they are." Trixie commented, "To go along with the 50s, it seems like with his straighter pants and the white t-shirt. It's hard to see what she has on, the sweater over her legs...I don't know. It seems like summer in Kansas.”

Hilary shared three other photos, and, for each photo, led a group discussion that was similar to the one above, though, of course, the specific items noted differed because the photos differed. .

\section{Creating personal collages.}

Avonlie: "As a way to practice creating stories and telling stories, and also introducing ourselves to each other, we are going to do collages. I think the best way to describe our next activity is speed collage. We have fifteen minutes. Take five minutes to look through the magazines provided. So, take the paper and adhere four or five images, or you can draw as well."

[I distribute paper, glue, coloring pens, etc.]

Lynne: "So, the collage is representative of our lives? You want us to pick out four or five images that represent our lives?"

Avonlie: "Yes, whatever you want us to know about yourself."

Lynne: "Some way to tell some part of the story related to us." 
After approximately fifteen minutes of working on the collages, Avonlie turned the facilitation of the session back to Hilary who led a discussion of the collages. Each of the participants was asked to share the images and accompanying stories.

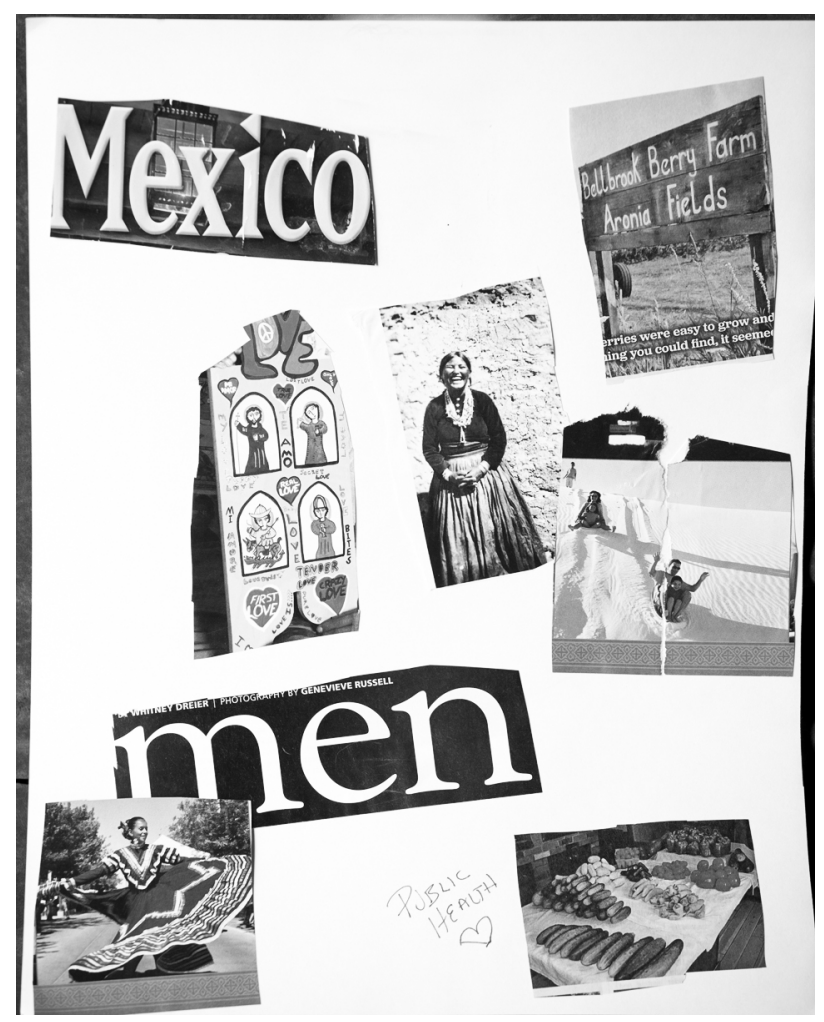

Figure 2. Rosa's Collage (Rosa, 2016).

Rosa: "So when I talked to Michelle about this project, it was really interesting because she asked me about all of these questions about myself, and what I thought about myself. She asked me all these questions when we did my timeline about where my family comes from and how I got here. 
“I'm from Mexico, central Mexico from a very, very rural town that is very indigenous, but obviously there is a lot [also] of Spanish and French influence. So, there are light-skinned people and our culture is indigenous. My grandfather came from the Bacero Program, which was a legal way to bring workers to work in the fields here [in the U.S.]. It turns out he worked in the strawberry fields, here in Los Angeles. As a result of talking to my family about our history, after taking with Michelle, I just found that out. I'm Catholic, and I love to attend church. I have a beautiful husband. [Laughs.] I mean a handsome husband, and two amazing kids. It's my favorite thing to do is to be a mom. I put this here [referring to the word "men" on her collage] because I come from a town that is very machismos, and has very strong women. And talking to my cousins about where I come from, all the women who have come to the U.S. in the last two decades. I've been very blessed to get a degree and work in public health. I love my job. “ 


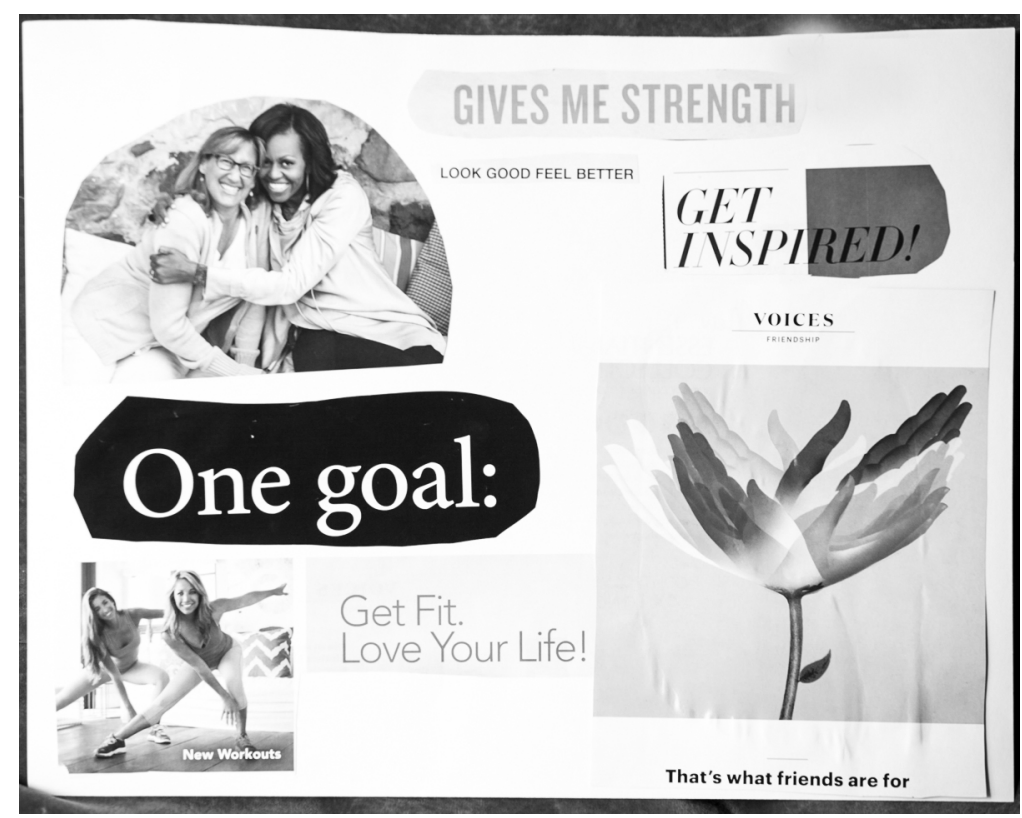

Figure 3. Lynne's Collage (Lynne, 2016).

Lynne: 'I'm so excited to share. This is only a part of me, because there is so much. But to give you an idea, I found these words, 'GIVES ME STRENGTH.' Everyday I'm looking for strength, whether it be communication through a friend, a loved one, a stranger it could be. I have here "LOOK GOOD FEEL BETTER." We look at our current circumstances sometimes that dictates how we react to it. So my philosophy, for myself, is to not look at the situation but respond to how I want to feel. For instance, if I'm broke, I don't have to look like I'm broke. So if I dress myself up, I'm not hiding it. I'm just saying I don't have to look like that situation. Okay, so that gets me inspired."

[Everyone appears engaged by leaning toward Lynne as she shared her collage.] 
Lynne: "I found this "VOICES," and you have these multi-colored hands, very diverse. I love everyone. And I'm a people person. And at the bottom it says, 'That's what friends are for.' I call myself a good friend to anyone, and I'm always there for them. And then here is a life-long goal is to get fit and love my life. And then I have picture here [points to the image of a Michelle Obama and woman hugging], and it's a symbol of the kind of relationship I have with my mom and grandmother. I still have my maternal grandmother. She's 93-years-old, and we have a close relationship. My mother is 75 , and we have a wonderful relationship. And so this is symbolic of the way I am in my relationships. I'm always embracing. And this is how I go through life, and kind of reminding me of these things to get me through."
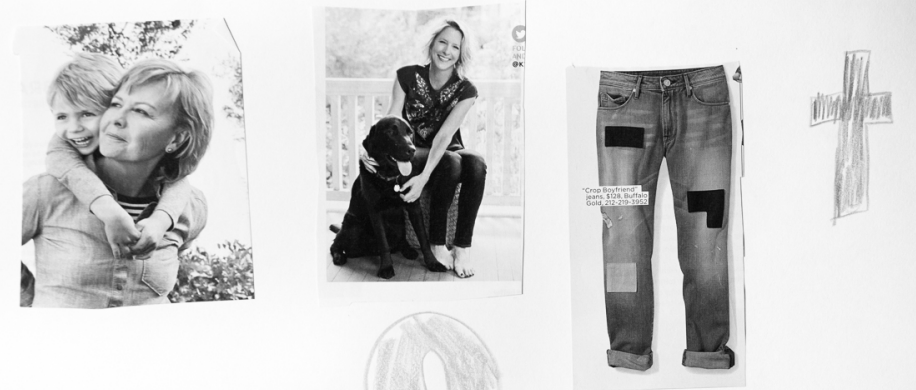

Work at Home

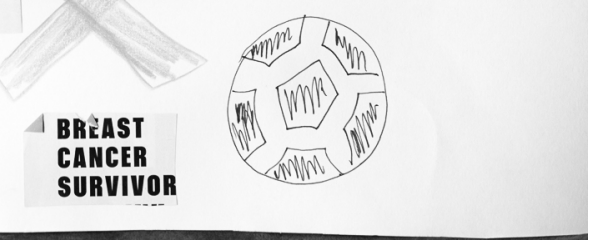

Figure 4. Trixie's Collage (Trixie, 2016). 
Trixie: “That's a tough act to follow [referring to Lynn's collage and story]. So I am a stay-at-home mom with two grown boys. I love dogs. I love all animals but dogs are special to me. I chose the jeans, because my favorite thing is to be casual. I wear jeans and a white $\mathrm{t}$-shirt all the time. I have faith. I have a lot of faith. I love to play soccer. I play soccer. I am a breast cancer survivor. I just realized this is more of who I am than what I feel."

Michelle: "So more about your identities, than how you feel?"

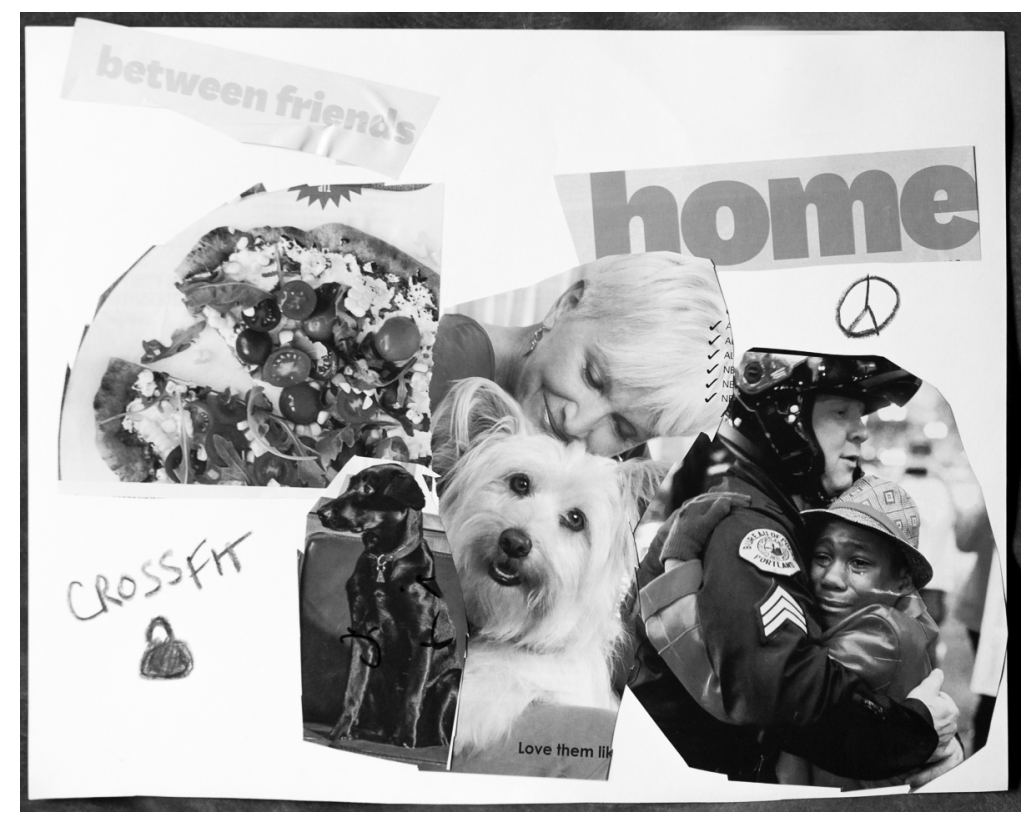

Figure 5. Meryl's Collage (Meryl, 2016).

Meryl: "This picture here [photo of the police officer hugging the boy], I was in law enforcement for 15 years. I just left in March. I'm a strong believer in service to community. 
"I picked this word "home" and peace symbol, because I believe peace is in the home, and if you don't have it then you can't be peaceful outside of it. I don't care if I live in a box or a mansion."

[Lynne nods in agreement.]

Meryl: "Speaking of peace, my puppies [pointing to picture of the dogs]. These aren't them, obviously."

[Laughter.]

Meryl: "I have black standard poodle and a white poodle. That's me. My dogs mean the world to me.

"CrossFit is more than...it's a passion for me, but it's also community. It's a family. It's a way of life. I can't say enough about how much it's inspired me.

"Speaking of CrossFit, the phrase "between friends," is not just with the law enforcement community but CrossFit, too. Through everything I've found passion about, I found best friends, and they became family.

"And pizza, it's not because I LOVE pizza. I actually could eat it all day. It's because I'm Italian, and I love to cook. In my family, cooking is an expression of love. Growing up, my Nani, and my mother made homemade pizzas on Saturday night. That was the best thing ever. Just last Friday, I had some friends over for homemade meatballs which is my Nani's recipe passed down to me. Anyways, that's the best I can do. So..." 
Lynne: "Homemade meatballs next week for our second session?"

PrinceFan69: "Saturday night? At your place?"

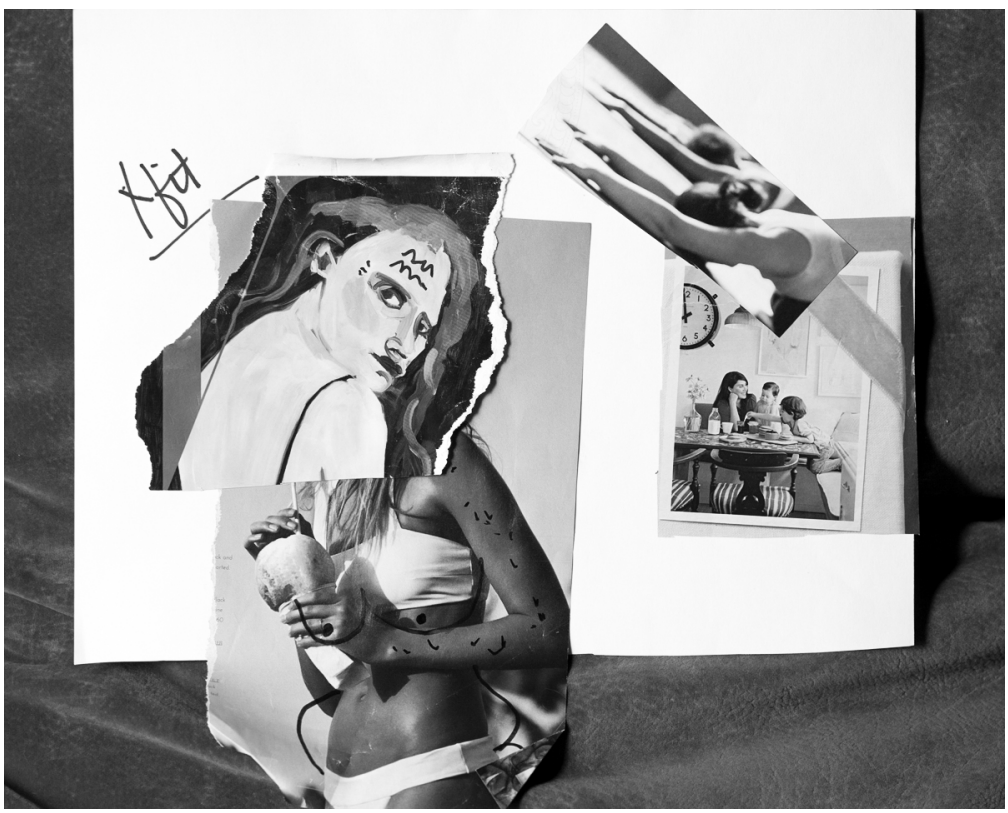

Figure 6. Michelle's Collage (Michelle, 2016).

Michelle: "Wow, Meryl, tough act to follow. So this is [points to the doctored image of a woman] from the Free People catalogue I love so much, but I don't look anything like the woman in the bathing suit. I feel like I look more like this. With a black sharpie, I put a stomach and some hips, some age spots, and some wrinkles to look more like me.

"I found yoga.

[Meryl claps.]

Michelle: "But yoga hasn't really found me. My hamstrings can attest to that. But this is child's poise and shavasana are my two favorite 
poses, and I do those well. Yoga is coming to me at a time when

I'm trying to be more present, and trying to be more meditative so

I'm not chasing my behind all the time.

"I'm a mom, that's the person I am first, I have wonderful, wonderful children.

"And then I put CrossFit up there."

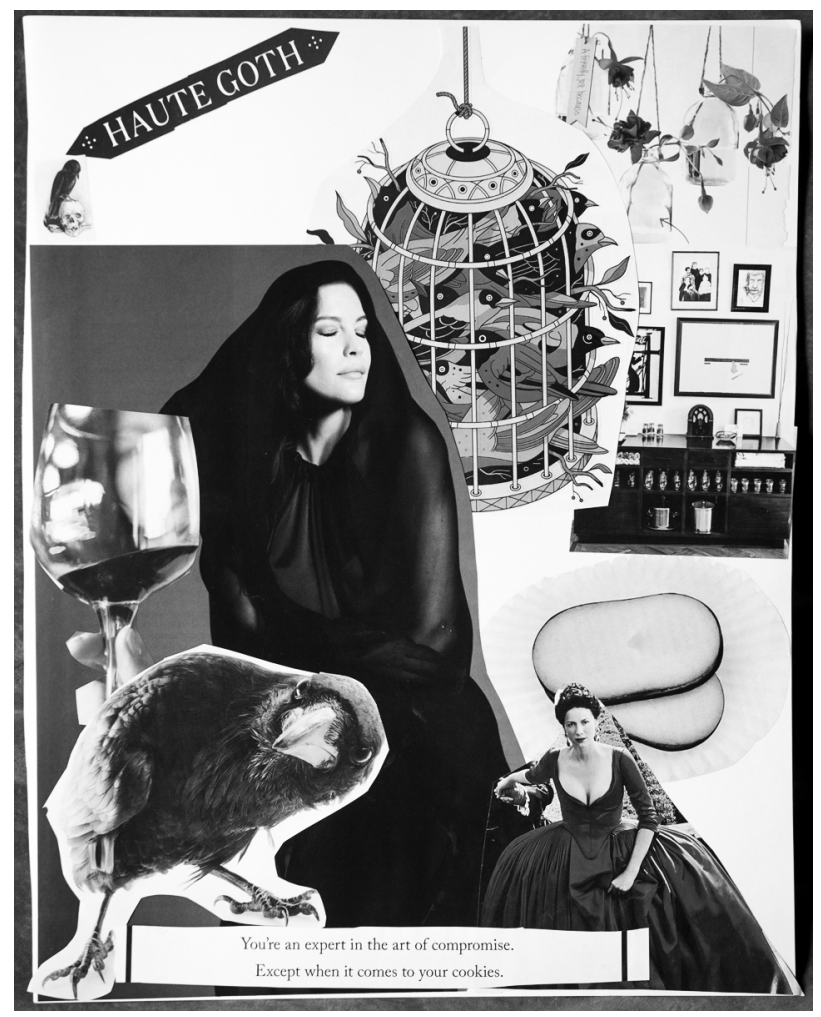

Figure 7. PrinceFan69's Collage (PrinceFan69,

[PrinceFan69 holds up her collage.]

Rosa: "Wow, that's beautiful."

Michelle: "She’s an artist." 
PrinceFan69: "This is Liv Tyler, who is an actress I really like. I admire the work she does. And it's perfect because she's shrouded in this darkness and mystery. This is the best way to be. I'm drawn to darkness and mystery.

"So, I like history. I like beautiful things, so this is a beautiful gown down here.

"I'm a big Poe fan. I write horror. I write a literary journal of horror. Got my raven. I also have a big tattoo of a raven on my back. That has meaning for me. And then my little raven. Haute Goth.

“There is a picture of cookies, because I love sweets. It's really important to take pleasure, and if it's small and simple, ENJOY it. That's why I love their [Pepperidge Farm cookies'] slogan: 'You're an expert in the art of compromise. Except when it comes to your cookies.' Enjoy it. I like having a standard like that, you can be flexible about a few things, but then there are things like your principles or your artistic goals that you won't compromise. "The birdcage [here] with birds inside symbolizes my brain, my creativity. I have so many ideas that are waiting for me. I'm a writer.

"I like home décor. I like pretty things. I like feminine things. And, drinking wine. I think it's important."

[Laughter.] 
PrinceFan69: “There's nothing here about pets or family or anything. But I've spent my whole life taking care of people. So it's important for me, now that I'm 46 and my kids are older, one's in college and the other is in middle school, that I get to stop spending so much of my time taking care of parents, and family, and kids and partners. And focus on me and my art, what I like, so this is me.”

Hilary: "Good stories and supplies. Thank you guys so much for sharing your stories. It was so amazing to see how much we got out of this in so little time, and how rich. And how symbolic it was in relation to your selves and connected with each other. I saw so many head nods throughout the room. Maybe it wasn't something you concluded at first, but then something would resonate with you, right? It was wonderful to see that process."

Lynne: "I didn't want to say it but everyone [she points to everyone] I identified with everyone, and I would add something to my collage now."

Hilary: "Who, at this table, would add something based on the conversation?"

[Each woman either raises her hand or nods.]

Hilary: "So when you were listening, what did you hear from around the table, whether you would have picked another image, or is there something else? What really resonated with you and others?" 
Some of the common connections that resonated with the group included: the tension of taking care of others such as children and aging parents while striving to find "me" time and focusing on us; the importance of family especially our older relatives who we do not know how much longer we have with them; and the acknowledgement that we have only scratched the surface of who we are. Yet, there was a general sense of ease, camaraderie, and openness in the brief time we had been together. Meryl said, "I felt initially nervous [rubbing her hands together], but then sharing my story, and hearing others. I got over that once I started talking."

Hilary asked us to discuss common themes or ideas we had seen in the collages and the discussion. We displayed all of the collages in the center of the table for everyone to see. Some words shared were multifaceted, interpersonal, and feminine. When PrinceFan69, who had been the one to say "feminine," was asked to explain, she said, "Yeah, very feminine. I mean they're women themes. I feel like if men were doing this, there would be army men, and cars. Our focus is on clothes, food, pets, babies...really focused on relationships."

The theme of middle-aged being a time of transitioning out of role of caretaker for kids (if we have them) to aging parents was discussed which can be a "chaotic time" in our lives, and at the same time having the feeling of “IT'S MY TIME, and I'm not apologizing for it." Rosa mentioned how self-reflective all the collages and accompanying stories were, and Lynne agreed by saying this is a time in our lives of discovering things about ourselves. As Lynne put it, this might be a unique to this group of women. Lynne continued: 
Not everyone looks to discover things about themselves. They're content with who they are in that moment, and that's okay. That's their lives and their decision. But every day we should look for opportunities to learn. What can I learn about myself? What opportunity do I have to get more substance to create something in me to be a better person? As long as we're living we are still growing. We're still developing. We're still processing.

Yet, even though the collages and stories were deeply personal about ourselves and "our community," we realized that once we started talking about families and support, and what's important to us we realized "we have more in common with each other than we thought."

\section{Introduction to photo essays using women photographers' work.}

Hilary: So now we're going to switch from dialogue to a little more monologue. I apologize for that since there was such beautiful dialogue. So thank you.

"I want to share with you is going through some specifics of photovoice or telling our stories visually. I am big on visualizations as well as some others in the room.

"I've been looking at, and chose, some women photographers of all ages who responded to something about themselves and have really wanted to explore this idea of what it's like to be a woman. I do this through a process called photo essay. Photo essay simply means multiple images on story, and using different kinds of images called stills to tell the story. So how you just selected five 
words or five images in your collages to tell your story, maybe selecting five photos to tell the story. But just like choosing five images from the magazine doesn't necessarily represent you entirely, how can you represent yourself more accurately and how can you start build your story? And I think we should use images since they can tell stories. So I wanted to share a couple of examples of these images/photo essays that I found, and answer any questions you have about photography and how they tell a story.

"So I want to share a couple of images. This is by a photographer called Andi Schreiber. She did a pretty amazing photo series called Pretty, Please. “

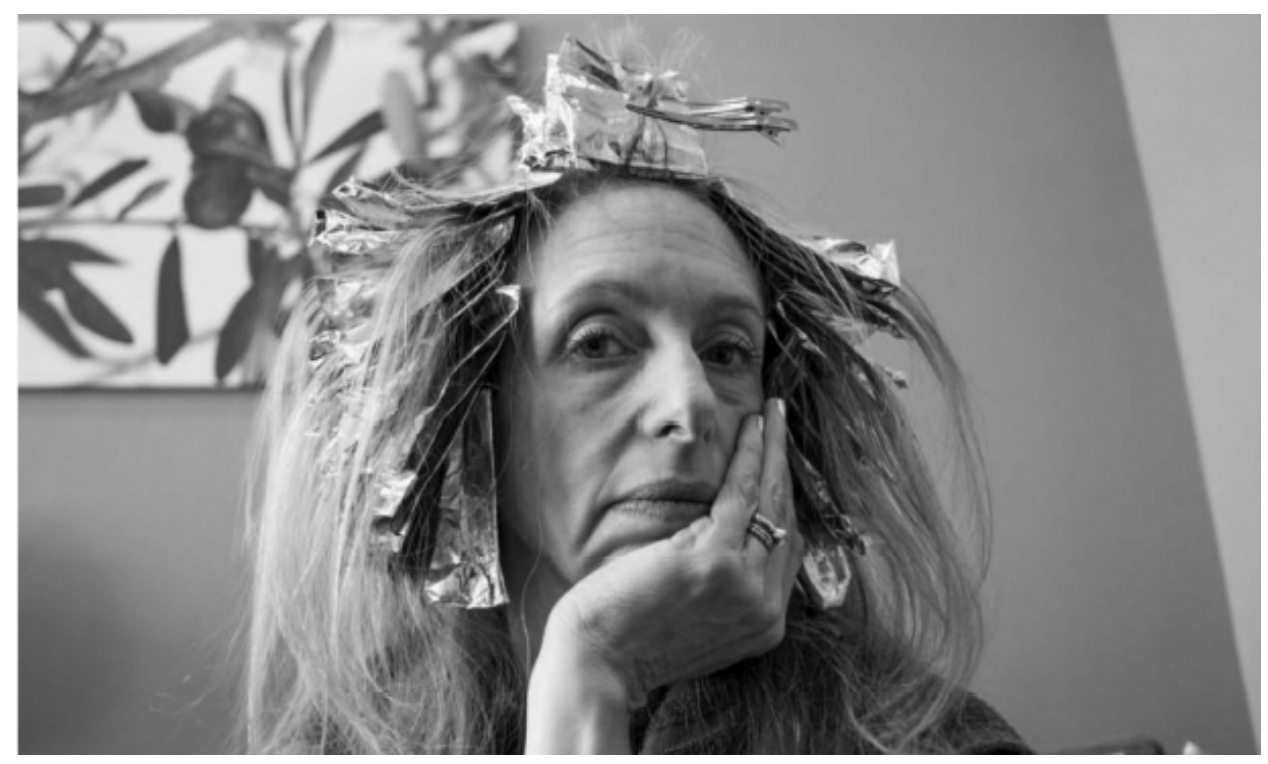

Figure 8. Lighten Up (Schreiber, 2014). 
Hilary: “Her [Schreiber's] point of interest for sharing this story was it came out of the idea of what is it like to feel pretty at this time "in my life and how I should go about it." She was, maybe, someone else who felt uncomfortable taking pictures of herself [refers to Trixie], and looking at herself in a certain way. And what I really love about this series is her creativity in which she started to explore this. And so as you can see here, this is a self-portrait of her, trying to maintain honesty and authenticity we saw in some of the earlier photos.

"Some or her photos are more abstract and how some of that detail can tell as much of a story as the bigger picture."

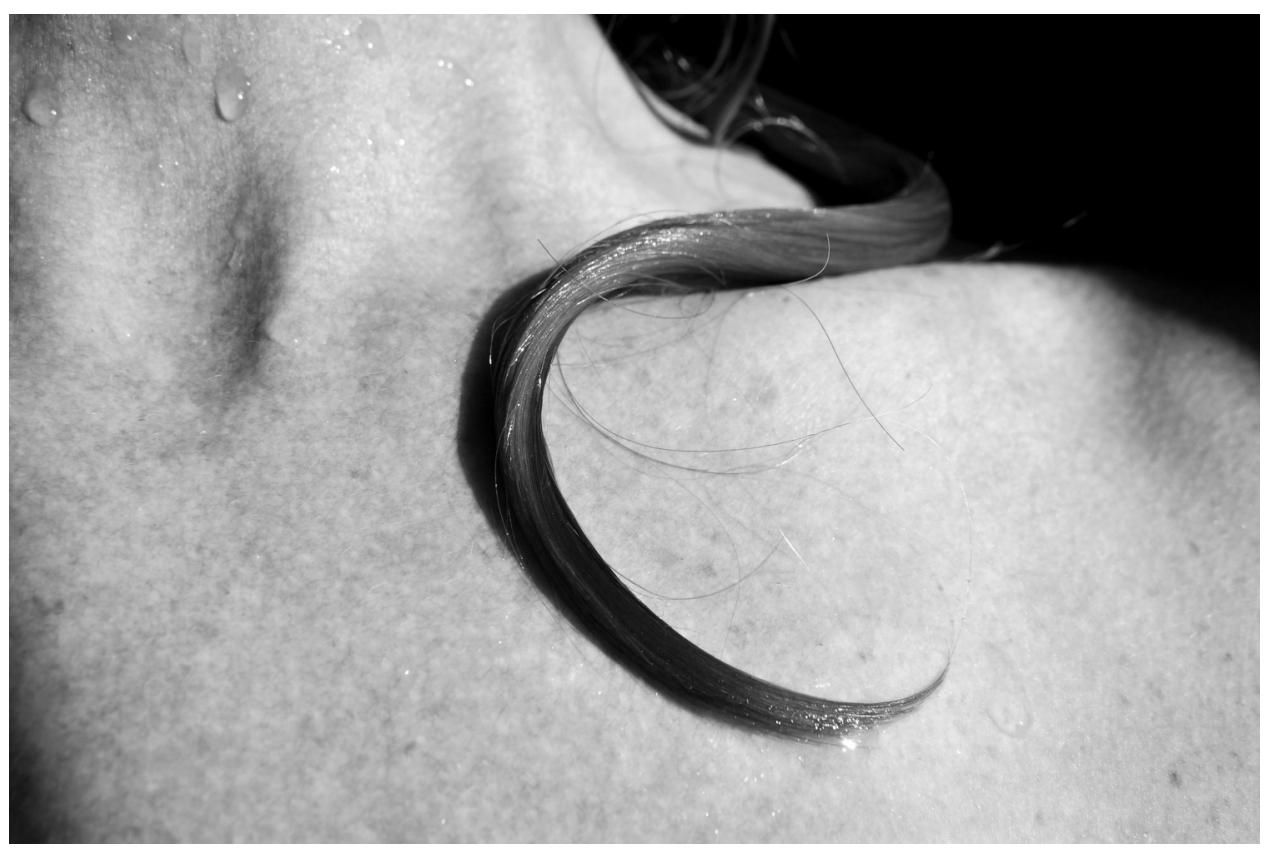

Figure 9. Curl (Schreiber, 2014). 
Hilary shared three other photos from the Schreiber's photo essay, Pretty, Please.

She commented on how changing angles of a photo can really "change things in an intimate way." She spoke of how using objects out in the real world, shadows, and reflection can go a long way in telling a story. Hilary encouraged us to be creative and "gutsy" in similar (if not exact) ways that Schreiber did.

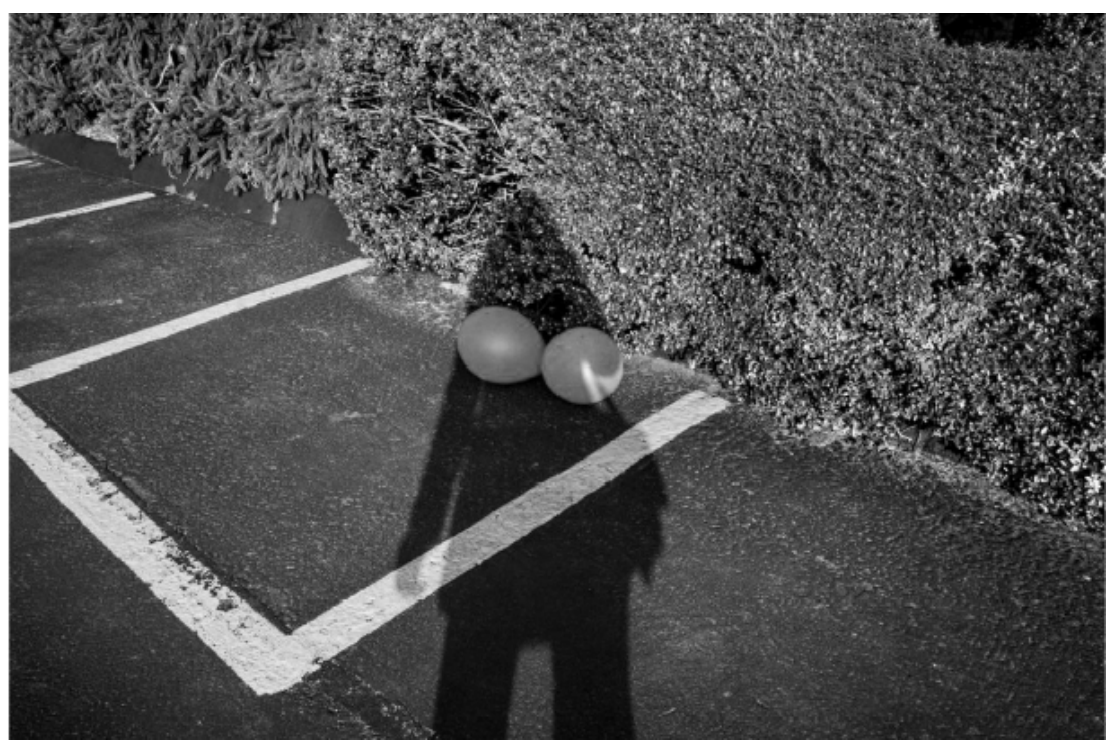

Figure 10. As If (Schreiber, 2014).

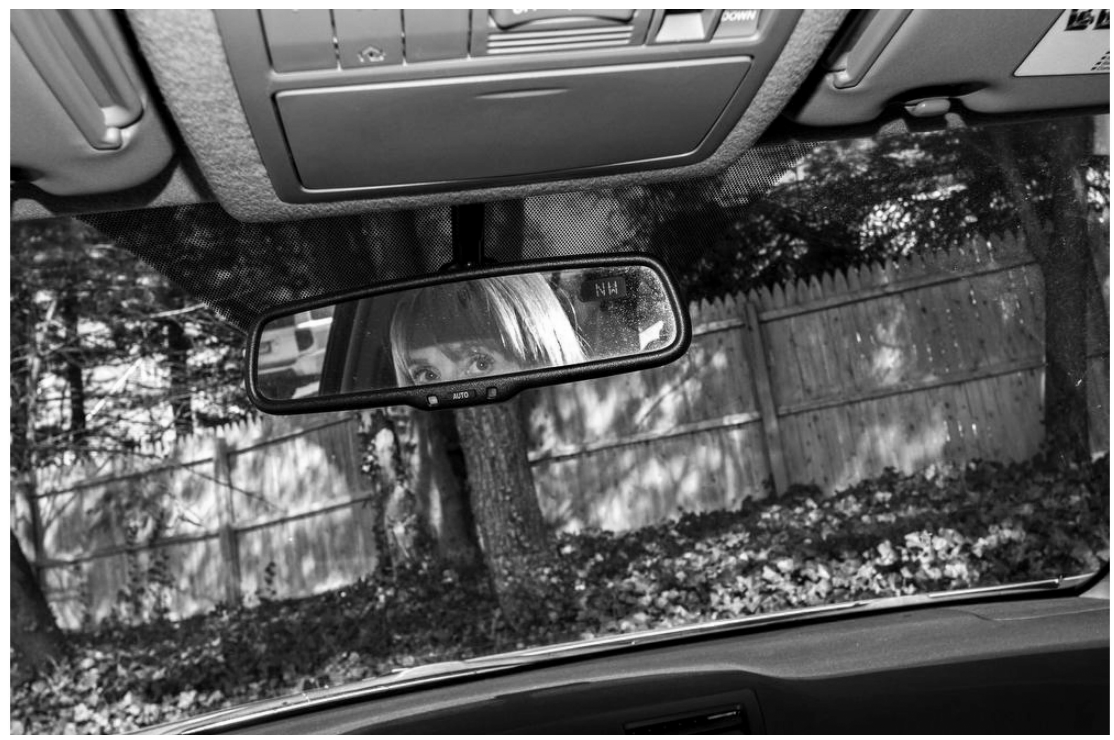

Figure 11. Rear View (Schreiber, 2014) 
Besides Schreiber's photos, Hilary shared three other women photographers' work including the work of Rebecca Webb, Adriene Hughes, and Sally Mann. Webb looked at herself through women in her circle of friends, Hilary noted. Hughes was interested in looking at women and defying norms and "putting that face forward." Webb was also interested in space, "physical space around us, as well as people so documenting people in their homes, places where they felt comfortable."

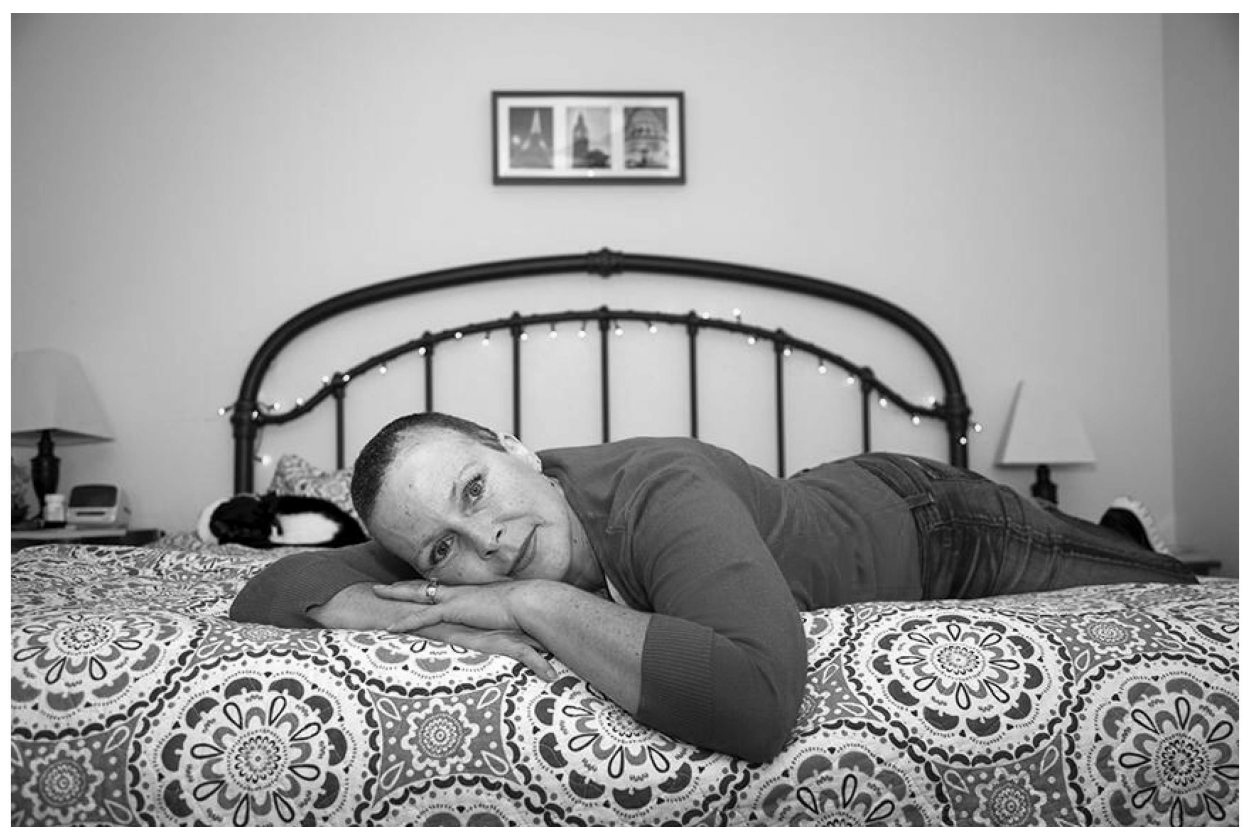

Figure 12. Ms. Rose Defies the Odds (Webb, 2014).

Hilary: "We start to notice, if you're looking deeper into these pictures, about those clues we spoke of earlier. You start to wonder about these women's lives."

[Hilary shows three more images from Webb's collection.]

Hilary: "Hughes used a creative response. She is a San Diego native and does a lot of really interesting dance and performance. She is a 
breast cancer survivor, and this was a series of photos she did after her treatment. She wanted to put on a mask [in this case a deer] as a way of separating herself, so almost like creating a persona, so she wasn't documenting herself. She was documenting this other thing but through that process in taking these photos she was able to process her treatment and really distance herself from her suffering through this other persona."

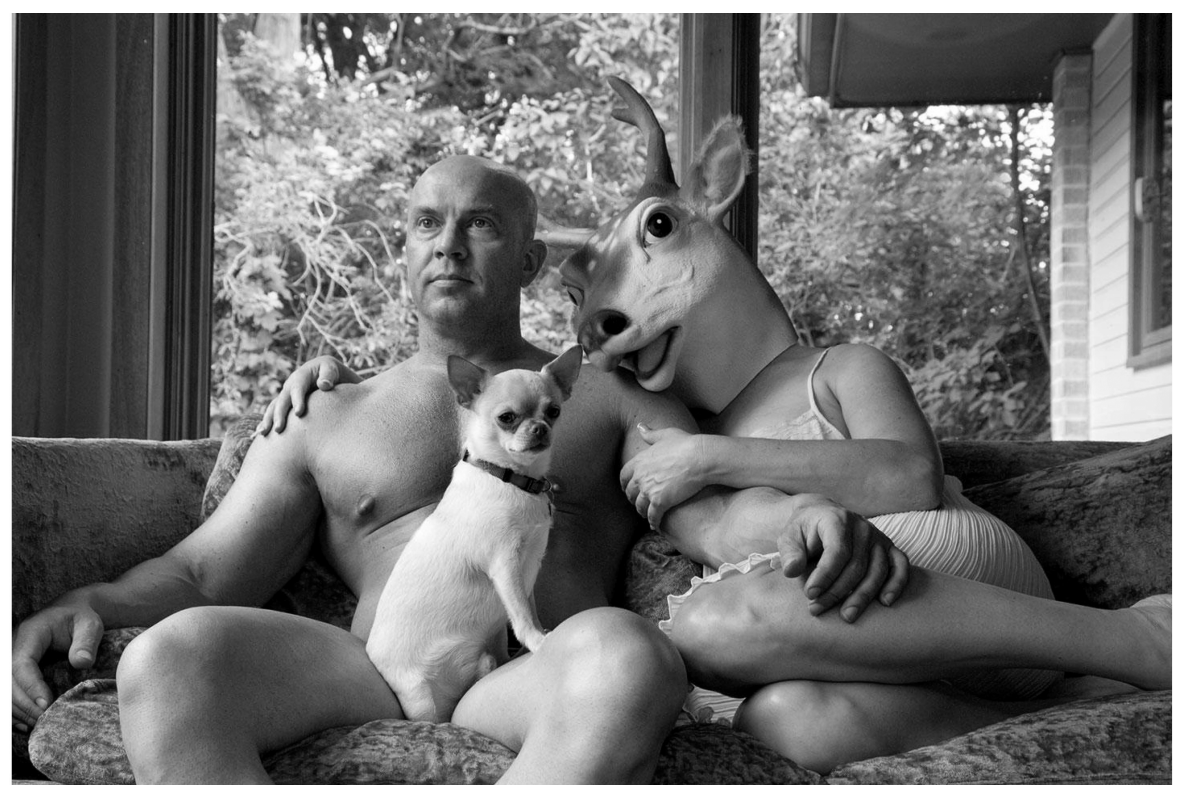

Figure 13. Deer Woman (Hughes, 2005).

[There is laughter and looks of disbelief from the group.]

Hilary: "So she [Hughes] used a kind of imaginative space. So photography can be a sense of documentation, right? So picking out things within our space, but I also encourage you to get creative and think about imaginative spaces." 
[Hilary shares four other photos from Deer Woman (Hughes, 2005). Hilary shares three photos from Sally Mann's work.]

Hilary: "Sally [Mann] is a really famous photographer, and for her looking at herself was looking at her kids, her family, and her personal space and place. And she's really known for the intimacy of her photos, which is quite controversial. She often showed photos of her children in the nude which people had varying responses to."

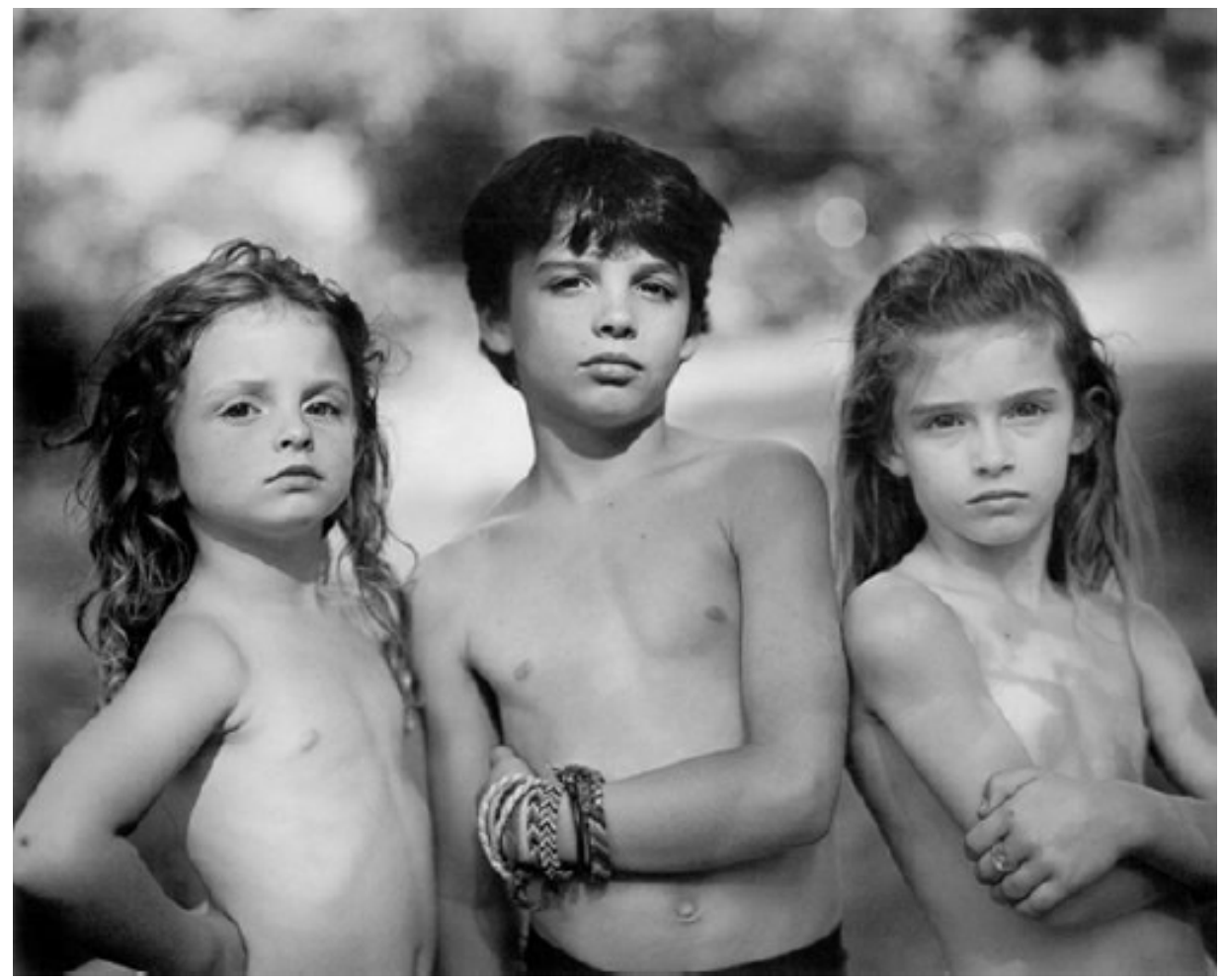

Figure 14. Emmett, Jessie, and Virginia (Mann, 1992).

Hilary: "But for her [Mann] and from her point and perspective, she said it was really that intimacy and her home, her freedom to express 
herself. For her, it was kind of examining herself and her age as well. She was talking about what it was like to be at different stages of her life. So she was documenting numerous friends as a means for really exploring that idea.

"What I love about her images, is this is candy [pointing to the candy cigarette], but with that pose we all think of something. What is really interesting about this image is this kind of that time, and how these younger women may see things around them differently."

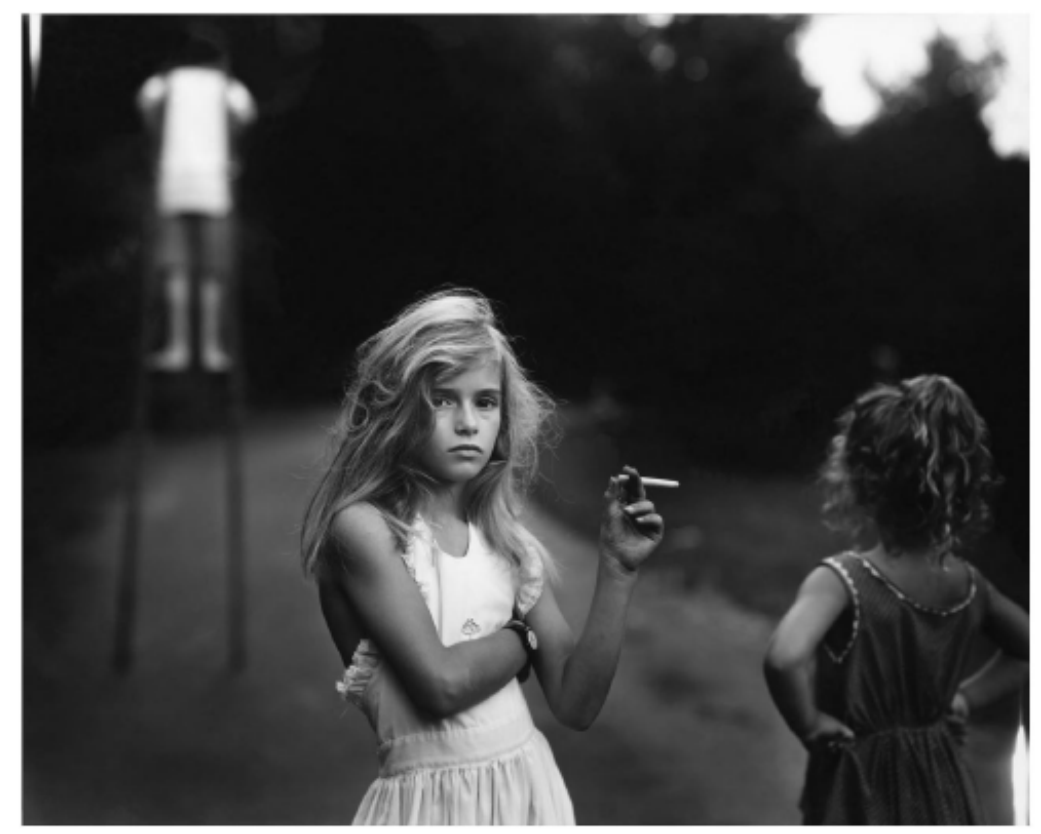

Figure 15. Candy Cigarette (Mann, 1992)

[Hilary reiterates that these were just a few examples of photo essays by women she wanted to share with the group. She also uses these examples for different ways to technically tell the story.] 
Hilary: "The biggest thing I want to encourage you is it's not about how the image looks it's about the story that it tells. So when you're looking around in your space, it's not about whether you use your phone, your computer, or a bigger camera, it's the story you want to tell. I even encourage you to start with your collage, and use these are images from magazines, images and symbols. But expand on it by thinking how you can represent these through your own space and your own home."

[Researcher gives instructions about the "homework" for the next session.]

Michelle: "So over the next week before Friday, I would like you take photos of what it's like to be a middle-aged woman in today's society."

Trixie: "That narrows it down."

Michelle: "Well, it's your own interpretation. So what we've heard from Hilary, it can be something that's staged. It can be something you witness out in the public. It's whatever that means to you. So you'll send your top two photos to me, although I'd really like to see all the photos you took."

Wrapping up session 1. The group was instructed to send me their top two photos (i.e., fiction, nonfiction, staged, not staged, etc.) by the following Friday so that I could enlarge them to 8 "x11" by the following Monday when we were scheduled to meet again.

Lynne: "I have a question, so does it help you with your project? Is it best if we include ourselves?" 
Michelle: “It doesn't matter. Because-I didn't say this at the very beginning — but this is really exploratory, in terms of this process, whether taking photos and telling stories really influence each other. That's really what the question is so it's awesome because it could, it couldn't, and it might in certain ways. So I'd be curious what you think is representative of how middle-aged women are represented or not."

Trixie: "So it's not what "we" feel as a middle-aged woman, it is what society...."

Michelle: "It's how you think society treats or the visualization...."

Trixie: "Or the stereotypical?"

Michelle: "It's up to you. It's whatever you feel the American society...."

Trixie: "Even if it's not what we feel [points to herself], as a middle-aged woman. That's what I'm trying to make the distinction about the pictures to take."

Avonlie: “She's saying she believes there is a stereotype but she doesn't feel it about herself."

Michelle: "If you feel there is a stereotype about middle-aged women in our society, that's what you need to take pictures of. And when it comes to the photovoice process there is short story, five sentences or so." 
[Hilary clarifies what she thought the accompanying story should look like, since I had focused on the methodology of photovoice which uses a five-sentence story to describe the image.]

Hilary: "I come from a straight photography background, so I tell my stories really visually. But I think if you want to have, a caption or a title for the photo then that would be an easy way to do that. Then maybe one or two sentences clarifying your ideas, so it's not very lengthy."

Michelle: "And be prepared for other people to look at your photos, and to make it personal. 'What did I see in your photos?' And therefore I didn't understand the caption or what you were trying to say. That's the kind of dialogue, the kind of work we did here today [referring to the collages].”

Avonlie distributed the three-question post-session survey for the participants to complete. She reminded the participants I was going to be calling them during the week about the first session and any questions/issues they were having over the week.

There were questions regarding the expectations of the process, the definition of middle-aged (i.e., based on the U.S. Census ages 40-64 are middle-aged).

Avonlie: "So we're almost done. The last thing I want to do is called check out. So going around the room and complete the session with one word. It could be anything."

PrinceFan69: "Interesting."

Rosa: "Commonality." 


$\begin{array}{ll}\text { Lynne: } & \text { "Intriguing." } \\ \text { Trixie: } & \text { "Fascination." } \\ \text { Hilary: } & \text { "Curiosity." }\end{array}$

Avonlie: "Engagement."

Meryl: "Excitement."

Michelle: "Gratitude. I'm getting goose bumps."

Post-session 1 evaluation. The three-question survey and the post-session interviews provided information on what worked and what did not work in the sessions, as well as what resonated with each of the women. Table 5.1 provides data regarding what the participants felt worked during the session. Briefly, the introductions and creating collages opened up the dialogue; the introduction of photovoice and using photography to tell a story; and "having a discussion that otherwise would not have happened" all were listed as things that worked.

There also were some constructive comments about what had not worked well during Session 1 (See Table 5.2), but fewer than those about what worked (Table 5.1) or resonated with the participants (Table 5.3). Most of these comments focused on a lack of outcome or product which caused confusion since they thought I was not making my expectations clear for the project. However, once I re-emphasized the exploratory nature of the project and that there were no predefined outcomes expected, the participants seemed to accept this ambiguity (and some even appeared to embrace it).

Table 5.3 highlights comments from the participants regarding the takeaways and things that resonated from the session. 
Table 5.1

\section{What worked during Session 1?}

PrinceFan69 "The exercises helped to shape the conversation, direct our thoughts, and provide focus for the larger process of the project."

Rosa "It was interesting to see how each woman interpreted photos differently. It was a good creative training session."

Michelle "My favorite parts of the session were sharing the collages and looking at the examples of photo essays, and hearing each other's stories."

Meryl "I loved the poster board exercise [collage], and the dialogue that followed. I knew that once this happened, I was all in. I told my mom how excited I was about this project, and how I looked forward to continuing."

Trixie "I had no expectations, so there was no pass or fail."

Lynne "The introductions, storytelling, and photo visuals were all helpful."

Some other comments that were shared with me during the interviews between Session 1 and Session 2 included:1) Lynne, Meryl, and Trixie appreciated the facilitators, and "how the agenda flowed" and how Hilary facilitated the dialogue; 2) Trixie, Lynne, and PrinceFan69 all felt that the group would not have "worked if we were all strangers;" and, 3) there appeared to be some acceptance of the "organic" nature of the group in terms of not having a scope of the project. As PrinceFan69 said, "Maybe the questioning, the not knowing, is part of the process."

To summarize, while the women were uncertain about the expectations of the session, and the overall project, they all expressed interest, and in most cases excitement, about the first session and looked forward to the next sessions (as well as how to continue the group beyond the three sessions. 
Table 5.2

What did not work during Session 1?

PrinceFan69 'I needed more clarity about the 'homework.' A written guide or page of important information (what, when, how, etc.) would have been great to have."

Rosa "I thought this group was about women in leadership roles, and I thought we would be concentrating on our work."

Trixie "I'm not clear about what you mean about 'taking a photo of middle-aged women in today's society.' What does that even mean?"

Lynne "I was unsure about the process and had questions like 'how do we respond to the photos and stories,' or 'are we responding in the right way?"' However, I realized when I spoke to you [Michelle during the post-session interview], 'We are the project.' 
Table 5.3

What were the takeaways or what resonated from Session 1?

Rosa "This demographic needs time for herself, and 'it's okay to feel this way' about most of us experiencing something similar during this time. And I felt there was an opportunity to really get to know these women through the sharing of the poster boards [collages], and the stories. Also, I really appreciated being able to share my story, and open up my whole life, with you [Michelle] and with the other women."

PrinceFan69 "I found it interesting that the group was more concerned with personal experiences rather than global issues of politics, future planning, etc. And while I agree with Rosa about having a defined outcome or product, I am open to the exploration, creation, and discovering aspects of the project."

Lynne "I like to learn and in this processed I've already learned a lot about myself and the other women. I became more comfortable as the session went on, where I felt we were building something. I'm even thinking about ways to continue group outside of the sessions like going to yogurt or something like that."

Meryl "I think the group was exactly what I thought it would be, although like I said before it wasn't until I shared my collage, and then PrinceFan69 spoke about her own collage, Meryl felt supported by the other women. It was like my childhood insecurities went away. And even though I'm younger than the other women around the table, and I don't have children, I felt support and validated. I called my mom after the session and told her how excited I was to take photos and go back next Monday for Session 2."

Trixie "I felt, as the session progressed, that I was becoming more present. I was also intrigued by how diverse the group is, and think there might be some issues because of the strong personalities. Does this make you [Michelle] scared? I'm praying for you."

Michelle "I have already been transformed by this process, and I am so thankful for all the women around me, including Avonlie and Hilary, who have already given so much to me and of themselves.

\section{Session 2}

Before the session began, there was conversation among the participants as we got our food and beverages. 
PrinceFan69: "Ever since last Monday [Session 1], I've been going along and seeing other [middle-aged] women and I see myself in them, and think, 'This is it. This is what middle-aged is.' People doing their normal, everyday things, yet suddenly I'm just probing it for additional meaning."

Michelle: "By snaking a toilet...."

[Laughter.]

PrinceFan69: "Yes. I was snaking the toilet, and I thought, 'Is this what it feels like to be a middle-aged women snaking a toilet?'"

[Avonlie welcomes the group back, and asks the group to say something about the last week, the day, "anything we wanted" to get us to "be present."]

Trixie: “Like I was telling Michelle, I think it's called middle-aged because life expectancy is between 80 and whatever. No one wants to call it halfway."

[Laughter.]

Michelle: "No, it's half full."

Trixie: "If I could get there [old age], that would be great."

[Trixie brings this up often since she had breast cancer having the feeling she may not make it to "old age," or perhaps a healthy old age since her mother had Alzheimer's and her father had strokes and dementia.]

PrinceFan69: "I don't know if there is positive description for this time. Partly I think [it's] because women's experiences are so negatively framed by so many aspects of our culture. Also, for most of history we 
[women] are defined by our roles: wife, mother, and daughter. So, we when we get to this point, what do we call ourselves as a positive term? It's the same for men, too. There's nothing that middle-aged men are called anything in particular."

[A number of women's heads nod in agreement.]

Rosa: "I kind of feel like it's ridiculous finally accepting I'm a middleaged woman. Having that exercise last week [of taking photographs], I've been looking at other women and trying to take photos. It's getting to me the fact, you know, I'm at this age. It's great and admire a lot of women who are middle aged. They are so proud of their middle-aged. To me the journey hasn't been easy getting there...."

Meryl: "I had a lot harder time in my thirties; I love being in my forties. And in reference to being in our middle age, I'm thinking, wow, if I live another 42 years and I don't have to go through the excruciating teenage years, $20 \mathrm{~s}$ and $30 \mathrm{~s}$, and I can live the next 42 years squared away [thumbs up] and happy. That would be awesome."

[The women's body language indicates this statement resonated with them.]

Lynne: "I had mixed emotions, but I resolved that middle-aged is a state of mind. It's just a state of mind, and depending on any day you can be on either side. You can feel, for me, there are days I feel youthful. There are other days when I feel like crap. So it just 
depends on what day, and what we experience or what we allow ourselves to experience because I believe it's a choice. I can wake up feeling bad, but that doesn't have to be my day or my narrative for my day. It's a choice."

Michelle: "I have already been transformed by my experience with all of you, starting with when I interviewed you [before the sessions]. I'm very excited to be here, and be present."

Hilary: "I think presence is important. For my organization, I have a big project that's due. When I came in the front door, I was so grateful for being here and being present, listening to your stories to see what it is you came up with, and then look at those together as a group. I really appreciate you all."

Avonlie: "For me, I really had a great time meeting all of you last week, and seeing all of your collages, and learning about each of you. That made me excited to be here again today and see what unfolds through your pictures. Let's go."

[I distributed the two photos to each of the participants. Hilary requests that all the photos be put out on the table for everyone to see. Each woman stands up, and walks around the table to look at the photographs.]

Hilary: "I just want to get comments in general about the images. On this first go around, what were your first impressions? Any words come to mind?"

Rosa: "I think I was able to relate to most of the pictures." 
Trixie: "Yeah, I saw something in each of the photographs that I could relate to."

Michelle: "Like?"

Rosa: 'Like friends, things about our appearance, some are looking at nature, and thinking where are we? Who are we?"

[Rosa tends to speak with hesitation, yet what she says is deep and thoughtful.

On the other hand, PrinceFan69 reflects with authority and confidence.]

PrinceFan69: "Yeah, there's different aspects of experiences, like the quiet, reflective side in the nature photos and people by themselves, and then the social side where we're having fun with friends. This seems like a portrait of a pretty full life [when considered collectively]."

[Rosa notes that many of the photos are personal, and not necessarily related to the group's identities.]

Sharing our photographs and stories. Hilary explained that she would hold up each of our set of photos. The photographer was told to remain quiet while the rest of us discussed the photos. Once we were done discussing the photos, the photographer would share her personal experience.

Hilary chose Rosa to present her photos first. 


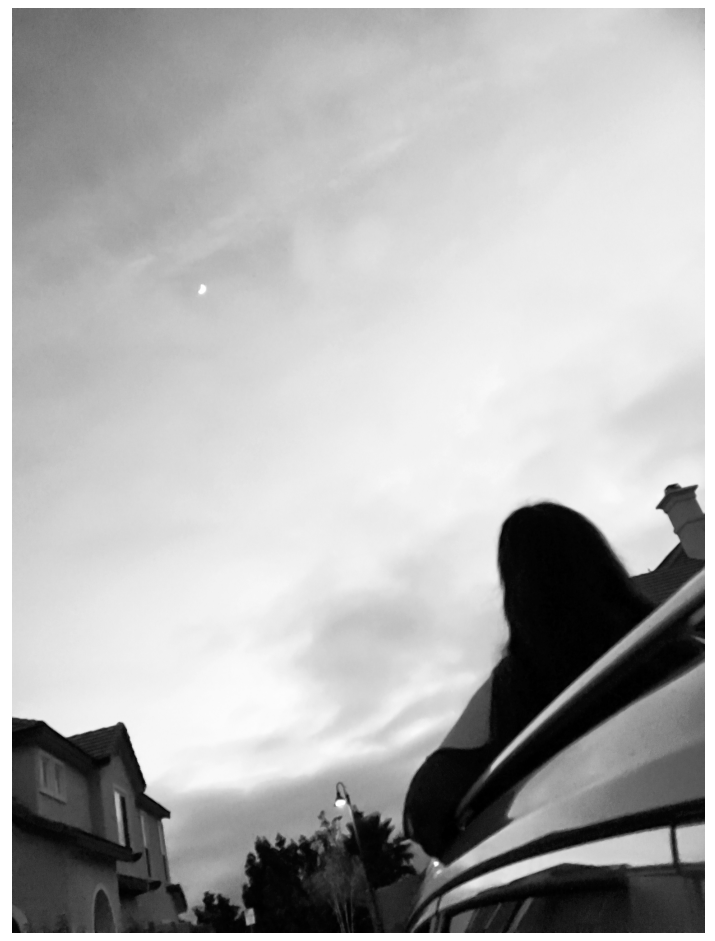

Figure 16. Universe (Rosa, 2016).

Hilary: "What are the stories you see emerging from these two photos? You can consider them separately or together, or in relation to other images you saw. What stories or words come to mind when looking at the images?"

Trixie: "Awe, the pink sky, the clouds [referring to the sky and moon]." Hilary: "So, the color tone and the subject matter?"

Trixie: "Just the subject matter, just God's great beauty."

Michelle: "I see connection that we're all part of this grand universe, and that we are all so small. We are just, you know, kind of awesome [a nod to Trixie]." 
Hilary: "So, I'm getting the sense of awe and space, something bigger than yourself in this one [moon and stars]."

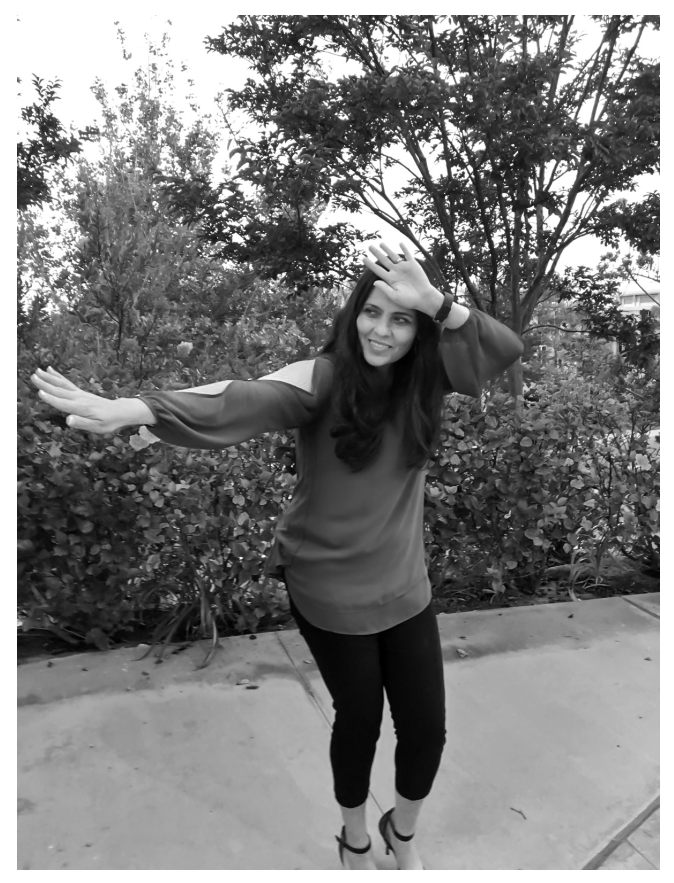

Figure 17. Being Cool (Rosa, 2016).

Hilary: "What stories do you see in here [Figure 17]? What words?"

Lynne: "Vibrant [referring to the one of Rosa]. The colors are so vibrant. They are just really standing out. Spring."

Trixie: "I see that she's posed like stay there, that's enough, enough." Michelle: "It's her body language?"

Trixie: "Yeah, there might be something out of the frame, like stay, stay." Hilary: "I hear that gestures are really interesting in this image. She has her hand placed over her forehead...." 
Trixie: "The drama, like the theatrical kind not the...or it could be otherwise."

PrinceFan69: "I see it as theatrical but in a different way. I see it as in the middle of a dance pose or something. So it's about confidence and power and the pleasure of being yourself and enjoying movement in the body."

[Rosa and Michelle share a moment of laughter since PrinceFan69 understands what was happening in the photo.]

Hilary: "Any other comments about these?

[No answer comes from the group.]

Hilary: "How about these as a pair?"

Lynne: "I don't see them together."

Hilary: "You don't see them together? You see them as separate? What about the details in the photos? Are there any other things we can see or notice?"

[Hilary brings the photos closer to the group.]

Michelle: "The angle of the photo [of the sky and moon] is incredible. I don't know...laying on the asphalt looking up at the big sky?"

Trixie: "And this looks like part of car, but is that a person?"

Rosa: "That's me."

Trixie: “See I didn't see it until Hilary moved it closer. I was thinking it was part of a car or shadows or something. It's actually Rosa."

Rosa: "My daughter took it lying on the ground, looking up at the sky." 
Hilary: "Excellent. You notice the angle. You notice the shadowy area, the...I guess we now know that it's Rosa, and her daughter took the image. Rosa, do you want to share about your images and why you chose them?"

Rosa: "This one [Figure 17] was taken first, I'm actually doing a dance pose. It's called the $D a b$.

PrinceFan69: [Laughs.] "Oh, dab.”

Rosa: "My kids say moms try to do cool things but they look ridiculous." [Laughter.]

Rosa: "So I'm trying to do the dab dance, but I enjoy doing that with my kids, doing the dab dance. But also I'm into fitness. I'm at the age now where I want to be healthy, and I'm thinking about my image. I've also read some articles lately; I'm the typical Latina where I wear high heels and have long hair. I also read that once you turn 40, and my friends who are also Latinas agree, you should not wear high heels and long hair. So, to me it's like looking at women of 40 and wearing high heels and long hair, and I am a mom in this picture, this photo reflects it. And it shows my age, I personally feel, for instance, this top is not my age, this is showing my arms. This is my personal interpretation of this top. I felt like I shouldn't be wearing this top because of the sleeves [and showing her skin]. And, I don't know, it's just the way I've been feeling. 
"For the second photo of the sky [Figure 16], I actually asked my daughter to take several different angles. Lately, I've been really thinking about essentialism and creationism. I'm Catholic and I came across this amazing cosmologist, physicist, scientist who is trying to answer questions about God and science. I've been so interested in this because it really talks about God, who are we, what's our purpose in life.

"And I've been thinking, why am I thinking about all this? It's really been over the last year, and realizing it's about turning 40 and getting older. Plus, I love to see how small we are, and the colors and my personal interest in cosmology."

Next I shared my two photos.

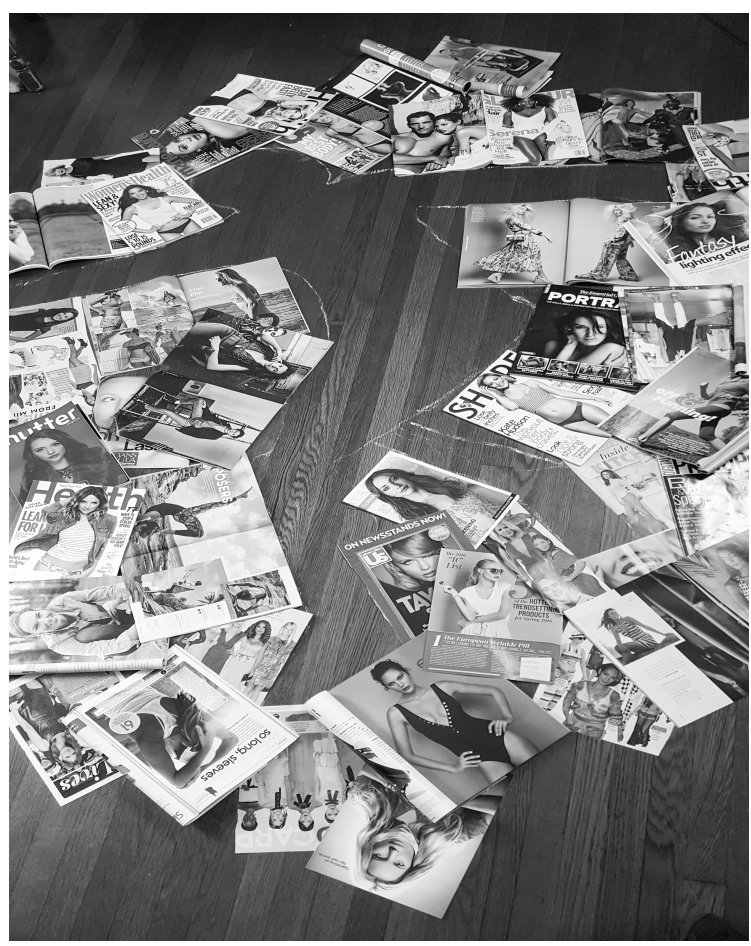

Figure 18. Middle-Aged Woman Missing (Zive, 2016). 
[Trixie notices the picture contains a chalk outline, and once she comments on it Meryl realizes it, too. Trixie thinks the shape was a skateboarder doing a kick flip or something, and Lynne agrees.]

Meryl: "Dead body. The dead body of youth."

PrinceFan69: "Death by beauty products. Death by trying."

Michelle: "Yes, I just gave up."

Hilary: "What about this image reminds of us of death?"

Meryl: "It looks like a chalk outline."

[Trixie agrees.]

Hilary: "So, that gives us a really good symbol of that, right? What else do we see in this image?"

Meryl: "Magazines, beauty magazines."

Hilary: "Beauty magazines kind of spread out, right? Filling the frame, taking up that space."

Rosa: "I think most of those images I can relate to. I want to look like that, but having to look like that it's not realistic."

Trixie: "You try to do everything in one of those photos, and it will kill you."

[The next photo is shown to the group for their comments.] 


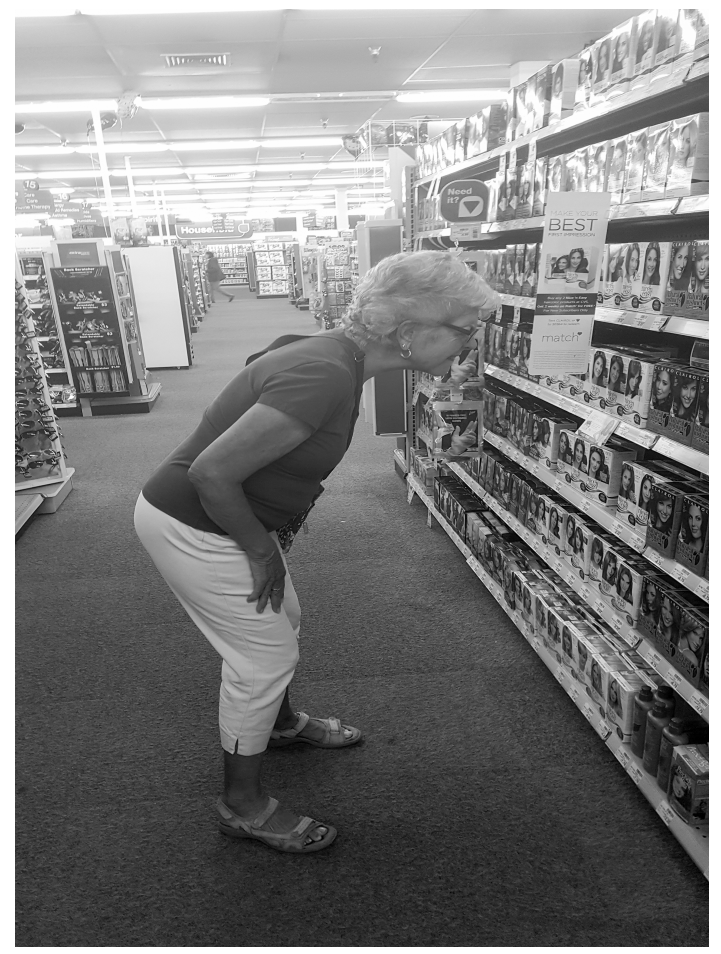

Figure 19. Dyeing to Be Young (Zive, 2016).

PrinceFan69: "I think there is an expectation that we have for ourselves, for other people, that at some point you're going to give up or stop trying. So, that's her effort to say, 'Hey, I still want to look at myself, and have fun, and be attractive the way that she can."'

When asked about what were the clues in the image that spoke to the woman wanting to be attractive, answers include "looking at the hair dye and her hair is completely gray, so it's not something she's done before," "she seems pretty fit and she doesn't appear overweight," "her posture is good," and "she's looking at trying to read which is the healthiest dye since she looks very healthy."

When the group was asked about my pair of photos, PrinceFan69 said the "missing body" was hopeless and Figure 19 was hopeful. I told the group that those magazines do not reflect me or my middle-aged friends; however, the group influenced 
my realization that magazines "don't represent anyone." I explained the other photo is of my mom. I had asked my mom to meet her at CVS (a large U.S. chain drugstore) to pretend she was middle aged and wanted to look younger. I explained, "My mom is clearly a senior." I said the photo represents to her what I feel society thinks middle-aged women look like, hunched and crouched over like senior citizens, "and we're trying to find youth in a bottle of dye kind of thing." The group influenced me to consider the photo of my mom is hopeful.

Meryl then shared her two photos.

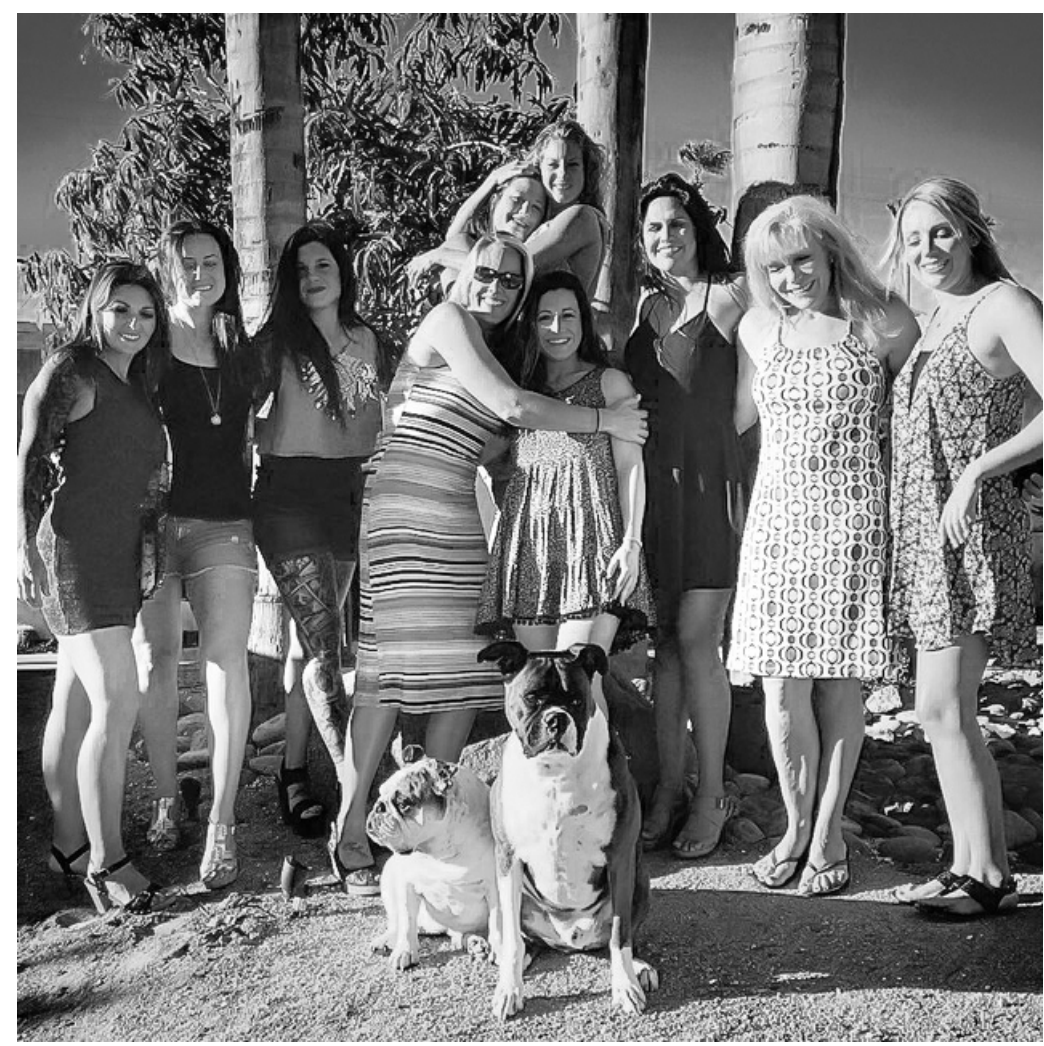

Figure 20. Connected (Meryl, 2016).

When asked what words came to us while looking at the photograph of the women posing [Figure 20], we responded with "good relationships," "happiness," 
"nature," and "fun." Trixie said, "The dogs are not having as much fun as the people." Other comments focused on the fact that it looked like some kind of celebration (i.e., birthday) because it was a gathering of women, the way they were dressed alike, and they were standing very close to each other. There was a recognition that the women were of varying ages.

When Meryl was asked about the photos, she explained the photo pictured ten friends whose ages ranged from 26 to 56 . She said,

The feeling I get when I look at this how grateful I am to spend time with these women. We spent three nights in a house in Palm Springs, not one argument, not one bit of gossip. And, yes, I got really drunk too.

Meryl continued that getting older comes with responsibility, and she doesn't ...look down at the younger women in this group for their lack of experience. We are all connected, and just because our youngest one is 26 doesn't mean she doesn't have something amazing to offer, and we don't have something amazing to offer her as mentors, teachers and friends and all that.

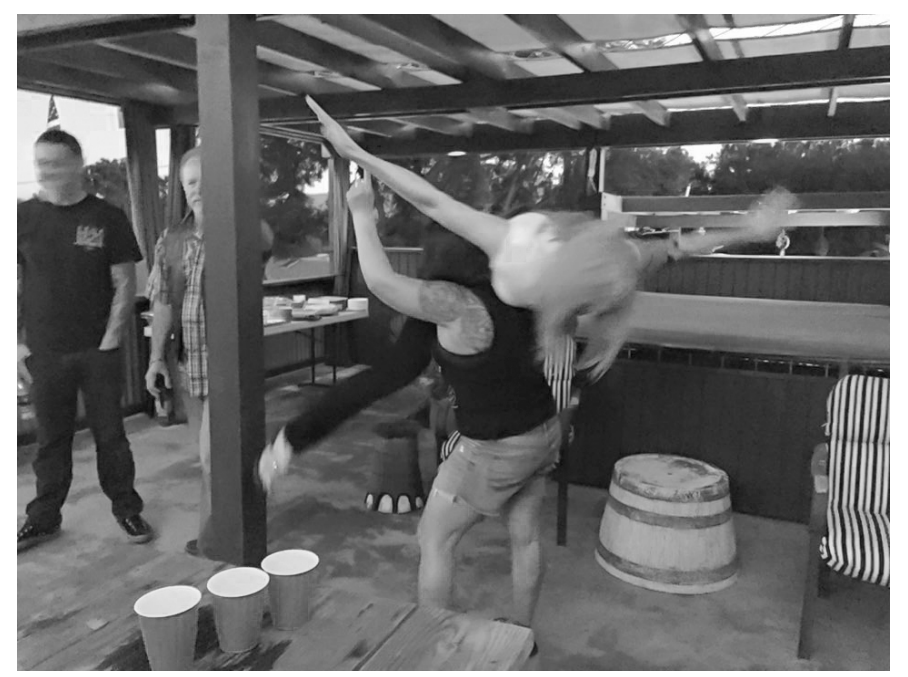

Figure 21. Life of the Party (Meryl, 2016). 
It took the group awhile to understand what was going on in Figure 21. This photo evoked comments like "there are some red cups," "someone lost a beer pong bet," and "it looks like a Karma Sutra pose or tandem yoga." PrinceFan69 said, "Those 40 cups in the corner definitely are like, 'Let me show you. Just trust me'." Rosa agreed there was a level of trust and love between the two of them. Meryl picked the one of her spinning Karen on top of her shoulder because "at this type of party, you will see the younger people more reserved. I just find the older I get, the less I care what people think." There were head nods and smiles from the women when Meryl said this (and the group was right about beer pong).

Next, PrinceFan69 shared her two photos.

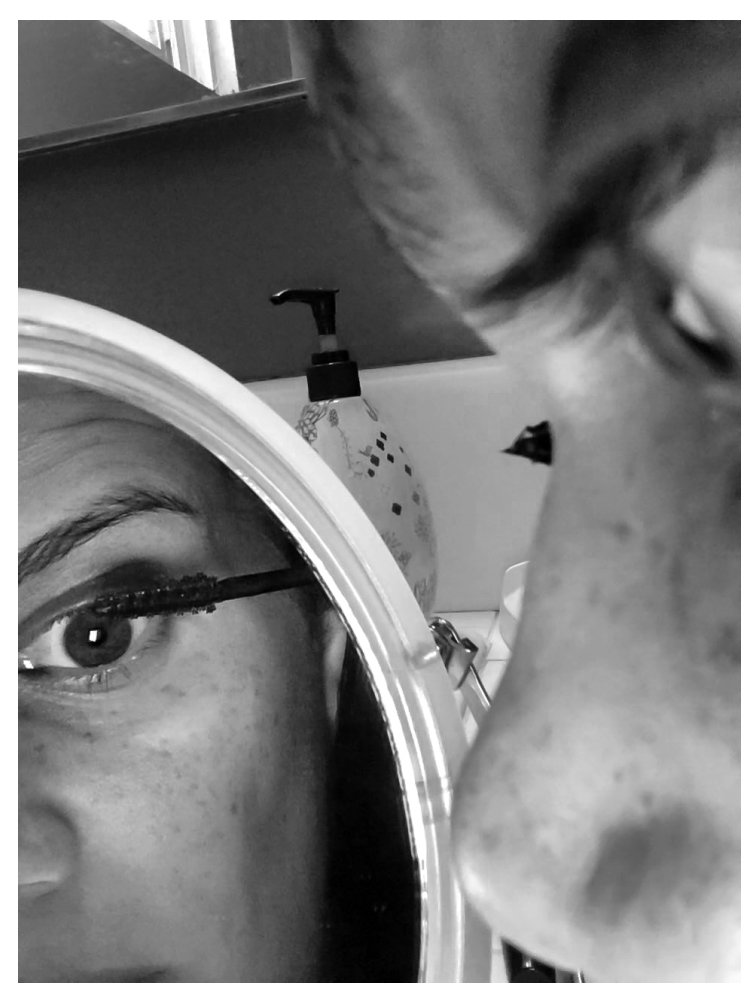

Figure 22. What We See, What We Don't See (PrinceFan69, 2016). 
Trixie: "I can relate to this photo. I don't wear mascara, but to pluck my eyebrows I have to get a magnifying glass, you know. I put on my readers but I still have to get close up to the mirror and I still move them down [showing how she moves her glasses up and down]. So I can totally relate to that. There was a time I didn't need a magnifying glass to take care of myself."

Michelle: “And now's the time when hair is coming out of your chin, and you're like really? You do need to have those magnifying glasses on hand. Before I got my contacts, I appeared in softer focus. But I didn't know that until I got contacts to be able to read, and holy shit, all of a sudden I could see the wrinkles and other things. At this point, you either can see or you don't."

Other comments included that the photo was "very artistic, like showing what middle-aged looks like close up," "the focus on the eye is cool," and the woman in the photo is "very confident" (and has great eyelashes and eyebrows).

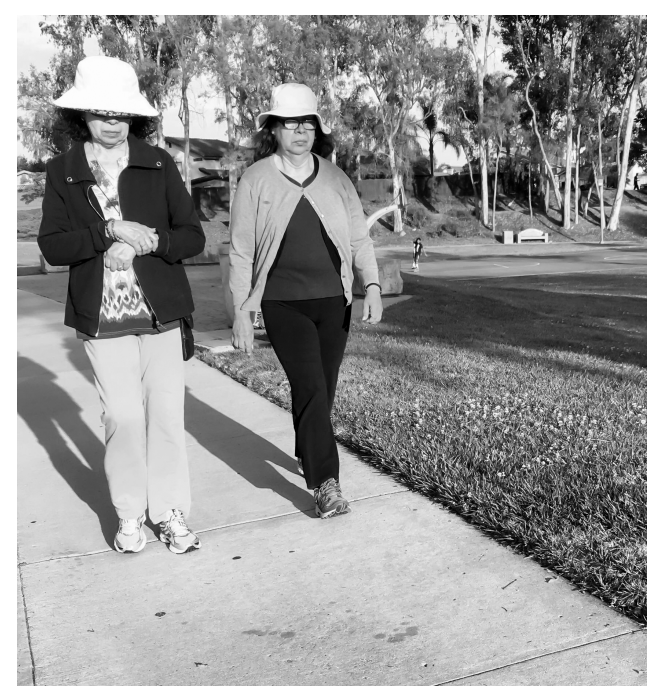

Figure 23. Middle-Aged Women

Walking (PrinceFan69, 2016). 
Figure 23 evoked words and phrases like "friendship" and "long-term friends." I commented, 'It's because they're dressed alike and you know, kind of like when you have a dog and you end up looking like your dog?"

PrinceFan69 stated she chose the two photos together "because they both represent aspects of being me, middle-aged, my experience." Rosa had expressed that she thought both of the photos were linked, as if the one of the "eye" was looking into the future of what it would be like being middle-aged (Figure 23).

PrinceFan69 explained,

This one [the eye] was really hard to take a picture of me, like I couldn't actually see myself, I was trying to get my face. But it's like you said, I didn't used to need glasses or magnifying mirrors. There was this kind of blurry place, literally, where I didn't realize it made a difference and then I had to wear my glasses consistently in the past year. And I had this moment of understanding, "Oh, this is why old ladies look so jacked up." I had the realization of, oh my god, I have walked into a room thinking I looked fine, and then I'd put my glasses on feeling like oh, wow. This shifted my perspective of what we see, and what we don't see. And if I don't look, I still feel super confident and fine about the way I look even if I have jacked up make-up, and don't know it. I'm like I kinda don't care. It's this moment of realizing, oh, this is why old people's houses are dirty. It looks clean to them, but they can't see the hairs in the corner of the floor or the layer of the dust or anything. So it was just like this next step of awareness and experience of aging. 
For Figure 23, PrinceFan69 referenced the comedian Ali Wong who has a Netflix special called Baby Cobra. Wong asks the question, "Why do old Asian ladies always wear giant sun hats?" When PrinceFan69 was at the park, she saw the two older Asian ladies and she thought, "Oh my god, she's [Wong's] right." She added, "I started seeing all these other woman, and it was like sunset and they were all coming to the park, doing their walks, and they had these big, floppy, ugly hats on." PrinceFan69 pondered if they were "trying to protect themselves from the sun to retain their youthful skin." She said, “They both have the same expressions like they're looking so dutiful, like this is what we do [walk around the park together]." PrinceFan69 said, "This is so emblematic of our experiences as we get older in doing things that aren't particularly enjoyable, but if we do these things we should be doing it with a friend."

Lynne shared her photos next.

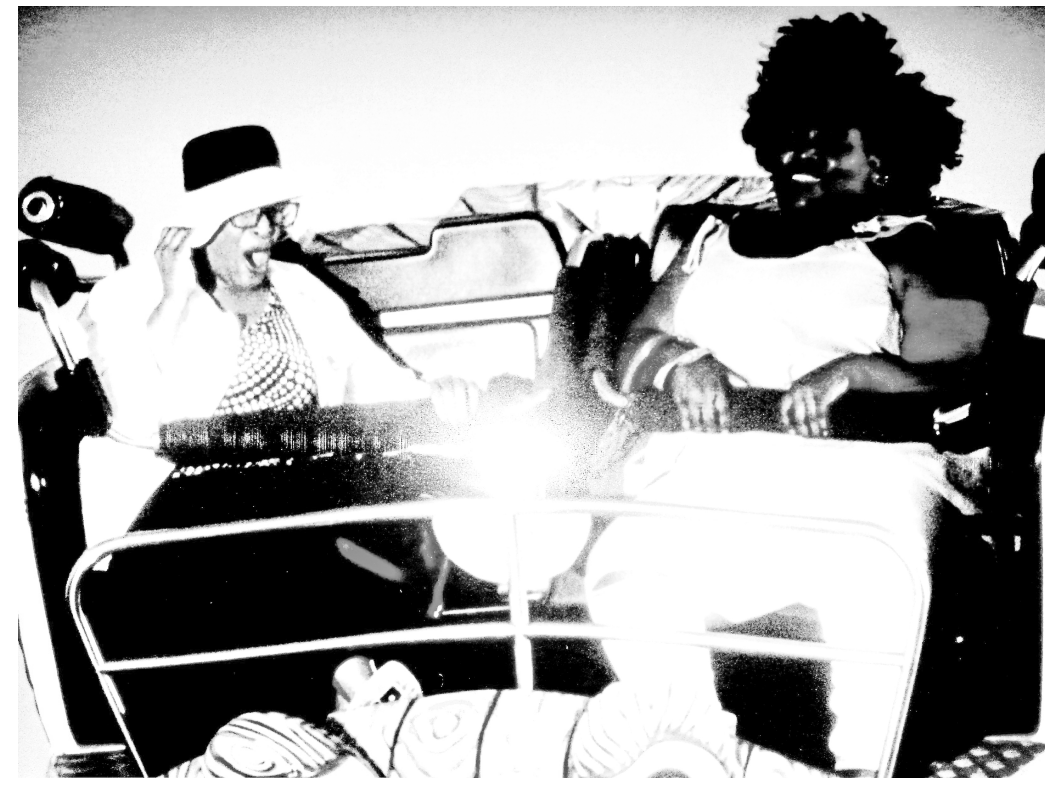

Figure 24. Wild Ride (Lynne, 2016). 
Meryl said, 'It's Disneyland or a theme park because obviously they're on a ride, the lap bar is down, and they're taking a photo of them when they're the most scared. Their expressions are awesome." The group noticed one is an older woman and one is younger, and agreed their expressions were "genuine" and "joyful." PrinceFan69 said, "That burst of light in the center, and then the smiles and expressions...in a way it fills up the whole frame of the picture." Rosa recognized "fashion and elegance" on a ride when you would not expect it. The group noticed a sense of feeling "comfortable even though it may be a thrill moment," as if they might be "mother and daughter" or related.

Figure 24 is of Lynne and her granddaughter at the Del Mar Fair.

Trixie: "Adventurous, I know."

Lynne: "It's one of those roller coasters that swerves and jerks around. I like rides. This is a moment in time when you're hanging out with the kids, and you're still able to do things with them. Joy. That's joyful to me."

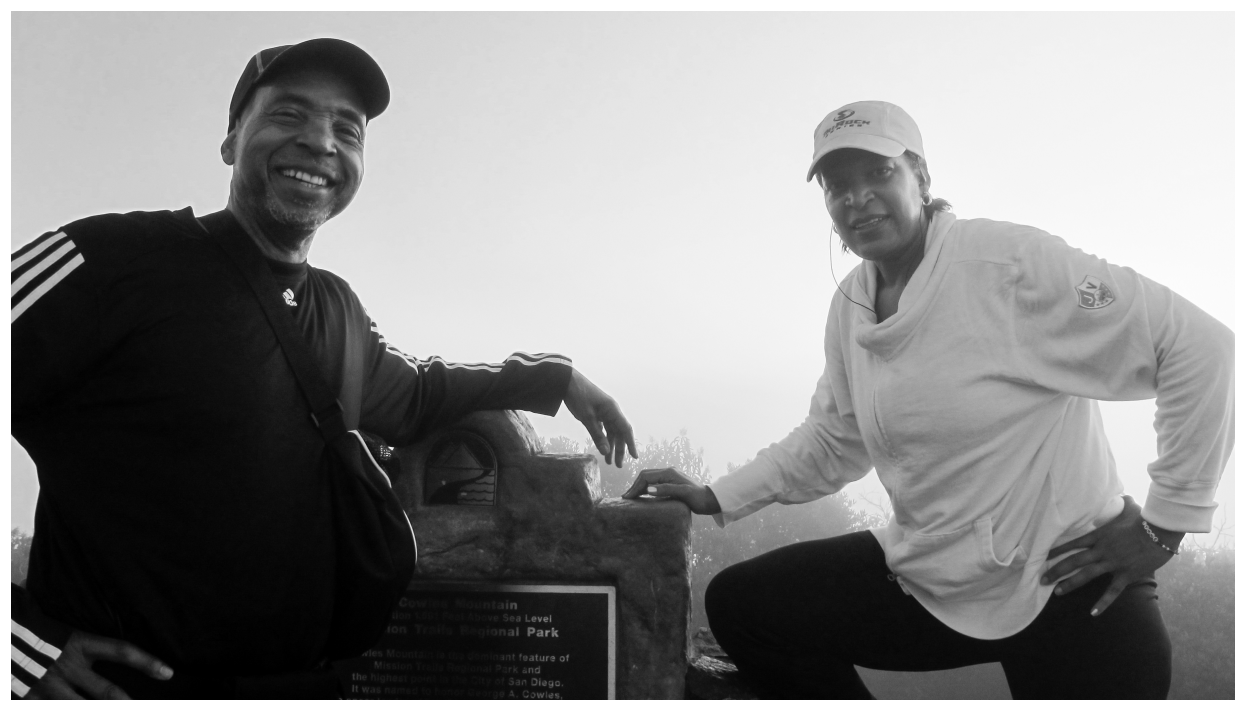

Figure 25. Climb the Highest Mountain (Lynne, 2016). 
When asked about Figure 25, words and phrases like "content," "partners," "sharing goals," and "fitness" were said. Initially it was thought there was a romantic relationship; but once the discussion continued we changed the relationship to "partners." Hilary asked where the group saw the "connection." The group suggested it was their hands, body language, and "kind of rising above together." Trixie continued, "Their relationship, their joy, brings them above whatever blanket of yuck, smog is out there." Rosa sensed that it was not a love relationship but more of a friendship, and that the man looked younger than the woman. We joked that she should never, ever say that again. Lynne shared that Figure 25 was a photo of her uncle and her at the top of Cowles Mountain (the highest point of the city in San Diego).

Lynne: "My uncle is 75-years-old, my mom’s brother."

Meryl: "Really?”

Trixie: "Especially because he's handsome."

Lynne: “Don't tell him that. He thinks he's all that. If anyone has done Cowles Mountain, it's a challenge. I think this was maybe my first time doing it. So this is just representative of my state of mind, challenges, and being adventurous and conquering."

Next, Trixie shared her two photographs. 


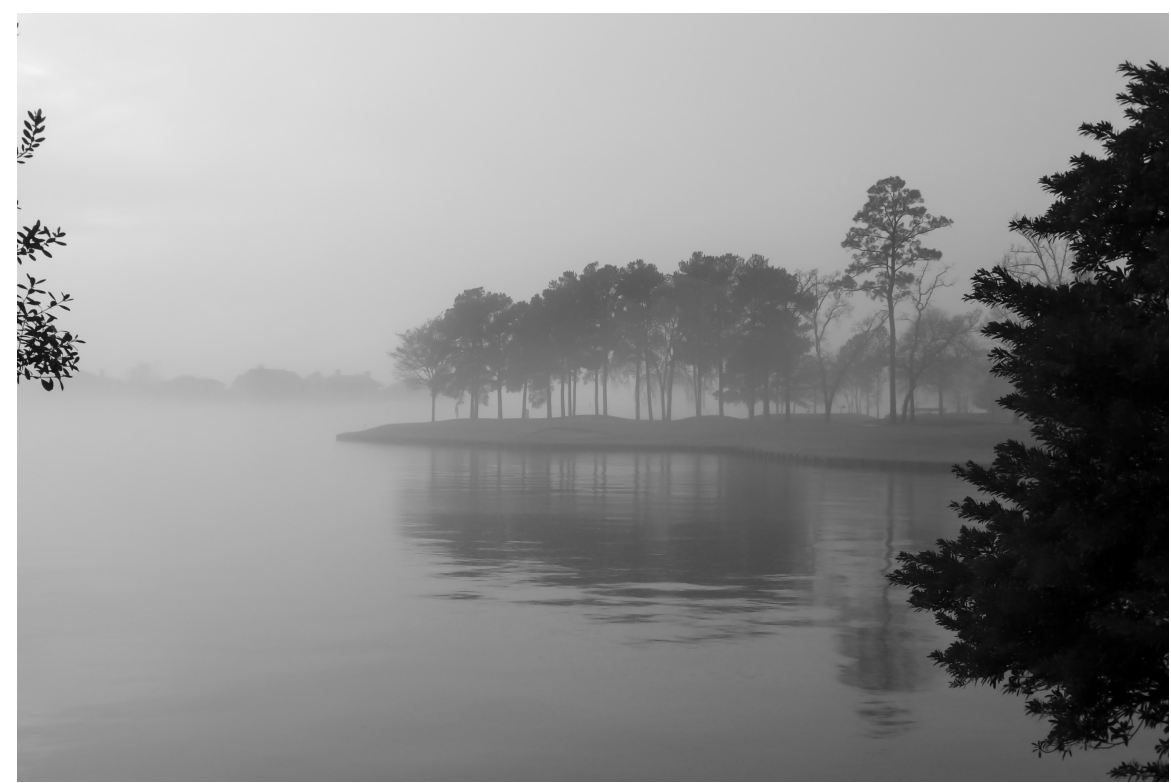

Figure 26. Contemplation (Trixie, 2016).

Words used to describe Figure 26 included: "serene," "meditative," "peaceful," and "contemplation." Meryl said, "Early riser..." I finished it with "catches the worm." I went on to comment that the photo seemed "kind of sad and melancholy."

PrinceFan69: "There's the reflections in this photo with the trees being reflected by the lake [it is one of the first things she noticed]. Reflection about the act of reflecting. And this sort of monochromatic color scheme it just looks like somebody standing there in that moment looking out enjoying the inner peace." 


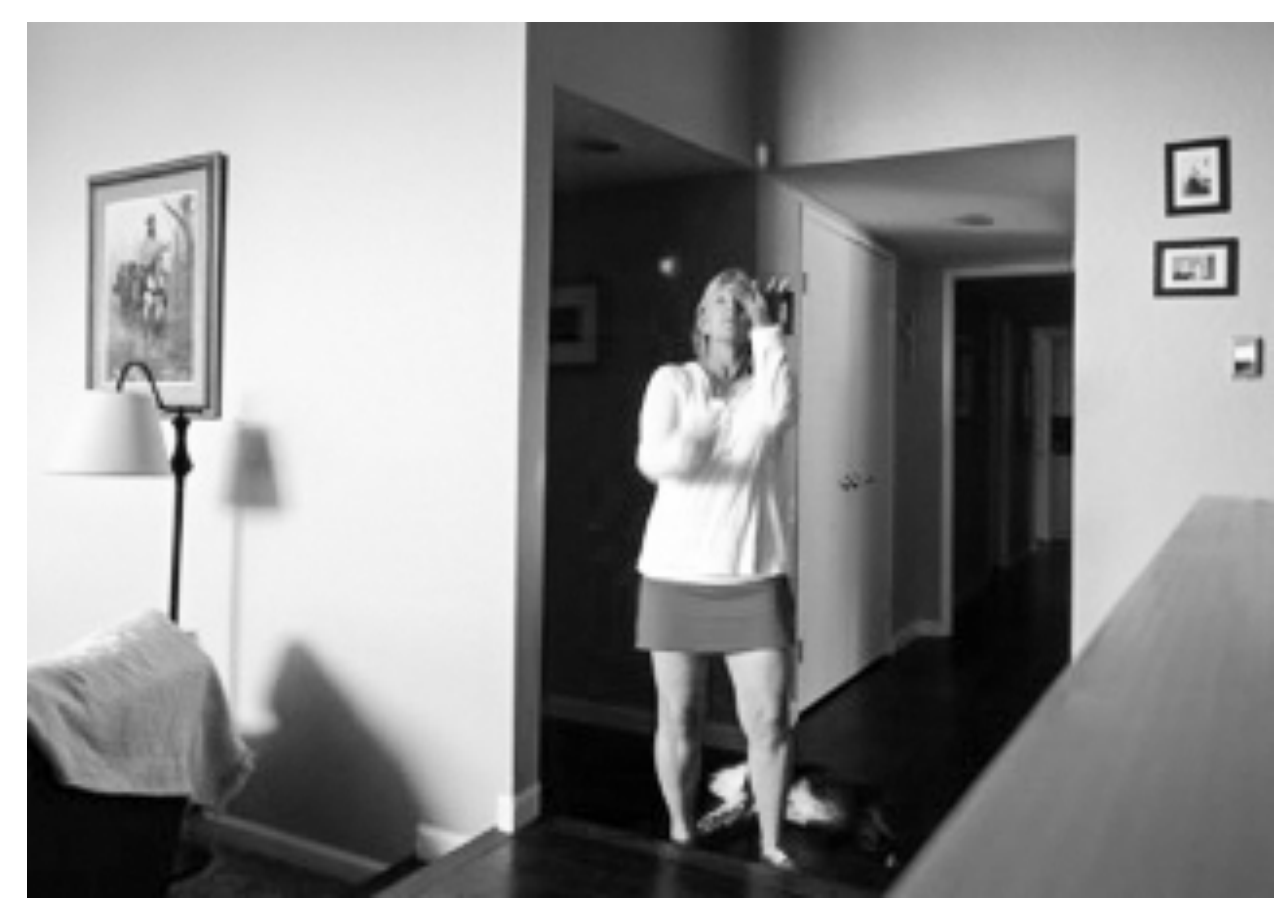

Figure 27. Juggling Life at a Nexus (Trixie, 2016).

The group tried to figure out what Trixie was doing. After a few minutes, we determined Trixie was juggling limes (they were the only thing she had three of), "juggling life," in a short skirt. Rosa said, "She looks really fit, and ageless." I said, "I find it interesting it's kind of like a hallway is behind her. What does that mean? If anything... Sort of like the journey. Either going backwards or forwards." Lynne thought Trixie was listening to music. Trixie hummed a circus song, and Lynne said, "Prancing through the hall with her limes."

When Hilary handed back the photos to Trixie, she said to the group we did really well with "deciphering the images." She explained:

I chose this one [Figure 26] because I do have a lot of alone time on my hands these days, and I do reflect a lot about what's my purpose. What should I be 
doing right this moment? There's a calm that I feel in owning where I am and not regretting where I've been. My caption for this was Even in the Calm Things Aren't All That Clear Until They're Right in Front of You. As I go through life, I'm not too focused too far out but can enjoy the view. There's a calm place in front of me but really all I can do is deal with what's in front of me, right here. For Figure 27, Trixie explained she was juggling limes and her dog was right behind her (he was cut off from the enlarged photo). She captioned this photo as, When Juggling Life, Or Limes, Beware of the Dog. Trixie went on to explain, So, even though I don't have a job I have to go out to or anybody to report to, I still have a lot of things I need to juggle. And as things come up, I get really irritated because that's not what I wanted to work on today but it has an urgency or it's someone else's priority.

Trixie feels that she is still "juggling all the mom things, and the wife things, and the house things, and health things, and pet things." Further, she chose a place in her house where "all these walls come together and it makes a little star." She admits this is symbolic of where she is in her life (i.e., nexus). Trixie said, "Where do I go from here? I could go back this way down this hallway, or I could go back down that hallway, or straight ahead to the kitchen."

Group discussion on photographs and stories. Hilary asked the question, "What kinds of connections did you hear after we went through all of the images? What commonalities did you see?" Some common themes included "joy," "self-reflection," and "We take care of our bodies." I said, "There is spirituality at this point in our lives." Rosa mentioned self-reflection and I agree with that. I explained, "I think it's reflection 
about how do I want to live the rest of my life and also being present." For me these concepts were illustrated in Rosa's photos (Figures 16 and 17), in Trixie's photos (Figures 26 and 27), and Lynne's photos (Figures 24 and 25). Further, I mentioned "there's a kind of tension between letting go and being present and also being concerned about the way we look."

Next, Hilary asked if there was anything that surprised us. Rosa said, "I feel that the way we decide to live our lives are different just based on the photos." Trixie agreed saying, "The diversity, and our lives are so multi-faceted. Two pictures can't do any of us justice, yet we can identify with everybody else's because there are so many [common] things to accept and embrace and things to let go." Rosa went on to say that she noticed that being around family and having fun is really about mental age, as Lynne pointed out "age is in the mind." Rosa clarified that even though our photos were different, "it was really through our children, being around different ages, and having fun that we are present," and "we don't care the way others think and feel [about us], like I shouldn't be so concerned about what I'm wearing." Trixie agreed:

We all have a picture in our mind what our midlife, is going to look like based on our experiences, and we're owning it and taking responsibility in writing our lives, our journey. And we don't care if our make-up is on perfect, or, that we're wearing "a skirt and juggling limes while trying not to trip over the dog," you know?

PrinceFan69 commented that she was "surprised" to see so much care and creativity went into the photographs. 
I guess when I imagined these [photos], I was thinking more in snapshots. These are all unique, carefully composed, and really well thought out and creative. And I feel like there is a lot of self-love, care, and concern. And we're representing what we are trying to say.

Rosa shared she saw self-focus in our respective photos. She struggled with this aspect of concentrating so much attention on herself and labored over what photos to choose. Rosa came to the conclusion "it is because we are always thinking about others, giving and being moms, and this time we made it about ourselves. I think I saw that coming out in this process."

Hilary asked whether the feedback on our photos was close to the original "story" of the photographer, or not close. Trixie and Lynne said that our reflections were "on point." Regarding my two photos (Figures 18 and 19), I had clear stories that I thought the images supported. The one of the older woman, my mom, looking at hair dye was about how if we only color our beautiful, gray hair or buy the myriad of beauty products we can look younger, at whatever cost. However, the comments on the photo focused on "hope," and being excited about dying hair for a "special occasion with her husband." For Figure 18, I captioned the photo as Middle-aged Woman Missing, Presumed Dead, because none of the photos had women who looked like me. But Trixie and Meryl had similar comments to each other that, "If you do this [try to look like the women in magazines], you will be dead."

This led into the next conversation about whether we saw middle-aged women stereotypes, or were the images stereotypical in any way, and the participants agreed there were no stereotypes in the photos. 
PrinceFan69: “It's just like you were saying, Rosa, about we shouldn't do certain things when we're in we're in our 40s. You know you just get to a point where you're just, "I don't care or afraid if anyone else likes it. I like it." You do it anyway, but you are aware that you are pushing against that expectation.”

Trixie: "Choosing to be a rebel."

PrinceFan69: "Right. So you're either giving in by saying, "I'm going to wear a pair of sensible shoes and get a sensible haircut." You know doing what other people think you should do in middle-age. Or pushing through this stage of life, and looking at those older ladies in their 80s in New York City with crazy, high-fashion, jewelry. Those women are really individualistic and expressive and artsy and fun and I'm like, 'I totally want to be like these kooky old ladies."'

Trixie: “Yeah, maybe that's why I didn’t feel like I didn't know what society's stereotype is because I had no intention of fulfilling it."

[Laughter.]

Trixie: "So, I'm just going to be me."

Rosa: "I work in public health and the work that I do is always around equity and disparities and minorities. Many times I look at everything in those terms, so when you talked about stereotypes, I think we are very diverse group of middle-aged women. In the photos I did see things that could be considered stereotypes like the typical Latina wearing high heels. I saw your photo in a miniskirt 
looking great [referring to Trixie]. And I think, 'Gosh, maybe I could wear a miniskirt one day.' Do you have any thoughts about middle-aged women based on diversity?"

Michelle: "Yes, if you look at these photos in the health or high-fashion magazines like Vogue and Bazaar, there's not a lot of diversity, right? I mean there's a lot of thin, young, mostly white women who are...."

Trixie: "Airbrushed. It's unreal."

Rosa: “I didn't know if culture has different expectations for middle-aged women, or do we all share many things regardless of culture?"

PrinceFan69: "I think as we get older we get more separated by economic status [than culture] because you've been low-income for a long time. You can't do the things that wealthy people can afford to pay for like $\$ 400$ shakes delivered to my house and a trainer and so on. The gap seems to get wider as you get older where it starts to show how hard your life has been, and whether you're fighting against expectations for us to look a certain way. So, do we want our story to show in our skin or our bodies of who we are or are we trying to hide it and pretend we are ourselves from 15 or 20 years ago?"

Lynne: "I think it just reduces the pressure of what society wants us to be embracing who we are whether it's a wrinkle, whether it's a bulge, whatever it is, that's who we are, that's who we've become and the 
physical appearance should not have any effect on the mental capacity of how you look at things. Because we didn’t know coming in, but just look in the short amount of time what we have been able to reflect upon. It's amazing to me. I'm enjoying it. I'm going to encourage more groups like this. It gets us talking about things that we think about, right? That we don't talk about. It's like the elephant in the room, one says anything we know we're thinking the same things.”

Trixie commented:

We need to be role models for these young girls who think they need to look like those impossible images in magazines. So they can see their mom or their aunt or their older sister or their grandmother not putting worth in print and unrealistic things. This could lead to acceptance of who they are from an earlier age so that when they become middle-aged they are going to be doing extraordinary things far beyond what we could imagine.

I gave the women their next assignment to go and take photos of those places where each of them frequented, such as the gym, church, their home, etc. We ended the session by sharing one word or phrase.

Trixie: "Go Warriors [reference to NBA playoffs]."

[Both Meryl and Lynne scrunch up their faces.]

Meryl: "Cavaliers."

[Meryl and Lynne give each other a "high five."] 
Other words included: "unity," "a lot of fun," "sharing," "feeling good," "listening," and “interesting."

Post-session 2 evaluation. The three-question survey, as well as the individual interviews between Session 2 and Session 3, provided information on what worked and what did not work in the sessions, and were the takeaways from Session 2. Table 5.4 presents data regarding what the participants felt worked during the session.

There were not any comments on the three-question survey about what did not work in the session. However, when interviewed there were comments made about how to "go deeper" in our discussions (see Table 5.5). This was the beginning of the conversation about how to continue this group.

Table 5.6 highlights comments from the participants regarding the takeaways and things that resonated from the session.

To summarize, there were some common themes that were evident after analyzing and synthesizing the data including the desire to have more of these sessions as a way to have deep and meaningful conversations; the importance of being present, the need to be reflective and meditative in order to listen and transform; and, that we have an opportunity to change the narrative about being middle-aged women by understanding we are unique and our journey is our own but shared. 
Table 5.4

What worked during Session 2?

PrinceFan69 "I was pleasantly surprised by the photographs taken. I thought they were going to be snapshots. And the opportunities to express meaning behind our images after the group discussion allowed me to see the work in new ways, including my own. I, also, liked hearing about the artistic process, and why each of us chose to take/share the photos we did."

Rosa "Looking at the photos and having a prompted/facilitated conversation about the images got us thinking, engaging, and analyzing on a deeper level. It's similar to a writing critique, and served its purpose well here. I think now that we've shared this experience we are learning and connecting, and it feels like 'we are in this together.'"

Michelle "I was honored to participate, to truly be present, as we shared our photos and stories. I was impressed by each and everyone's careful insight and the care we took with each other. I felt a great deal of trust, and thus connection."

Meryl "I really loved sharing photos with everyone and hearing their stories behind the pictures they chose."

Trixie "I felt a lack of judgment which made me feel happy. And I think it's a gift to take time to hear the stories since oftentimes we make our own assumptions or fill in the blanks with our judgments which can be dangerous."

Lynne "The interaction, the discussion, and sharing all worked. I enjoyed the process. I've been pleasantly delighted. It's gone by so fast." 
Table 5.5

What did not work during Session 2?

PrinceFan69 'I'm interested in this process, and the storytelling. I think it would be better if we had longer sessions over a longer period of time like a couple of months, then we could get into some 'juicy' conversations. There could be topics like sexuality and relationships, how we have changed through the process, and what 'things' mean after we have this experience."

Rosa 'It would be great to get Hilary's [the photographer and educator] thoughts on the process, and the stories. She would give us and intergenerational perspective."

Meryl "I think we need to meet once a month for six to twelve months. That way we can be more vulnerable with each other, and talk about things like depression, empty nest, and body image."

Lynne 'I'm exhausted on comments [she shared this thought more than once, however she did complete the survey and I did interview her]. I would say that it would be exciting [for Michelle] to do varied subjects with different groups like men, teenagers, a different middle-aged women group, and so on. You could also do families, individuals, around a particular project, or event." 
Table 5.6

What were the takeaways or what resonated from Session 2?

Rosa "We need more groups like this. There is such a need to connect. I think about continuing this group and what kinds of conversations (and impact) we can have on individual needs, commonalities/community, and the larger community/society. Finally, I think about what we didn't talk about, the 'elephant in the room' and that is fear of death."

PrinceFan69 "The importance of being present in each moment, to exist outside expectation, and to pursue moments of inner peace, meditation and connection."

Lynne "I'm going to do me."

Meryl "The first magazine I picked up, when we were doing the collages on the first night, was Robin Williams on the cover and an article about his depression and death. And I thought about my anxiety and panic attacks, and how I take medication. I'm not ashamed of this but I wasn't going to share it on the first night. But look I did tonight. I am so excited by our diversity, and despite this I was able to open up about my mental health and insecurities. This is important that I felt so comfortable with this group I just met to share something so personal. I see this as a venue for self-exploration, too. This experience was very diverse and real."

Trixie "Midlife is not definitive; it is flowing in whatever direction; there really is no 'normal' or 'standard.' Also, I have to say I am so proud of you [Michelle]. For years I've watched you spinning your wheels 'seeking justice.' I'm glad to see this process work on you, too. You seem like you have some traction, and some peace, through this."

Michelle "After this session, and the positive responses to my photos, I decided to change the types of photos I present next session. I love that I've been impacted by this process, and to see the changes in the women around me."

\section{Session 3}

Reflections. The group was welcomed back by Avonlie for the third and final session. She asked us to "go around the room and be connected" and present "so let's have everyone say something about being here, about last week, or anything." 
Lynne: 'I'll start. So, I as I was driving over and reflecting about everyone's lives, I realized how happy I was to be here. I'm glad I took the time to be part of the group. We need more of this [sessions/meetings]."

Michelle: 'I know I've already mentioned how transformative this has been, and not that I've been surprised, well, I guess I have been. But I was surprised by how immediate and intense the transformation has been. I really had the opportunity to be part of the group, and it's so beautiful to see how the group has come together in a very short amount of time. Thank you."

Anvolie: "For me, it's been a great pleasure to meet all of you and "work," if you want to call it that. From the beginning, it was so interesting to meet you, Michelle, and work together on how to work the sessions, and to be here. The icing on the cake was to meet all of you and hear the interactions and the conversations. It's been a real pleasure."

Trixie: “It's been a comforting process for me because I think for, I don't know how many years, I've been struggling to find my place, my niche, my purpose. This [process and group] has made me keenly aware that I'm okay. You're okay. There is no benchmark of my life. I understand that however I decide to proceed I'll be okay." Meryl: “I'm getting very emotional. I've enjoyed being here, and I was telling Michelle that I can see this group carrying on. I see doing 
this type of forum, I don't know maybe not once a week but maybe every couple of months, and seeing how much deeper we can get. There's only so much you do in only three sessions. I think we've only scratched the surface and if we spent more time we could talk about "real issues." I mean things that matter in the world, like world events."

PrinceFan69: "I agree with everyone else's sentiments. I have really enjoyed getting to know everybody and being part of the discussion and process. And like I was telling Michelle it would be really interesting to see how the conversation continued to develop over time because it takes time for people to get to know each other and make them feel comfortable and allow their barriers down."

[There is a lot of positive body language like heads nodding.]

PrinceFan69: "It would be great to have these groups with people who are in your life stage and it's not focused around on "being middle-aged," but you know interested (or not) in your same movies. We are just united by being in the same place in our lives, and all the differences we bring to the table and discussion could be interesting. It would be neat to have, not necessarily more focused talks, but just more of a forum for open discovery and talking about issues that we are facing in our lives as women. You know partly I bring this up because I know a lot of people in this age range and we don't necessarily get together and talk meaningfully. 
I mean one-on-one, but not generally as a group and I really like that because you get so many different perspectives, backgrounds, and everybody brings something new and different to the conversation. So, it's been really fun and I've enjoyed the shift in my thinking as a part of the assignments. I like looking at life as "Is this really middle-aged?" Everything I was doing [in the last week] I was like 'Is this it [the middle-aged experience], is it happening now?'

"And then this last week doing the assignment where it was at home, and we were so focused on confronting some of the things [around us and in our personal spaces]. I started looking and thinking about the result of what I was photographing. I have never done that [before]. If I hadn't been asked to do that [to document our lives through photography], I would not have started thinking about myself in another way. Thanks for including me." [Rosa comes from work late, and apologizes.]

Hilary: "This experience has been an incredible privilege to be here. It's been really cool honoring where I am about using my voice, and hearing your stories. Also, to see how photography, a process that I love and value very deeply, has been used and to hear that it has been a valuable process for you was incredibly meaningful to me. So, thank you for trying it on, and I'm glad it was of value to you." 
Avonlie: "Rosa, we were just going around the room to get us in this space.

Whatever you need to say to be here."

Rosa: "To be here? I love it, and there should be more of this [group sessions]. This has made me feel like I'm not alone, and I'm just happy to be here."

Sharing visuals of personal spaces and places, sharing stories. The two enlarged photographs were distributed to each of the women, and displayed on the dining room table so we could walk around and look at them. Trixie volunteered to go first.

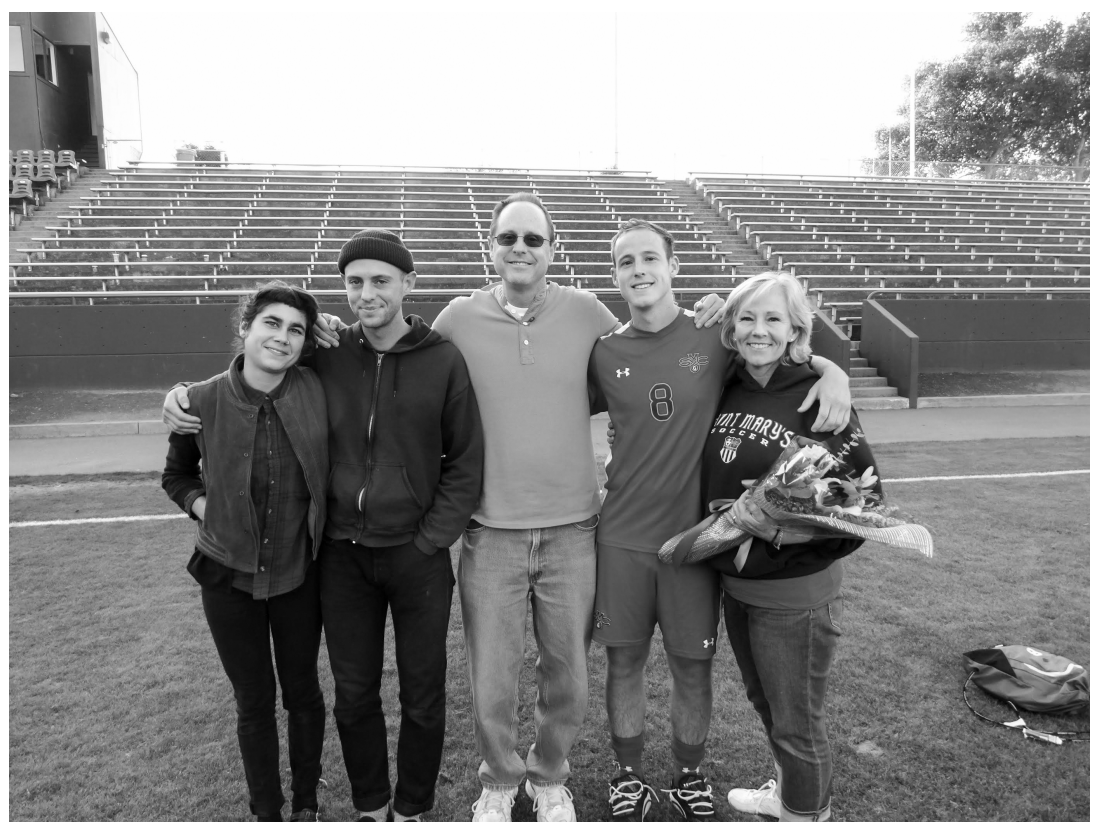

Figure 28. You Are Loved (Trixie, 2016). 


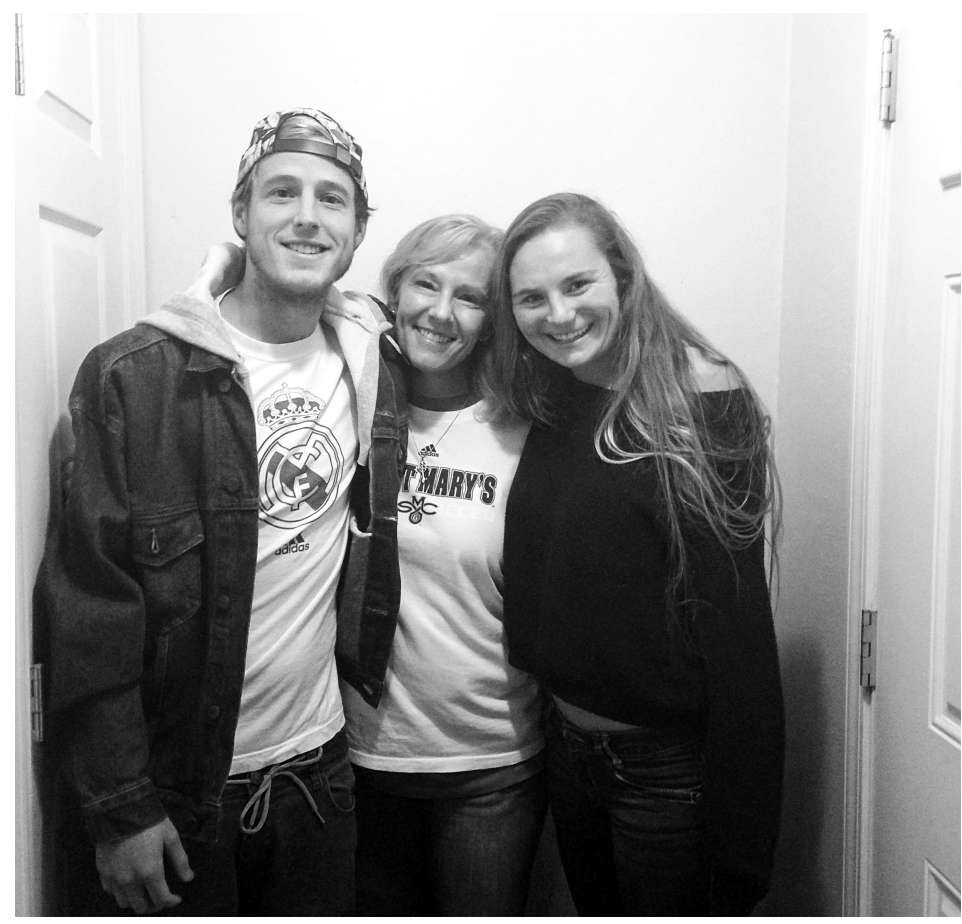

Figure 29. Just the Three of Us (Trixie, 2016).

Hilary reminded us to "go ahead and hold the two photos up first, and then I'm going to ask for comments from everyone else after they have looked at them." For this session, Hilary asked us to consider the images as a pair since the prompt was more personal (to take photos in personal places and spaces) and there was a more likelihood that the photos would be "connected."

Hilary: "What stories do you see told in these images? Or things you noticed these images are saying."

Lynne: "Love and family."

Rosa: "Closeness."

Meryl: "Proud mom."

Michelle: "I was going to say the body language shows they're very close." 
Lynne: "Happy to be embraced or squishy. You can tell the closeness. There's no apprehension of getting together to take a photo. Their body language is not saying, 'Let's hurry up and take the photo."'

Michelle: "Especially the photo with the three of you [Figure 29] where the heads are tilted toward each other [showing with hands like a triangle]"

Trixie: "They're framing me."

Michelle: "Yeah."

Hilary: "Is there anything else you notice in the image beyond the people?"

Rosa: "They look comfortable expressing love and affection."

Lynne: "And the photo [Figure 28] looks like it's an outing so it's clearly a place where families gather to do something."

Meryl: "Like you and your husband are supportive, of like, your kids'

friends, you're comfortable around them and they seem like part of the family based on these photos."

[Trixie nods her head.]

There were more comments about the images conveying a sense of a "cohesive family" and "a family very comfortable with connection," although Rosa pointed out that "there's one gentleman here not embracing everybody" referring to the young man on the left side of Figure 28.

Hilary asked Trixie to share her stories of the images. 
Trixie: "So the place I like to go, my happy place and I go a lot, is a soccer field after my son's soccer game. This was a special game because it was senior day at St. Mary's. It's very special because this is my youngest son, Thing \#2, and Thing \#1 and Thing \#1's girlfriend, and my husband. It was after the game. They won, and so we were super happy. I really liked Rosa's comment about my son appearing to be away from the rest of the family. My older son and I are close, but he has some anxiety [Lynne nodded her head] so he hates, hates his picture being taken. I think he was leaning on his girlfriend. I recognize this in a lot of other photos where I see he [Thing \#1] would hold his head up like this [referring to Figure 29], and she would be constantly checking to see how he was doing. I love that they have each other's back. So, that was very perceptive [of Rosa] that he didn't have his arm around his dad. "This one [Figure 29], it was my birthday. I was hanging out with my son and his girlfriend (and another roommate) at his apartment after a soccer game. The "kids" were going across the parking lot to another apartment where the rest of the soccer team was, and Thing \#2 said, "Come on, say hi to the guys." The team was partying or what not, and we walked in and they sang me happy birthday. It was just incredible. So, this was after the singing. I love being together. I can't think about being away from them even now. I love them growing up, and all that, but I 
have separation anxiety. But that's my happy place, family, soccer, playing soccer also, but these pictures won out."

Meryl went next.
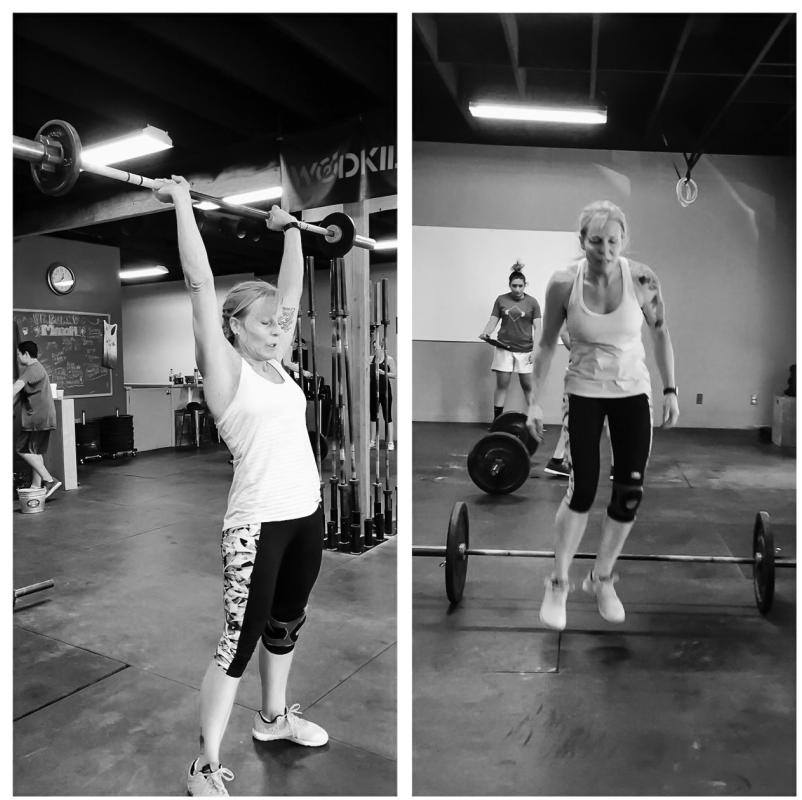

Figure 30. Hero (Meryl, 2016).

Some of the comments from the group included: "triumph and exhaustion," "strength and perseverance," "someone who has made a commitment to herself to be strong and fit, to be healthy" and "concentration." Lynne made the connection that this is the same woman from Figure 21, who Meryl was swinging over her shoulder, which made the women laugh. 


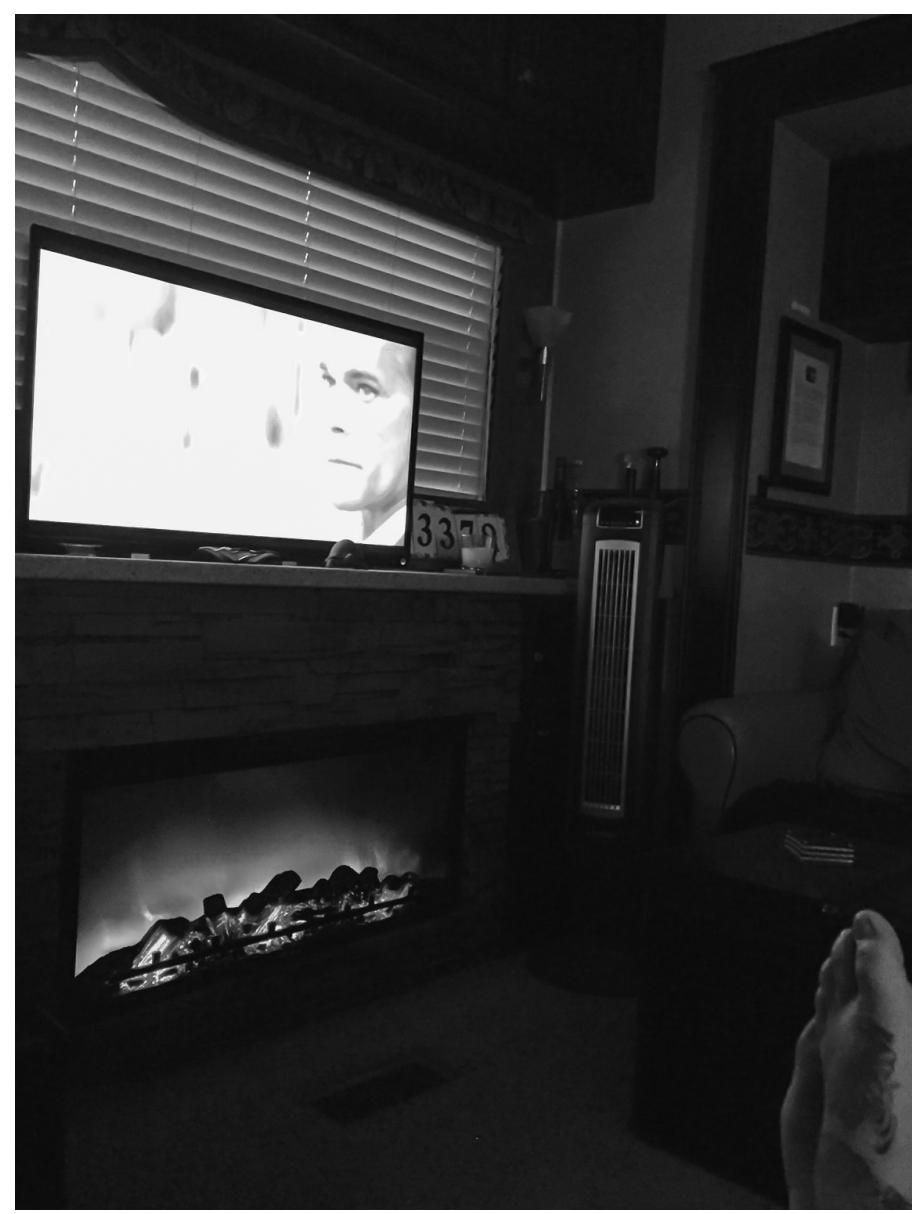

Figure 31. At the End of the Day (Meryl, 2016).

This was a difficult image for us to discern. Trixie recognized a foot in the lower left corner. Other clues were a TV, a fireplace, and "in the dark." I suggested it was a “home.” Lynne said “enjoying a pastime,” and I said, "It's Meryl’s woman-cave, and she's alone." Other ideas included: "winding down," "isolation," "retreat, in either a positive (self-rejuvenation) or negative (retreat from the world)," and "I don't see them as a pair. They're two different images."

Hilary asked Meryl to share.

Meryl: "Since we were supposed to take photos of places that we frequented, this is my gym [Figure 30] and this is my home [Figure 
31]. So, for the gym image, I was going to take a photo of me, but I decided against that. This is my friend, Karen, the same one I spun on my shoulder in the photo from last week. She's 56-years-old. I was in law enforcement for fifteen years, and I never had female mentor in either my department or in law enforcement in general. So, I was hoping I would encounter a female mentor that I could look up to. That's what I have in Karen. I can bounce things off her, and she's very supportive. Karen is a retired firefighter, and her husband is a paraplegic. And it's not so much what she says, but I listen to what she does. She doesn't gossip, and I've never heard her say a negative word about anybody, so to have this woman in an environment [CrossFit] who is older than me, who I respect, who is funny, and crazy; I hope I end up just like her. "This one [Figure 31] is of my home. My favorite word is balance. I wasn't always this way. I was always trying to figure where I was supposed to be. I could never sit still. I was a nervous kid, so I have a lot of anxiety issues. What I would say, in the last five years or so, is my home is my peace. This is me at the end of the day. Basically, I had worked out really hard that afternoon, so I took a shower, and got in my PJs [Meryl calls them "my quitters"]. There's probably a glass of wine in one hand, and my two dogs right next to me, and I'm like 'ahhhhh.'”

Next, Lynne shared her two photographs. 


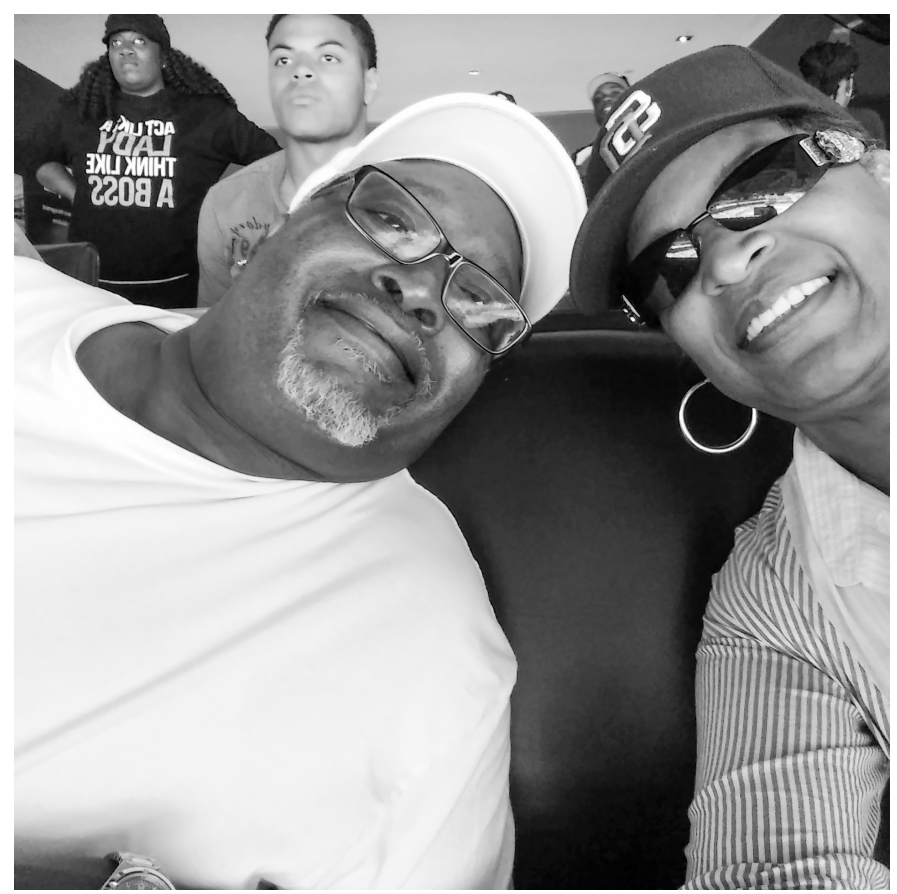

Figure 32. Take Me Out to the Ballgame (Lynne, 2016).

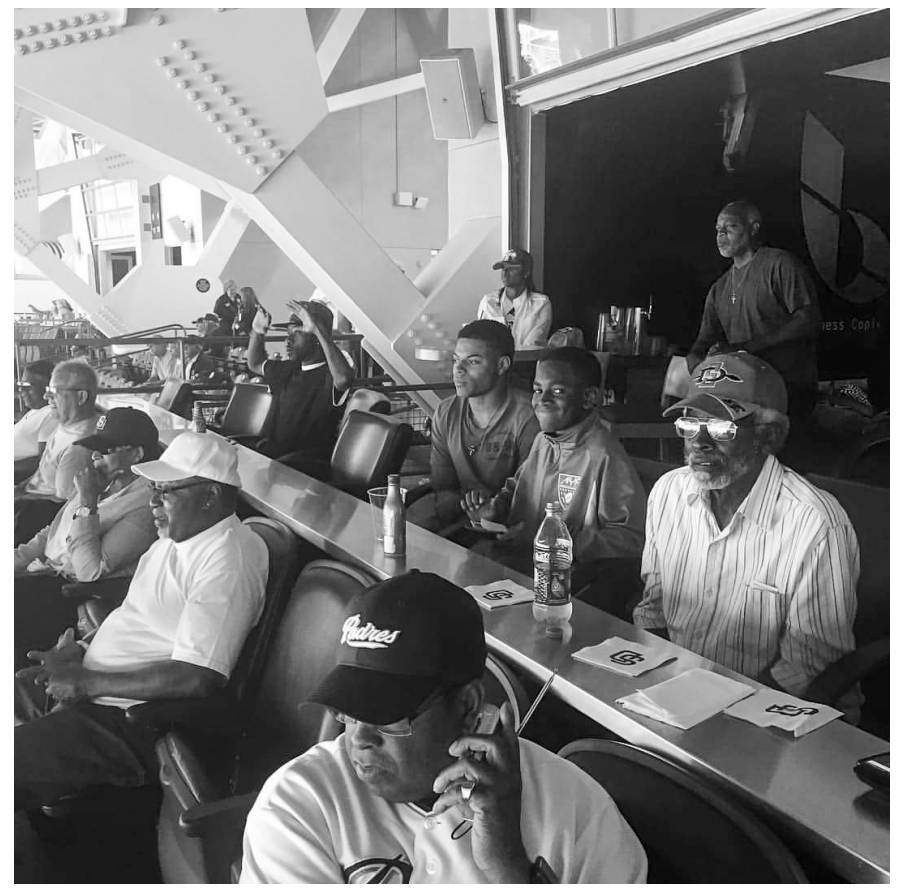

Figure 33. We Are Blessed (Lynne, 2016). 
Lynne: "The photos both go together obviously, and we're at a Padres game in a box. These are my co-workers and their families. We do a lot of team building and outings, which is really cool. As a matter of fact, in August we're going on a cruise. For this event, we were told to block off all of June 15 th. They didn't give us any other hints, except to dress comfortably. When we got to work that day, we went into a meeting to find out where we were going. The bosses said, 'Go close up your offices; we are going to the Padres game."”

Next PrinceFan69 shared her two photos. It is worth noting that these images had a huge impact on the group, including Hilary and Avonlie, the facilitators.

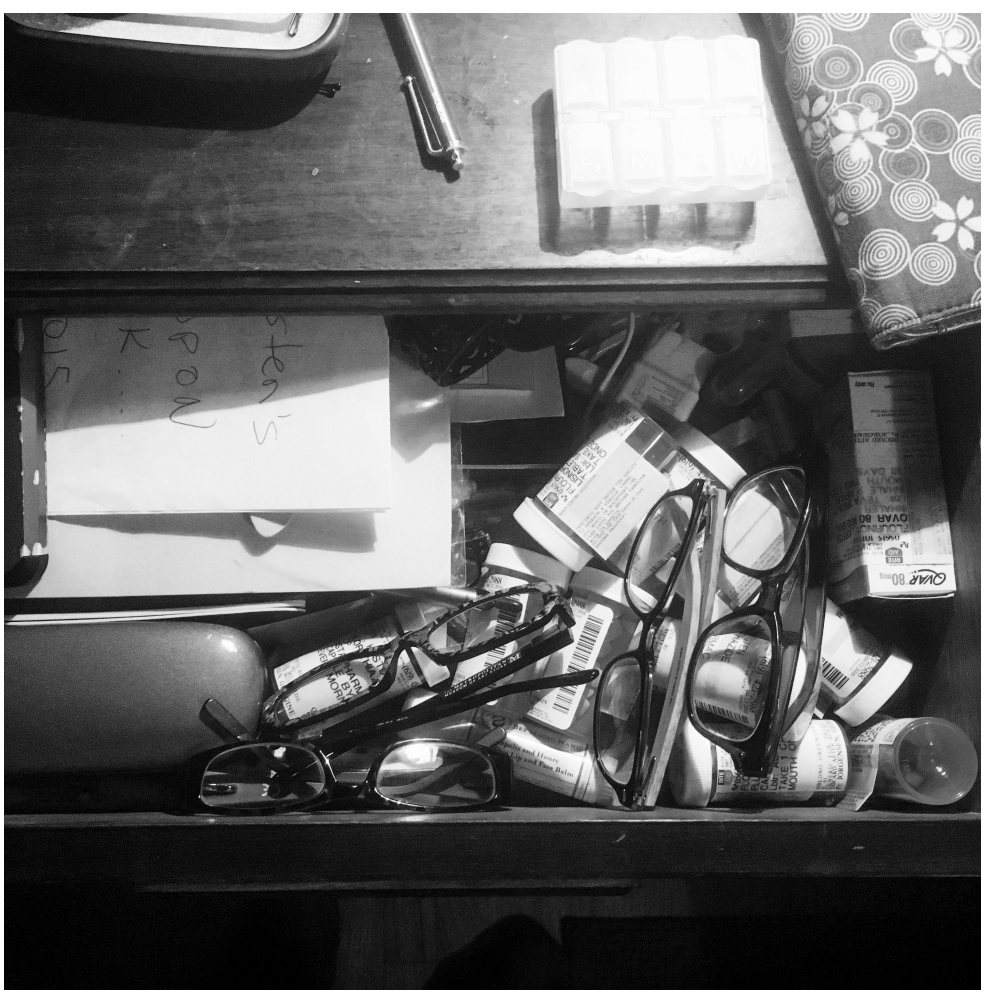

Figure 34. What Lies Beneath (PrinceFan69, 2016). 
PrinceFan69: "This is a photo of my bedside table [Figure 34]. I had this little table and this antique lamp for twenty years, and I've been trekking it from house to house and it's always at my bedside. It's falling apart a little bit; it has a lot of sentimental value. I put all my medication there, because I take four pills a day and I have inhalers. I've always had to take a lot medication for my asthma and my blood pressure. But I've also gone through periods of having insurance and not having insurance, and so my secret, why it's hidden in the drawer is because it's my feelings about having to take medication. And I hadn't thought about it [until she took the photo] but this is the only spot that is a "jumble drawer." It's really messy and everything else in the house is pretty neat. And I collected all my reading glasses, and said, "Damn, there's glasses everywhere." I put them in there with the medication. Yeah, I hoard the medication. It's like depression-era. I'm saving it, in case I don't have insurance again. This makes me think of grandmother with all those bottles. So, I thought this was kind of funny, and sad." 


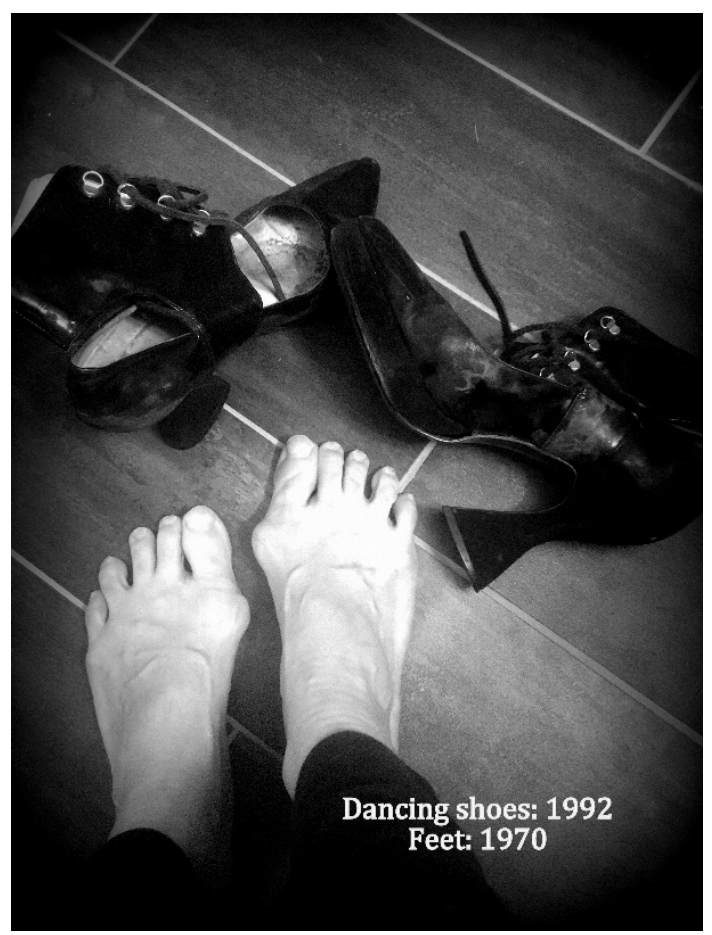

Figure 35. Dancing Queen, Circa 1992 (PrinceFan69, 2016).

PrinceFan69: "Lynne, you totally nailed it [she had guessed correctly what the photo was about]. I was born in 1970, and I bought these shoes in 1992 and these [her feet] are the results of wearing high heels and dancing. At the time when I bought the shoes, they were $\$ 70$. It was a huge purchase, and I loved them so much that I've saved them. Since then I've replaced the leather because it rotted. Now they're getting moldy and the soles are falling off. They're so worn, because I was a dancer and I used to dance on carpet for up to six to eight hours at a time. Now I have these feet, which are getting worse so I don't wear the shoes anymore. I can't wear 
heels every day. It makes me sad. [Laughs.] I look down and I just see these hideous, old lady feet."

Rosa: "What kind of dancing did you do?"

PrinceFan69: "I worked in a peep show in San Francisco."

Meryl: "That is so cool."

PrinceFan69: "This photo [Figure 35] just reminds me of being young and free, and having a lot of fun in makeup and costumes. Just a really bizarre time in my life, so this image reminds me of that."

Lynne: "So did you have this portrait prior to this?"

PrinceFan69: "No, I just took this."

Lynne: "I think that's awesome. It's something that you could hang on the wall."

Meryl: "Very artistic."

Lynne: "There's so many stories for you personally."

PrinceFan69: "Yeah, it's funny because it's such a little assignment but when I'm explaining it...this layer has meaning...this layer..."

The videotape indicates that the entire group, through their body language, was affected by what PrinceFan69 shared.

Rosa shared her two photos next. 


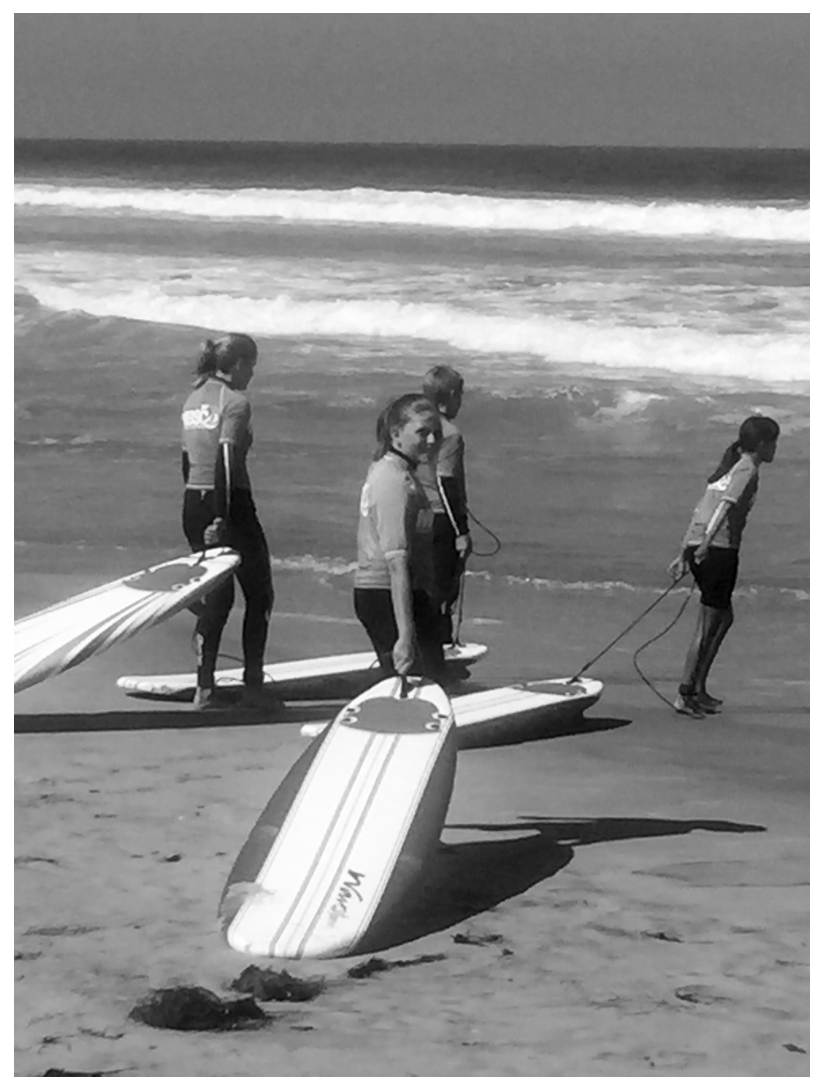

Figure 36. Letting Go (Rosa, 2016).

Rosa: “This is my daughter, and she's been asking me for years to learn how to surf. I'm terrified of the sea. This was her opportunity, last Friday, to go surfing. My son, who is six-years-old, had a near drowning three years ago. He's fine. It's a miracle; we prayed for a miracle. He woke up and there was no brain damage. And this was an opportunity for me to be supportive of my daughter, and to let go.

[Hilary recognizes a release in the photo.]

Trixie: "She looks like she's saying, 'I'm going to be okay."” Lynne: "She looks like she's asking, 'Are you going to be okay?"” 
Rosa: "She [her daughter] was so happy."

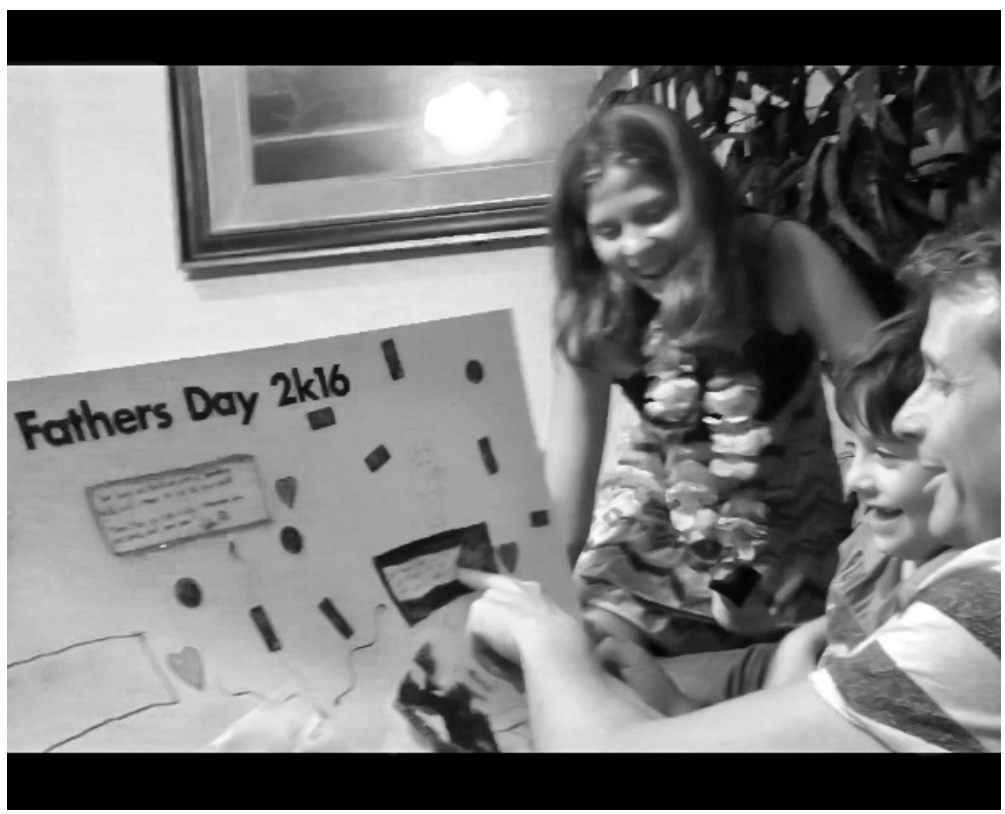

Figure 37. Father's Day (Rosa, 2016).

Rosa: "And this one represents how we spend a lot of time together as a family. They [her children] couldn't wait for Father's Day; they wanted to serenade their dad at midnight. My niece was there playing the ukulele, my daughter was singing, and my son was holding up the poster. It was their idea to create the poster board with special poems."

I shared her photos next. 


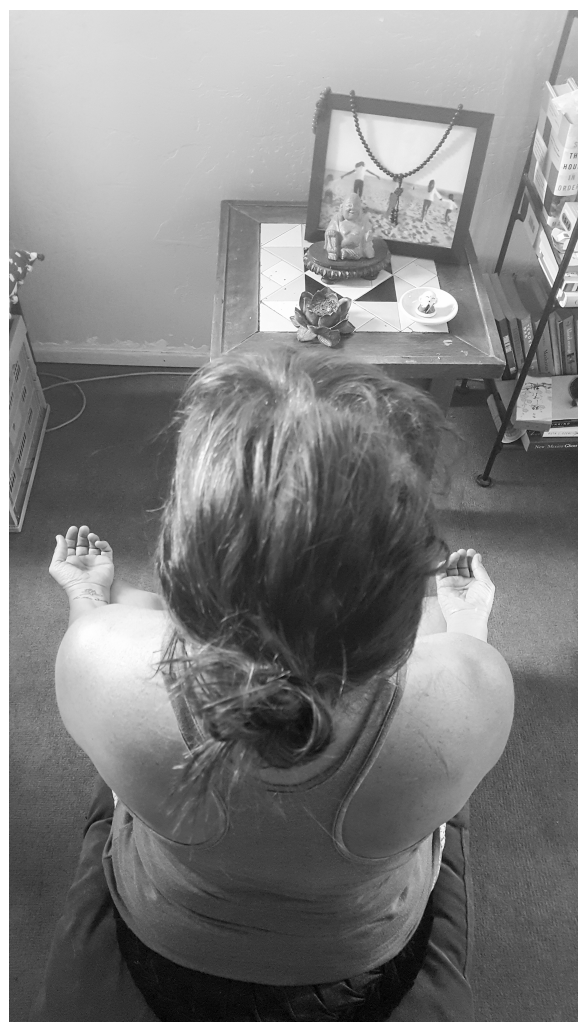

Figure 38. Peace (Michelle, 2016).

There were so many moments throughout this process where I knew the women around me had impacted me through their sharing of stories and images, and mostly of themselves. This photo is another example of how I was transformed. Originally, I was going to take a photo(s) of me walking with my daughters in a public place to prove how invisible I can feel around younger women. However, after being with the group for two sessions, I realized I needed to let go of this narrative and embrace the positive things that age has afforded me. One of these things is peace. For too many years, I had been chasing my tail, running, and had rarely been present. Then thirteen years ago (when I was 40) I went to Taos, New Mexico, and fell madly, deeply, peacefully in love with the 
place. Now I meditate, practice yoga, and go to Taos every summer or whenever I want in my mind.

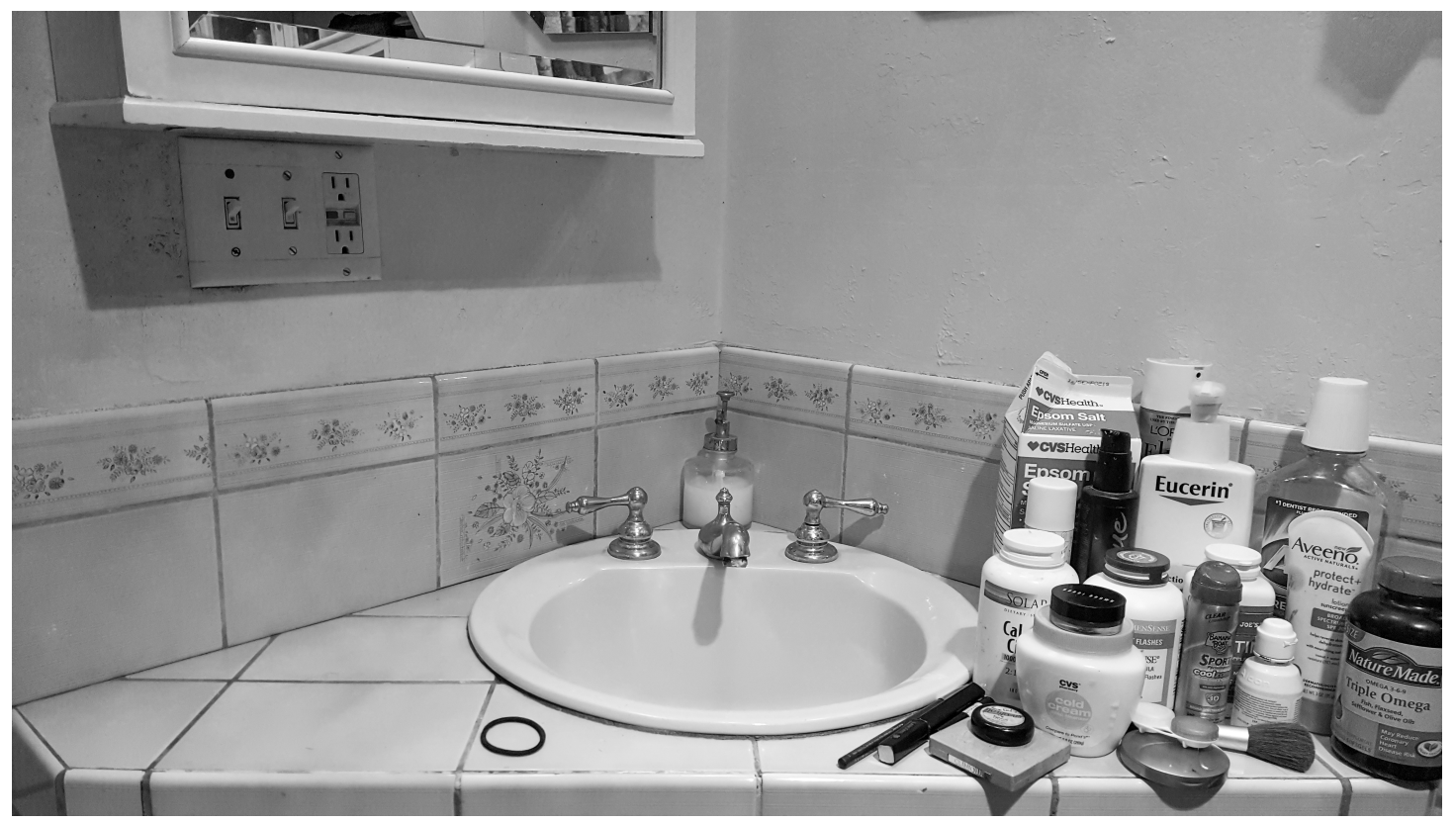

Figure 39. Before and After (Michelle, 2016).

George Bernard Shaw said, "Youth is wasted on the young." This image (Figure 39) makes me think of that quote, and how when I was younger I took my health, looks, and life for granted. To get ready in the morning in my younger days, I would put my hair in a ponytail (see left side of Figure 39). Today, I wear contacts, SPF 50, and more make-up than I ever have (to look natural). I take calcium, triple omega oil tablets, and a multi-vitamin meant for peri-menopausal women.

After the discussion with the group, I came to realize I have an attitude problem. I have focused on loss (i.e., loss of my 20/20 vision, loss of the elasticity of my skin, loss of a robust metabolism, etc.). Through their words and stories, I realized I need to be 
grateful for my health, looks, and life. I realized I need to focus on the gains (and not losses) in my life like inner peace, authenticity, becoming more of myself every day, etc.

Post-session 3 evaluation. Only the three-question survey was distributed to the group since I was going to interview each of the women within two weeks of Session 3 in the post-intervention interviews. Again, there were not many comments and those that were shared were similar to what was shared after the previous two sessions, such as the women loved sharing photos and stories; having "great discussions" on images and Hilary's prompts; and, "continuing to enjoy the expressions of everyone sharing themselves." PrinceFan69 and Meryl mentioned again their desire to continue with the group with the suggestion of PrinceFan69 to "spread out the sessions so we could go deeper." Both Rosa and Trixie shared a similar feeling of satisfaction and acceptance about being middle-aged. Trixie said, "This process reinforced the feeling that I am handling this 'age' just fine." Rosa said, "This personal process has made me introspective about who I am, and that has led to acceptance."

\section{Conclusion}

Based on the data presented from the three photovoice-inspired sessions, there are a number of conclusions that can be made. First, the process of sharing images and stories, and the resulting critical dialogue, was positively received by the participants. In fact, with the exception of Trixie who seemed satisfied with her results after three sessions, five out of six of us wanted to continue this group in some capacity. Second, and more importantly because it is directly related to the first research question (i.e., was there evidence that photovoice techniques facilitated the exercise of narrative leadership by the individual group members?), there is evidence that each of us had changed our 
thinking as result of participating in this group. Finally, because there was an overwhelming response to continue the group in some form, and each of us had suggestions and ideas about how often the group should meet, the kinds of topics we would like to discuss or the activities we would like to do to go deeper indicated there that all three aspects of shared leadership (i.e., leadership that is (a) distributed and interdependent, (b) embedded in social interaction, and (c) attained through mutual learning) were exhibited during the process.

Chapter 6 presents the results from the post-intervention interviews, which will be used to answer the two research questions. 


\section{Chapter 6: Results, Part III - Post-Intervention Interviews}

Within a two-week period, after the last session on June 6, 2016, I interviewed the participants. I used the developed guide (see Appendix E) to interview the women. I interviewed Meryl in her home, PrinceFan69 in my home, and Rosa, Lynne, and Trixie on the phone. In addition, I interviewed both facilitators; Avonlie (who is middle-aged) on the phone and Hilary (who is 25 ) at a coffee café. Interviewing the facilitators was not part of the original methodology; however, the importance of getting their input emerged after hearing from both of them how "impactful" the experience had been for them both personally and professionally.

The data from the interviews were used to answer the two research questions which are as follows:

1. What evidence, if any, supported or refuted claims that the storytelling engendered by the use of photovoice techniques influenced the thinking, behavior, and/or actions of group members: in other words, was there evidence that photovoice techniques facilitated the exercise of narrative leadership by the individual group members?

2. Did narrative leadership appear to contribute to the development of group characteristics associated with the concept of shared leadership?

The last section focuses on the facilitators' thoughts and recommendations given during the post-intervention interview.

\section{Evidence of Narrative Leadership Using Photovoice-Inspired Techniques}

When each of the women were asked about those things (e.g., stories, images, the process, etc.) that stayed with them as a result of participating in the project, there was a 
number of responses which spoke to the impact of the process on each of them, and collectively. Table 6.1 gives examples of those things that resonated with them. Each woman was asked about what she learned about herself as a result of participating in the group, as well as what she learned from the other participants about being middle-aged. Table 6.2 presents the data on these subjects.

Table 6.3 presents data on what was surprising, if anything, about the process or experience of participating in the project.

Table 6.4 focuses on data regarding what each of the women thought "happened to you and the other women" as a result of participating in this project.

In summary, based on the data presented in Tables 6.1 through 6.4, there is evidence that photovoice techniques enacted narrative leadership in the group. In other words, there appeared to be a change in each of the woman's thinking based on the sharing of images and stories, and the critical and reflective discussion that followed. 
Table 6.1

Question: What resonated with you after participating in the project?

Rosa 'Until I had these conversations, I didn't want to recognize I was middle-aged. Now I feel like I'm part of the group, one of 'those women,' and I'm comfortable being part of this 'group.' I learned we all have our struggles, but we also offer great things during this time. As a result of participating, I've accepted my age, and I feel proud and I'm thankful for my career and being a mom, all that I've accomplished in my 40s."

PrinceFan69 "The thing that has stayed with me is definitely my own shifting, my deeper analyses, from sharing photos and having discussions and my own self-discovery through this process I call it 'A-ha Therapy' in the way you begin to see something, to discover something."

Trixie 'I learned we shouldn't focus on what 'mainstream' society thinks about us, and don't get involved in things that don't pertain to me [us], and what I struggle with are 'normal' struggles [that all of us go through] like weeding out my purpose."

Meryl "I really enjoyed the whole process like the photos that prompted the discussion, and getting to know why we took and shared the photos we did. The excitement of the whole process has stayed with me. I really think you [Michelle] have something awesome here."

Lynne "This process has really magnified my [life, daily] experience, and to live life in the moment. I just really enjoyed the whole process."

Avonlie "I was very touched by the process. It warmed my heart that a group of women could share so honestly and deeply about their lives. The specific stories that resonated with me were PrinceFan69's feet and shoe story, Lynne's sense of family and how 'she takes things on [like climbing Cowles Mountain and riding on a rollercoaster] to enrich her life; and that Trixie is a cancer survivor and how she showed us her love for her family and their relationships. It was captivating."

Hilary "I was struck by the creation of community through the process, and how impactful this experience was in just three sessions. I think it might be because you all had something in common [middle-aged women] and 'we' were developing this group/community in a safe place [my house] Without this common connection and safe place, they wouldn't have taken the risks they did in creating thoughtful photographs, sharing and listening to stories, which created deep discussion. It was like the women made a "care investment.", 
Table 6.2

Question: What did you learn about yourself and from the other women as a result of participating in the project?

Rosa

"I learned we are pretty strong, and I appreciate being a woman. I learned I [we] have the ability to overcome challenges, and this came out in the sharing. I know I am more comfortable with who I am, and I think I can say we all are more comfortable with who we are because we shared so much in the group. I felt valued after this project."

PrinceFan69 "I felt shame about my physical problems and the drawer full of prescription drugs and reading glasses [Figure 34], and my photo of my dancing shoes and my feet [Figure 35]. However, after sharing the photos and telling my story and hearing the responses to these stories, I knew we had so much in common which led to a feeling of selfacceptance. I realized we all choose to hide or show those parts of us we are ashamed of, and this group allowed me to show who I am."

Trixie "My focus on finding a purpose, now that my sons are out of the house, lessened as we went on [in the sessions]. I realized I was the one putting, pressure on myself, but after being part of the group I know 'I am okay.' I have my husband and close friends. I've been stressing myself out with this question of purpose. It's not life or death. There is wisdom I've gained through my journey. All is beautiful."

Meryl "I feel like I have a strong support system and a connection with women of substance. There was no bullshit with this group. This was important because I'm always searching for connections with other women, and getting different perspectives. I learned so much about myself and about the other women, and I wanted more."

Lynne "I am more aware and conscious of being and present in the moment. I understand the need to 'balance' between needs of self and the needs of those around me. Age is in the mind, and you can let your emotions, or those around you [including society and media] to tell you how to feel or not. You have the choice. Just like choosing happiness or not."

Avonlie "I recognized that the group was able to form deeper relationships in a quick amount of time, and I saw a greater comfort [for the women] to be 'themselves.' I learned to be appreciative [of this stage], and after this group I have a better feeling of being appreciated."

Hilary "Professionally, I learned I could facilitate [with a different demographic than she usually does (e.g., school-aged students)]. I was excited to see how the visual could be used in a different way than I've been using it. Personally, I realized I can use this visual method with the women in my life like my mom. This process has made me consider being more attentive to these women's stories and voice. Until now, I never considered they [the older women around her] didn't have a voice, and maybe it's because I haven't asked them about their stories." 
Table 6.3

Question: What surprised you?

Rosa

"I was surprised that I came to the realization of who I am. I have greater self-awareness. Look at me, 'I'm beautiful.' I will go back to my family with more interest, appreciation, and feeling more comfortable with myself."

PrinceFan69 'I learned you don't have to slow down [during this stage of life] This was obvious from Meryl's images of vibrancy, liveliness, and physical strength, and Lynne's photos that were full of life and fullness of life with older and younger generations. These images contradict the messages we get about being middle-aged. Once you're a woman of a certain age, you are expected to give up, wear housedresses, and stay in your tenement eating. Maybe that was previous generations when they looked old and acted old, but this is the 'new normal' and it's perfect."

Trixie "I know I keep saying that a big outcome or surprise from this experience is the relief I feel to not find a purpose. I can just be and let it find me. But there were a couple of other surprises and that was that cancer and God were 'afterthoughts.' But maybe my relationship to God doesn't need to be announced, and maybe I've come to terms that I am a cancer survivor. I love it."

Meryl "I knew that I needed and would benefit from this group and the process, but I was physically and emotionally exhausted from it, and still so enthusiastic. I laughed throughout the process and that was an unexpected surprise."

Lynne "This process helped me to understand the challenges and thoughts of other [middle-aged] women. They were able to see themselves, and I could see them from listening to them. There was a lot of feeling of unison. I noticed it with the 'head nodding.' I know there was diversity but God created us so we have bonds and links."

Avonlie "I grew professionally from this experience. I did something 'outside the box' and something outside of my 'organizational' education and experience. For the group, I was surprised by the images the women chose, and how this process was so reflective and opened things up."

Hilary "I will keep on trying this facilitation because there was such richness and depth, such rich material, through the women's observations. Like I said, I use a similar process with younger people, but I can see how because of the women's life experiences they were able to make 'connections' more quickly." 
Table 6.4

Question: What happened to you and the other women after participating in this project?

Rosa 'I think this experience helped us feel we're not alone. Beyond this, we are valued and appreciated for being strong women. We found out what we have in common and our differences, and how this has connected us through our conversations. I feel blessed to have participated in this process, and I appreciate the sense of humor we have about ourselves and this time in our lives."

PrinceFan69 "I think we are all feeling encouraged and enlivened by this experience. We are bonded to each other. We are open to and interested in our discussions and continuing to know each other. I think there is a sense we have created a community filled with learning and friendship. This came from recognizing we have experienced similar things, and taking comfort in this."

Trixie "I understand the need to have a sense of community. I have that with CrossFit, the various soccer teams I play with, having close intimate friends and my husband. This has been important work. It was authentic, but while the others may feel a need to continue I am going to be the subject of the next part of my life."

Meryl "I think we got some sense of control over our stories, and we have a 'new' perspective in that we see ourselves through other people's eyes. We've also come to an understanding of why we took the photos we did and why we shared the stories we did, and that's gratifying."

Lynne 'I witnessed a change based on 'their' [the other women's] expressions. I think we are moving forward together. I think we enjoyed the three sessions and want to continue this experience in some way in the future."

Avonlie "I think this experience opened up the individual women and the group. I think they enjoyed it and were surprised by the creativity they had. Ultimately, I think they learned to be comfortable with themselves."

Hilary "I hope they look differently at spaces and places they frequent because of this process. I hope they continue to examine their personal spaces and relationships as an opportunity to go deeper. I hope they consider using photography as a tool to go deeper with a group of people." 


\section{Evidence of Shared Leadership Using Photovoice-Inspired Techniques}

Shared leadership focuses on "living systems of relationships" and "practices embedded in a system of interdependencies" (Fletcher \& Kaufer, 2003, p. 21), and this kind of leadership emphasizes influence relationships that get played out through interpersonal interactions much like what is proposed in the narrative leadership literature. Fletcher and Kaufer (2003) describe the shared leadership model as one where: (a) leadership is distributed and interdependent; (b) leadership is embedded in social interaction; and, (c) leadership is attained through mutual learning.

Based on the findings that narrative leadership was enacted as a result of the women participating in the photovoice-inspired process, there appears to be evidence that all three of the characteristics of shared leadership was observed as well. Regarding the first aspect of shared leadership (i.e., leadership is distributed and interdependent), the process was such that all of the women had an equitable amount of power and influence within the group. This held true despite the fact that I could have been "seen" as the leader since it was my research project. However, once I explained the project at the beginning of the first session, and any other of the "technical" aspects such as logistics, I became a participant in the process and was treated as such. Because having facilitators and an outline to guide the process allowed the creation of a "safe and calm space," which led the women to share and discuss openly with each other. The second aspect of shared leadership, which is that is embedded in social interaction, was integral to the photovoice process. Finally, there is evidence that the photovoice process led to mutual learning. There appeared to be was a fundamental shift within each of us, and as a group, that we learned to value ourselves, our experiences, our journey, and this stage in our 
lives. Further, there was a collective desire to continue this group in order "to go deeper" and to "discuss profound and varied topics that organically come from the group," as well as have the group meet in each of the respective women's homes.

\section{Methodology Observations by the Facilitators}

When Avonlie was asked what worked in the sessions, she responded that "the images and visuals helped the women to connect and have open dialogue," "the collage activity worked to break the ice and get everyone comfortable," "the sessions in your home which created a welcoming environment," and "the hands-off facilitation which allowed things to unfold and transpire and be more organic which is what I wanted." All of these factors created "a safe, calm, and welcoming environment" which made the dialogue richer and deeper. Hilary agreed that "using visuals to facilitate a discussion was important to the success of the project." She also believed the facilitation was essential to the "rich material" of observation and dialogue that was witnessed during the sessions and the process. Hilary also commented on the "hominess of the space that you created" and "how personal it was to be invited into your home" which led to a safe space for the women to share. She said, "I, also, think your vulnerability was key to the women being vulnerable themselves and opening up." Like the other women, there was not much offered in terms of what did not work during the sessions. The only comment that Avonlie had was "changing the videotapes during the session was a bit disruptive." Since both Avonlie and Hilary were so enthusiastic and supportive to hear about the group meeting once a month, they have been invited to "officially" join the group. 


\section{Chapter 7: Conclusion}

This final chapter includes the following: a brief overview of the project, a concise summary of findings, a discussion of the implications of this study's findings, a discussion of recommended future research, and recommendations based on the study's results.

\section{Overview}

Over the last two decades, narrative leadership has received a great deal of attention in the Leadership Studies field. For the most part, the literature focuses on narrative leaders who use stories to impact others both in large-scale political and social movements, as well as in organizations. Most of the literature on narrative leadership concentrates on an individual narrative leader with formal or informal positional power to influence others. Yet, there has been movement away from associating leadership with the actions of a single individual with positional power toward a view of leadership practice that emphasizes group-level processes. For example, shared leadership is a leadership approach in which two or more members of a group jointly attempt to influence what happens. Currently, we have no images of what narrative leadership looks like in shared leadership situations or of the techniques that can be used to foster narrative leadership in small-groups.

The purpose of the study was to examine whether a photovoice-inspired strategy can be used to facilitate the effective implementation of narrative leadership within a small group of middle-aged women. The photovoice technique encourages group members to take photographs and to use these images to prompt storytelling and a resulting critical discussion that is oriented toward changing individuals', and, 
potentially, the group's thinking. This study explored whether photovoice-inspired techniques can promote narrative leadership within a small group and whether any observed narrative leadership facilitated or inhibited shared leadership among group members.

The research design involved recruiting five diverse middle-aged women (ages 40-64) to participate in three two-hour sessions of a photovoice-inspired project. My role was that of a participant-observer making me the sixth group participant. Prior to the sessions, I interviewed each of the women who drafted a timeline of the significant events that influenced her life to help structure the life-history interview. The sessions were held at my house on three consecutive Mondays. The group was led by two facilitators, one to oversee the main agenda, and another, a photographer and educator, to facilitate the photography discussions.

The first session was an introduction to using visuals to tell and share stories. The last two sessions focused on each of the women's two photographs they brought to the group and the subsequent discussions. The prompt for the second session was to take a photograph of what it is like to be a middle-aged women in today's society, and the prompt for the third session was to take a photograph of what it is like to be a middleaged woman in "your" personal spaces and places. Sessions were videotaped. In addition, participants completed three questions regarding the session (i.e., what worked, what didn't work, and what was a takeaway from the session). Each woman was interviewed between the first and second sessions and, then, again, between the second and third sessions, to understand their immediate reactions to what had transpired during group meetings. Within two weeks of the last session, each of the women, as well as the 
two facilitators, were interviewed for a final time about such topics as their experience of the process, what they learned, and how they had been impacted at specified points during the process.

The qualitative data set that was analyzed during this project included: 1) the transcripts for the interviews conducted with the women prior to the sessions; 2) videotapes of the sessions, as well as the photographs taken and stories told by the participants; 3) the written open-ended feedback collected after each session; (4) the interview transcripts of between-session interviews; and, 5) the post-intervention interview transcripts of the participants and the two facilitators.

The data were organized into three results chapters: "Chapter 4: Narrative Profiles," "Chapter 5: Sessions," and "Chapter 6: Post-Intervention Interviews." For the "Narrative Profiles" results, the data collected and analyzed were a life history of significant events that "made the women who they are today." I, as participant-observer, also provided my narrative. There were two main reasons life histories were collected: 1) to demonstrate the diversity of the group; and 2) to understand how participants' life stories were similar and different in order to have a baseline to assess whether changes in thinking had occurred. The results chapter on the three sessions consisted at times of direct transcripts of what had transpired during a session and, at other times, a summary of what had happened. This allowed me and the readers to begin to understand if the photovoice-inspired techniques led to narrative leadership and shared leadership within the group, or if not, why not. Finally, the post-intervention interview data focused more directly on the study's research questions, and distilled the session data from Chapter 5 to directly answer the two research questions as follows: 
1. What evidence, if any, supported or refuted claims that the storytelling engendered by the use of photovoice techniques influenced the thinking, behavior, and/or actions of group members; in other words, was there evidence that photovoice techniques facilitated the exercise of narrative leadership by the individual group members?

2. Did narrative leadership appear to contribute to the development of group characteristics associated with the concept of shared leadership?

\section{Results}

There is considerable evidence that photovoice techniques (i.e., sharing images and stories and engaging in critical dialogue) allowed both narrative leadership and shared leadership to occur.

Photovoice-inspired techniques and narrative leadership. Regarding the first research question questioning if photovoice-inspired techniques led to a change in the participants' thinking, behavior, and/or action (i.e., narrative leadership), there is evidence from the session data, which consisted direct transcripts and summaries (See Chapter 5), supporting narrative leadership. During the first session when observing and then discussing the image of the couple on the train (Figure 1), there was a change from how Trixie initially felt about the photograph. At first she used words like "intimacy" and "romance" to describe the photograph to after the discussion "she [the woman] does seem distraught."

The completing and sharing of the personal collages was another opportunity to see how sharing these stories could influence the group. The most significant conclusion was despite our differences in our ethnicity and culture, whether we had children or not, 
our sexuality, etc., we shared many things in common such as the importance of family. This was significant because as Meryl said, "I felt initially nervous [rubbing her hands together]. But then sharing my story, and hearing others. I got over that once I started talking." Indeed, once the group started sharing its personal collages and the accompanying stories, the individuals and the collective were able to see common themes and ideas such as "multifaceted," "interpersonal," and "feminine." This seemed to lead to the feeling that "we have more in common with each other than we thought."

The second and third sessions also yielded evidence that narrative leadership occurred. Perhaps this was most evident in the way the group began to think again of those things we had in common (despite our apparent diversity). Some common themes included self-reflection and spirituality, "we take care of bodies," and that "age is a state of mind." The latter concept was something that impacted me as participant-observer since I had focused on the loss of youth (i.e., dying her hair, getting facials, moisturizing, etc.) and after participating in these sessions I had a deeper understanding and appreciation for the spiritual, creative, and special place this time is in my life. Other ideas included the importance of being around family, being present, and having fun. By the third session, it was evident by the opening remarks, including "I'm glad I took the time to be part of this group," "It's been a comforting process for me because I think for, I don't know how many years, I've been struggling to find my place, my niche, my purpose that each of us had been impacted by the process," and "I know I've already mentioned how transformative this has been, and not that I've been surprised, well, I guess I have been... surprised by how immediate and intense the transformation has been" that individual participants, and the group as a whole had been changed as a result of 
participating in the project. The main example of how the collective changed, or in this case came together, was the fact that five out of the six participants, and the two facilitators, wanted to see the group continue since "we had only scratched the surface." Trixie was the exception to wanting to participate in the group. She had been transformed by the group (i.e., "this [process and group] has made me keenly aware that I'm okay. You're okay.”). Yet, when I interviewed her post-sessions she shared with me she already had close friends and a support system that was "enough" for her.

The post-session interviews yielded data indicating the photovoice-technique supported narrative leadership. Tables 6.1 through 6.4 present concrete examples as to how sharing images and stories and the resulting discussions led to transformative ideas, concepts, and new knowledge which continued to resonate with each of the participants, as well as the two facilitators.

Photovoice-inspired techniques and shared leadership. The study results suggest that all three of the characteristics of shared leadership were evident during the photovoice process, including leadership that is distributed and interdependent, embedded in social interaction, and where mutual learning occurs in all of the participants. Indeed, the photovoice-inspired process seemed to lead to an environment where we all had the opportunity to share leadership through the sharing of visuals and stories and engage equally in critical dialogue. As a result, there appeared to be a fundamental shift within each of us, and within the group as a whole, in terms of valuing ourselves, our experiences, our journey, and the stage of life we are in.

While all three of the prerequisites for shared leadership seemed to be present, there appeared to be no or little opportunity for shared leadership to be implemented. 
Yet, there was a small opportunity for participants to actually enact a modest form of shared leadership at the end of the project: the collective desire to continue the group in order "to go deeper" and to "discuss profound and varied topics that organically come from the group." Additionally, the group proposed to meet not just in my home but in each of the participant's homes. Therefore, an example of shared leadership could be gleaned from the collective decision to continue the group and discuss varied topics based on who was hosting the session in her home could be seen as at least indicative of a modest form of shared leadership.

\section{Discussion}

This section presents the study's findings from the perspective of the review of literature presented in Chapter 2, the photovoice methodology, and the projects' findings focusing on narrative and shared leadership.

Storytelling. Evolutionary psychologists suggest storytelling functioned to motivate cooperation and create shared intentionality in groups (Boyd, 2009). There is evidence in the current project to suggest that both cooperation and shared intentionality occurred within this newly formed group of diverse middle-aged women in the course of telling stories prompted by the photos the women took. For instance, originally there was confusion about the "outcome" of the project, but after the first session Lynne stated, "We are the project." In addition, the fact that the group met for only three sessions (without an outcome or end product per se), and were able to work together through the process, speaks to the shared intentionality of the group.

Despite the research and our evolutionary history suggesting we are storytelling animals, the rational world paradigm has been the modus operandi in understanding 
human communication since the days of Aristotle who argued that science, facts, and logic are used to defend a hypothesis. The rational world paradigm is contrary, some would argue, to our evolution. Both Walter Fisher (1984) and Bormann (1985) proposed alternative theories of communication called the narrative paradigm and symbolic convergence theory, respectively. Both of these models speak to the importance of storytelling to "communicate across cultures, genders, ethnicities, socio-economic status, and ideologies" (Fisher, 1984) and transcend historical boundaries and are transcultural (Bormann, 1985). Ultimately, these paradigms allow diverse groups to make decisions based on whether a story resonates with "our shared values and beliefs" (Fisher, 1984), and when a group of people share a collection of fantasy themes and types, then the participants may integrate them into a "coherent rhetorical vision of some aspect of their social reality" (Bormann, 1985, p. 133). Therefore, there was evidence that the use of images and stories within our group transcended the ethnic, cultural, sexuality, and religious diversity of the group. Additionally, using storytelling to communicate our images and stories, as well as have "deep and rich discourse" led to a symbolic climate and culture that allowed people to achieve empathic communion as well as a 'meeting of the minds"' (Bormann, 1985, p.134). In other words, the participants experienced "group fantasies" of what it is like to be a middle-aged woman in today's society and within each participant's places and spaces that "generated a merging of appropriate feelings amongst the group members," including "we are in this together and we shouldn't focus on what the mainstream media thinks," "we had so much in common which led to a feeling of self-acceptance," and "age is in the mind, and you can let your emotions, or those around you [including society and media] to tell you how to feel or not." 
Photovoice. Photovoice was chosen as a potential modality to enact both narrative and shared leadership. Briefly, photovoice is based on the principles of participatory action research where group members use photographs, and other visuals, such as collages, to reflect their concerns and passions related to their community or environment (Simmonds, Roux, \& ter Avest, 2015; Wang \& Burris, 1997). These reflections and stories are shared with the other participants to inspire critical dialogue in order to transform the individual, the collective, and sometimes to a larger extent the community or society (Wang \& Burris, 1997). The section below gives specifics examples as to how the photovoice-inspired methodology allowed for narrative leadership and shared leadership to be realized.

Narrative leadership and shared leadership. Until now no literature could be located which examined how narrative leadership could lead to a model of shared leadership. In fact, most research on narrative leadership focuses on the traditional ways leadership has been studied; it is the person who tells stories who is the leader. Then it follows that it is the leader who has the power to influence "followers" thoughts, behaviors, and actions through his or her storytelling. However, new models of leadership are emerging which are alternatives to the predominant leadership models, much how Fisher (1984) and Bormann (1985) challenged the rational world paradigm with their respective communication models. This means narrative leadership studies of theory and research are moving away from $a$ leader telling stories to impact other's thoughts, behaviors, and actions to narrative leadership as a discourse (Auvinen, Aaltio, \& Blomqvist, 2013; Boje, 2006; Parry \& Hansen, 2007), and potentially to the observation of characteristics that are prerequisites to shared leadership. 
Evidence has been presented in the aforementioned section of this chapter that narrative leadership occurred within the group of study participants. The review of literature (See Chapter 2) may explain why narrative leadership happened. First, narrative leadership is founded on relationships. As Lawrence and Pirson (2015) stated, “Our understanding of leadership can be no better than our understanding of what motivates human behavior, because leadership is all about relationships with others" (p. 383). There were comments made by the participants which indicated that our "quick relationships" developed within three sessions may be one of the reasons for the change in participants' thinking. For example Meryl stated,

I feel like I have a strong support system and a connection with women of substance [when referring to the group]. There was no bullshit with this group. This was important because I'm always searching for connections with other women, and getting different perspectives. I learned so much about myself and about the other women, and I wanted more.

In addition to the importance of relationships as a way to influence and motivate others, there is also an emphasis on non-hierarchical relationships which "creates less distance between people allowing for better bonding and fosters the kind of trust associated with face-to-face relations (Burns \& Stalker, 1994; Lawrence \& Lorsch, 1986). As Hilary, the photographer and educator, said, I was struck by the creation of community through the process, and how impactful this experience was in just three sessions. I think it might be because you all had something in common [middle-aged women] and 'we' were developing this group/community in a safe place [my house]. Without this 
common connection and safe place, they wouldn't have taken the risks they did in creating thoughtful photographs, sharing and listening to stories, which created deep discussion. It was like the women made a 'care investment.'

This study showed a promising technique (i.e., photovoice) that could lead to a narrative leadership model which moves away from $a$ leader with positional power to influence "followers" as seen with leaders who led national and international movements such as Eleanor Roosevelt, Mahatma Gandhi, and Martin Luther King, Jr. (Gardner \& Laskin, 2011) or CEOs such as Steve Jobs, Cheryl Sandberg, and Richard Branson (Wainwright, 2013) to a leadership model that is based on non-hierarchical relationships. Shared leadership is just such a model. Specifically, this study explored whether any narrative leadership that was enacted through photovoice led to the development of group characteristics that are associated with shared leadership. These characteristics include leadership that is (a) distributed and interdependent, (b) embedded in social interaction, and, (c) attained through mutual learning. The results indicated all three shared leadership elements were observed. For example, PrinceFan69 said,

I learned you don't have to slow down [during this stage of life]. This was obvious from Meryl's images of vibrancy, liveliness, and physical strength, and Lynne's photos that were full of life and fullness of life with older and younger generations. These images contradict the messages we get about being middleaged. Once you're a woman of certain age, you are expected to give up, wear housedresses, and stay in your tenement eating. Maybe that was previous generations when they looked old and acted old, but this is the 'new normal' and it's perfect. 
And, Lynne said,

This process helped me to understand the challenges and thoughts of other [middle-aged] women. They were able to see themselves, and I could see them from listening to them. There was a lot of feeling of unison. I noticed it with the 'head nodding.' I know there was diversity but God created us so we have bonds and links.

Finally, while unexpected since there were only three sessions and there were no products established or anticipated as a result of participating in this project, there was a modest shared leadership outcome of the group wanting to continue the group where leadership is shared among the women, and where topics and meeting places are rotated.

\section{Implications}

Based on the results, there was an overwhelming positive response to using photovoice-inspired techniques to enact narrative leadership and shared leadership within a group of middle-aged women. All six of the participants, as well as the facilitators, thought the employed methodology created a "safe and calm space" to share images and stories which led to "deep and critical" discussions about what it is like to be a middleaged women which changed the thinking of the individual participants. Like the consciousness-raising groups of the late ' 60 s and early ' 70 s, where small groups of women shared stories about gender-based experiences, the photovoice-inspired group of middle-aged women had the same experience. In other words, using photovoice-inspired techniques appears to elicit both narrative leadership, and an opportunity for shared leadership to be realized. Therefore, there is evidence that the use of photovoice techniques may lead to both narrative leadership and shared leadership. 


\section{Further Research}

Based on the results of this study there are a number of recommendations for future research including:

1. To extend from three consecutive weekdays to once a month (for example) to explore a varied amount of topics and in order to "go deeper";

2. To explore the methodology with other groups including middle-aged men, an intergenerational group of females and/or males, white police officers and African-American men, new immigrants and "established" immigrants, etc.; and,

3. To elevate the resulting conversation, and these results based on the methodology, to advocate for policy changes.

\section{Conclusion}

This dissertation brought narrative leadership and shared leadership through enacting the photovoice methodology to the conversation. The exploration of photovoice-inspired techniques on these leadership modalities proved promising. In other words, sharing images and stories, and the resulting discourse, led to changes in the individual participants' and collective thinking, and the potential for shared leadership to be observed. 


\section{References}

Auvinen, T., Aaltio, I., \& Blomqvist, K. (2013). Constructing leadership by storytellingthe meaning of trust and narratives. Leadership \& Organization Development Journal, 34(6), 496-514.

Bandura, A. (1997). Self-efficacy: The exercise of control. New York, NY: Freeman.

Bandura, A. (2000). Exercise of human agency through collective efficacy. Current directions in psychological science, 9(3), 75-78.

Bartunek, J. M., Walsh, K., \& Lacey, C. A. (2000). Dynamics and dilemmas of women leading women. Organization Science, 11(6), 589-610.

Bass, B. M. (1996). A new paradigm of leadership: An inquiry into transformational leadership. Alexandria, VA: US Army Research Institute for the Behavioral and Social Sciences.

Bass, B. M. (2008). The Bass handbook of leadership. Theory, research and managerial Applications $\left(4^{\text {th }}\right.$ ed.). New York, NY: Free Press.

Bass, B. M., \& Riggio, R. E. (2006). Transformational leadership. New York, NY: Psychology Press.

Bergman, J. Z., Rentsch, J. R., Small, E. E., Davenport, S. W., \& Bergman, S. M. (2012). The shared leadership process in decision-making teams. The Journal of Social Psychology, 152(1), 17-42.

Boehm, C. (2000). Conflict and the evolution of social control. Journal of Consciousness Studies, 7(1-2), 79-101.

Boje, D. M. (2006). Book review essay: Pitfalls in storytelling advice and praxis. Academy of Management Review, 31(1), 218-225.

Boje, D. M., \& Rhodes, C. (2006). The leadership of Ronald McDonald: Double narration and stylistic lines of transformation. The Leadership Quarterly, 17(1), 94-103.

Boyd, B. (2009). On the origin of stories: Evolution, cognition, and fiction. Cambridge, MA: Harvard University Press.

Bryman, A., Stephens, M., \& Campo, C. (1996). The importance of context: Qualitative research and the study of leadership. The Leadership Quarterly, 7(3), 353-370.

Burns, T., \& Stalker, G. (2006). Mechanistic and organic systems. Organizational Behavior 2: Essential theories of process and structure (2 ${ }^{\text {nd }}$ ed.). New York, NY: Routledge. 
Bormann, E. G. (1985). Symbolic convergence theory: A communication formulation. Journal of communication, 35(4), 128-138.

Boyd, B. (2009). On the origin of stories: Evolution, cognition, and fiction. Cambridge, MA: Harvard University Press.

Burns, J. M. (1978). Leadership. New York. NY: Harper and Row Publishers.

Burns, T., \& Stalker, G. (2006). Mechanistic and organic systems. Organizational Behavior 2: Essential theories of process and structure ( $2^{\text {nd }}$ ed.). New York, NY: Routledge.

Byrne, R. W., \& Whiten, A. (1997). Machiavellian intelligence. Machiavellian intelligence II: Extensions and evaluations (pp. 1-23). Cambridge, MA: Cambridge University Press.

Bryman, A. (1996). Introduction. The Leadership Quarterly, 6(4), 491-493.

Carlson, E. D., Engebretson, J., \& Chamberlain, R. M. (2006). Photovoice as a social process of critical consciousness. Qualitative Health Research, 16(6), 836-852. doi: $10.1177 / 1049732306287525$

Catalani, C., \& Minkler, M. (2010). Photovoice: A review of the literature in health and public health. Health Education \&Bbehavior, 37(3), 424-451.

Centers for Disease Control and Prevention. (2013). CDC finds suicide rates among middle-aged adults increased from 1999-2010 [Press Release]. Retrieved from http://www.cdc.gov/media/releases/2013/p0502-suicide-rates.html

Charmaz, K. (2006). Constructing grounded theory: A practical guide through qualitative research. London, UK: SagePublications Ltd.

Corballis, M. C. (2003). From hand to mouth: The gestural origins of language. Studies in the Evolution of Language, 3, 201-218.

Creswell, J. W., Klassen, A. C., Plano Clark, V. L., \& Smith, K. C. (2011). Best practices for mixed methods research in the health sciences. Bethesda (Maryland): National Institutes of Health, 2094-2103.

Danzig, A. (1999). How might leadership be taught? The use of story and narrative to teach leadership. International Journal of Leadership in Education, 2(2), 117131.

Darwin, C. (2013). The origin of the species by means of natural selection (6th Ed). Copenhagen, Denmark: Filibooks Classics.

Dawkins, R. (1976). The selfish gene. Oxford, UK: Oxford University Press. 
Dennett, D. C. (1991). Consciousness explained. United Kingdom: Penguin.

Denning, S. (2005). The leader's guide to storytelling: Mastering the art and discipline of business narrative (Vol. 269). Hoboken, NJ: John Wiley \& Sons.

Denning, S. (2011). The secret language of leadership: How leaders inspire action through narrative (Vol. 40). Hoboken, NJ: John Wiley \& Sons.

Driscoll, C., \& McKee, M. (2007). Restorying a culture of ethical and spiritual values: A role for leader storytelling. Journal of Business Ethics, 73(2), 205-217.

Dobzhansky, T. G. (1962). Mankind evolving: The evolution of the human species.

Dunbar, R. I. (2001). Brains on two legs: Group size and the evolution of intelligence. In F. B. M. de Waal (Ed.), Tree of origin: What primate behavior can tell us about human social evolution (pp. 173-191). Cambridge, MA: Harvard University Press.

Dunbar, R. I. (2003). The social brain: mind, language, and society in evolutionary perspective. Annual Review of Anthropology, 163-181.

Faugier, J., \& Sargeant, M. (1997). Sampling hard to reach populations. Journal of advanced nursing, 26, 790-797.

Fawcett, S. B., Schultz, J. A., Holt, C. M., Collie-Akers, V., \& Watson-Thompson, J. (2013). Participatory research and capacity building for community health and development. Journal of Prevention \& Intervention in the Community, 41(3), 139141. doi: $10.1080 / 10852352.2013 .788340$

Fletcher, J. K., \& Kaufer, K. (2003). Shared leadership. Shared leadership: Reframing the hows and whys of leadership (pp. 21-47).

Fisch, B. (2014). Narrative leadership in a quality organization: a meaningful alternative to management by measurement. International Journal of Leadership in Education, 17(2), 154-173.

Fisher, W. R. (1984). Narration as a human communication paradigm: The case of public moral argument. Communications Monographs, 51(1), 1-22.

Fleming, D. (2001). Narrative leadership: Using the power of stories. Strategy \& Leadership, 29(4).

Ford, L. A. (1989). Fetching good out of evil in AA: A Bormannean fantasy theme analysis of "The Big Book of Alcoholics Anonymous." Communication Quarterly, 37(1), 1-15.

Freire, P. (1973). Education for critical consciousness (Vol. 1). New York, NY: Bloomsbury Publishing. 
Freire, P. (2000). Pedagogy of the oppressed. New York, NY:Bloomsbury Publishing.

Gardner, H., \& Laskin, E. (2011). Leading minds: An anatomy of leadership. New York, NY: Basic Books.

Gardiner, M. E., Howard, M. P., Tenuto, P. L., \& Muzaliwa, A. I. I. (2014). Authentic leadership praxis for democracy: a narrative inquiry of one state superintendency. International Journal of Leadership in Education, 17(2), 217-236.

Goodenough, W. (1990). Evolution of the human capacity for beliefs. American Anthropologist, 92(3), 597-612.

Gottschall, J. (2012). The storytelling animal: How stories make us human. New York, NY: Houghton Mifflin Harcourt Publishing Company.

Hall, D. T. (2004). Self-awareness, identity, and leader development. Leader development for transforming organizations: Growing leaders for tomorrow (pp. 153-176).

Hamilton, W. D. (1963). The evolution of altruistic behavior. The American Naturalist, 97(896), 354-356.

Hamilton, W. D. (1966). The moulding of senescence by natural selection. Journal of Theoretical Biology, 12(1), 12-45.

Hergenrather, K. C., Rhodes, S. D., Cowan, C. A., Bardhoshi, G., \& Pula, S. (2009). Photovoice as community-based participatory research: A qualitative review. American Journal of Health Behavior, 33(6), 686-698.

Hollander, E. P. (1978). Leadership dynamics. New York: Free Press.

Hughes, A. (2005). Deer Woman [Photographic Series]. Retrieved from http://www.adrienehughes.com/deerwoman/

Jerison, H. J. (1973). Evolution of the brain and intelligence. New York, NY: Academic Press.

Kouzes, J. M., \& Posner, B. (2007). The leadership challenge: The most trusted source on becoming a better leader. San Francisco, CA: Jossey-Bass/Pfeiffer.

Kravetz, D., Marecek, J., \& Finn, S. E. (1983). Factors influencing women's participation in consciousness-raising groups. Psychology of Women Quarterly, 7(3), 257-271.

Lawrence, P. R., \& Lorsch, J. W. (1986). Organization and environment: managing differentiation and integration (Harvard Business School Classics).

Lawrence, P. R., \& Pirson, M. (2015). Economistic and humanistic narratives of leadership in the age of globality: Toward a renewed Darwinian theory of 
leadership. Journal of Business Ethics, 128, 383-394.

Little, G. (1985). Political ensembles: A psychosocial approach to politics and leadership. Oxfored, UK: Oxford University Press.

Luker, K. (2008). Salsa dancing into the social sciences: Research in an age of infoglut. Harvard, MA: Harvard University Press.

Macmillan, R., \& McLaren, V. (2012). Third sector leadership: the power of narrative. Third Sector Research Centre.

Mann, S. (1992). Candy cigarette [photograph]. In S. Mann, Immediate family: Photographs by Sally Mann. New York, NY: Aperture.

Mann, S. (1992). Emmiett, Jessie, and Virginia [photograph]. In S. Mann, Immediate family: Photographs by Sally Mann. New York, NY: Aperture.

McBride, G. (2014). Storytelling, behavior planning, and language evolution in context. Frontiers in Psychology, 5, 1131.

Mead, M. (2001). Coming of Age in Samoa: A Psychological Study of Primitive Youth for Western Civilisation (Reprint Ed). New York, NY: William Morrow Paperbacks.

Miles, M. B., Huberman, A. M., \& Saldana, J. (2013). Qualitative data analysis: A methods sourcebook. Los Angeles, CA: SAGE Publications, Incorporated.

Miller, J. B., Jordan, J. V., Kaplan, A. G., Stiver, I. P., \& Surrey, J. L. (1997). Some misconceptions and reconceptions of a relational approach. Women's growth in diversity: More writings from the Stone Center (pp. 25-49).

Minkler, M., \& Wallerstein, N. (2011). Community-based participatory research for health: From process to outcomes. Hoboken, NJ: John Wiley \& Sons.

Mitchell, C. (2011). Doing visual research. Thousand Oaks, CA: SAGE Publications.

Ospina, S. M., \& Dodge, J. (2005). It's about time: Catching method up to meaning: The usefulness of narrative inquiry in public administration research. Public Administration Review, 143-157.

Patton, M. Q. (2005). Qualitative research. Hoboken, NJ: John Wiley \& Sons, Ltd.

Parkin, M. (2004). Tales for change: using storytelling to develop people and organizations. Kogan Page Publishers.

Parry, K. W., \& Hansen, H. (2007). The organizational story as leadership. Leadership, 3(3), 281-300.

Pearce, C. L., \& Conger, J. A. (2002). Shared leadership: Reframing the hows and whys 
of leadership. Thousand Oaks, CA: Sage Publications.

Peters, K. E. (1997). Storytellers and scenario spinners: Some reflections on religion and science in light of a pragmatic, evolutionary theory of knowledge. Zygon ${ }^{\circledR}$, 32(4), 465-489.

Phillips, J. A., Robin, A. V., Nugent, C. N., \& Idler, E. L. (2010). Understanding recent changes in suicide rates among the middle-aged: period or cohort effects?. Public health reports, 125(5), 680.

Polkinghorne, D. E. (1988). Narrative knowing and the human sciences. Suny Press.

Polkinghorne, D. E. (1995). Narrative configuration in qualitative analysis. International Journal of Qualitative Studies in Education, 8(1), 5-23.

Potvin, L., Gendron, S., Bilodeau, A., \& Chabot, P. (2005). Integrating social theory into public health practice. American Journal of Public Health, 95(4), 591.

Rosenthal, N. B. (1984). Consciousness raising: From revolution to re-evaluation. Psychology of Women Quarterly, 8(4), 309-326.

Saldaña, J. (2012). The coding manual for qualitative researchers. Thousand Oaks, CA: Sage Publications.

Saldaña, J. (2015). The coding manual for qualitative researchers. Thousand Oaks, CA: Sage Publications.

Sanon, M. A., Evans-Agnew, R. A., \& Boutain, D. M. (2014). An exploration of social justice intent in photovoice research studies from 2008 to 2013. Nursing inquiry, 21(3), 212-226.

Senge, P. M. (1997). Communities of leaders and learners. Harvard Business Review, 75(5), 30-32.

Schreiber, A. (n.d.). As if [Photograph]. In A. Schreiber, Pretty Please [online photographic series]. Retrieved from http://www.andischreiber.com/prettyplease/

Schreiber, A. (n.d.). Curl [Photograph]. In A. Schreiber, Pretty Please [online photographic series]. Retrieved from http://www.andischreiber.com/pretty-please/

Schreiber, A. (n.d.). Lighten up [Photograph]. In A. Schreiber, Pretty Please [online photographic series]. Retrieved from http://www.andischreiber.com/prettyplease/

Schreiber, A. (n.d.). Rear view [Photograph]. In A. Schreiber, Pretty Please [online photographic series]. Retrieved from http://www.andischreiber.com/prettyplease/ 
Shackelford, T. K., \& Liddle, J. R. (2014). Understanding the mind from an evolutionary perspective: An overview of evolutionary psychology. Wiley Interdisciplinary Reviews: Cognitive Science, 5(3), 247-260.

Simmonds, S., Roux, C., \& ter Avest, I. (2015). Blurring the boundaries between photovoice and narrative methods: gender-based research through narrativephotovoice. International Journal of Qualitative Methods, 14(3), 33-49.

Smith, J. M. (1982). Evolution and the theory of games. Cambridge, MA: Cambridge University Press.

Snowden, D. (2001). From Storytelling to Narrative. Archetypes as an instrument of narrative patterns. Knowledge Management Magazine, 5(4), 5-10.

Spillane, J. P., Halverson, R., \& Diamond, J. B. (1999). Distributed leadership: Toward a theory of school leadership practice. Institute for Policy Research, Northwestern University.

Stogdill, R. M. (1950). Leadership, membership and organization. Psychological Bulletin, 47(1), 1-14.

Tennov, D. (1973). Feminism, psychotherapy and professionalism. Journal of Contemporary Psychotherapy, 5(2), 107-111.

Tomasello, M. (2009). Why we cooperate. Cambridge, MA: MIT press.

Tomasello, M. (2014). Natural history of human thinking. Cambridge, MA: Harvard University Press.

Tomasello, M., Carpenter, M., Call, J., Behne, T., \& Moll, H. (2005). Understanding and sharing intentions: The origins of cultural cognition. Behavioral and brain sciences, 28(5), 675-691.

United States Census Bureau. (2010). 2010 Census Data [Data file]. Retrieved from https://www.census.gov/2010census/data/

Wallerstein, N. B., Yen, I. H., \& Syme, S. L. (2011). Integration of Social Epidemiology and Community-Engaged Interventions to Improve Health Equity. American Journal of Public Health, 101(5), 822-830. doi: 10.2105/AJPH.2008.140988

Wainwright, C. (2013). 10 of the world's best storytellers. Hubspot, 149. Retrieved from http://blog.hubspot.com/marketing/10-best-storytellers

Wang, C., \& Burris, M. A. (1997). Photovoice: Concept, methodology, and use for participatory needs assessment. Health education \& behavior, 24(3), 369-387.

Wang, D., Waldman, D. A., \& Zhang, Z. (2014). A meta-analysis of shared leadership and team effectiveness. Journal of Applied Psychology, 99(2), 181. 
Webb, R. L. (2014). Ms. Rose Defies the Odds.

Wheelan, S. A. (2009). Group size, group development, and group productivity. Small Group Research.

Yang, C. C. (2013). Telling tales at work: An evolutionary explanation. Business Communication Quarterly. doi:1080569913480023

Yuk1, G. (1999). An evaluation of conceptual weaknesses in transformational and charismatic leadership theories. The Leadership Quarterly, 10(2), 285-305.

Yukl, G. (2011). Contingency theories of effective leadership. The SAGE handbook of Leadership (pp. 286-298). Thousand Oaks, CA: SAGE Publications.

Zive, M. (2011). Creating community for middle aged white women through storytelling: A qualitative study. (Unpublished manuscript). San Diego, CA: University of San Diego.

Zive, M. (2013). Creating community for middle aged white women through storytelling: A qualitative study. (Unpublished manuscript). Sand Diego, CA: University of San Diego. 
Appendix A

Examples of Timelines 


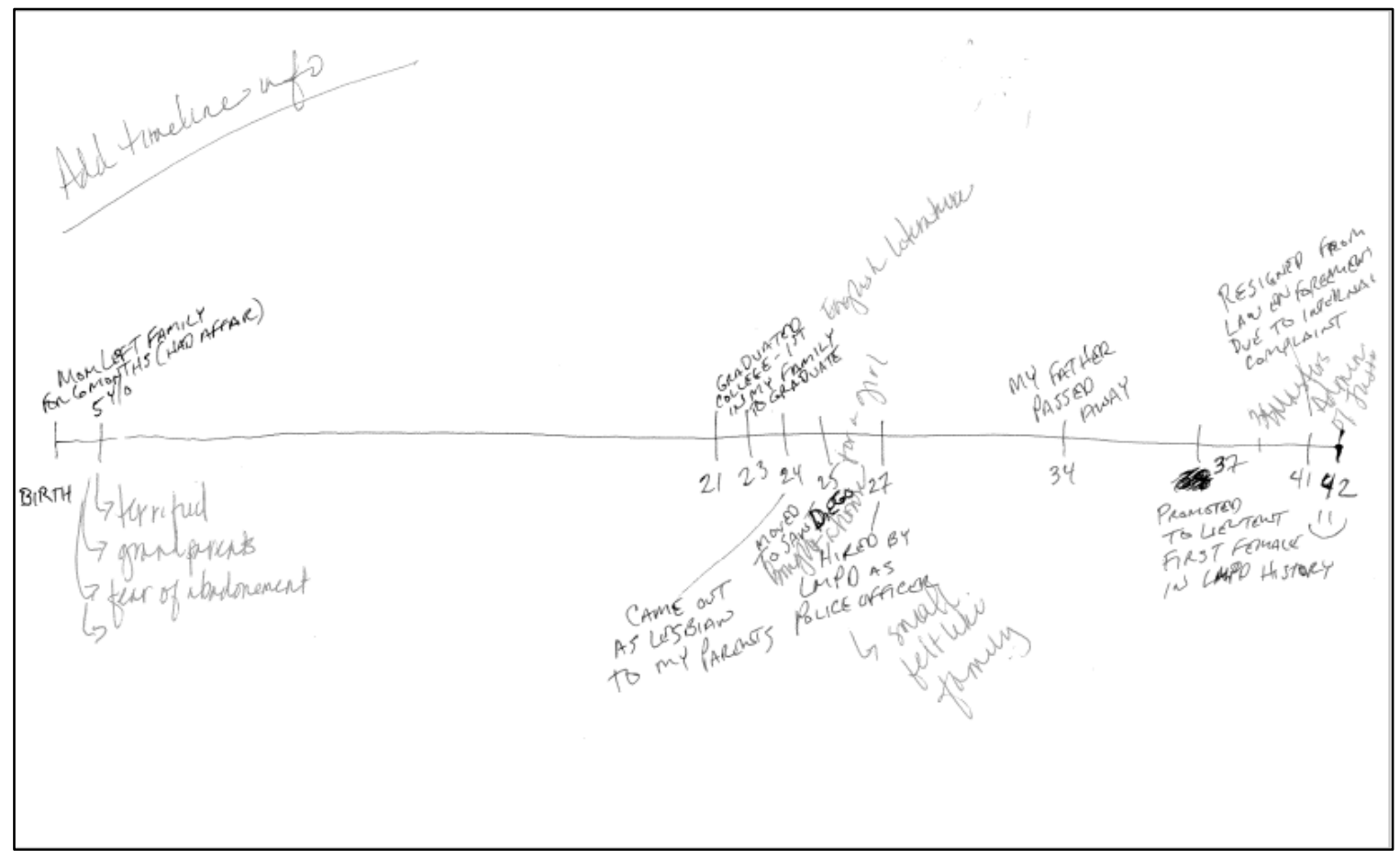

Figure 40. Meryl's Timeline (Meryl, 2016).

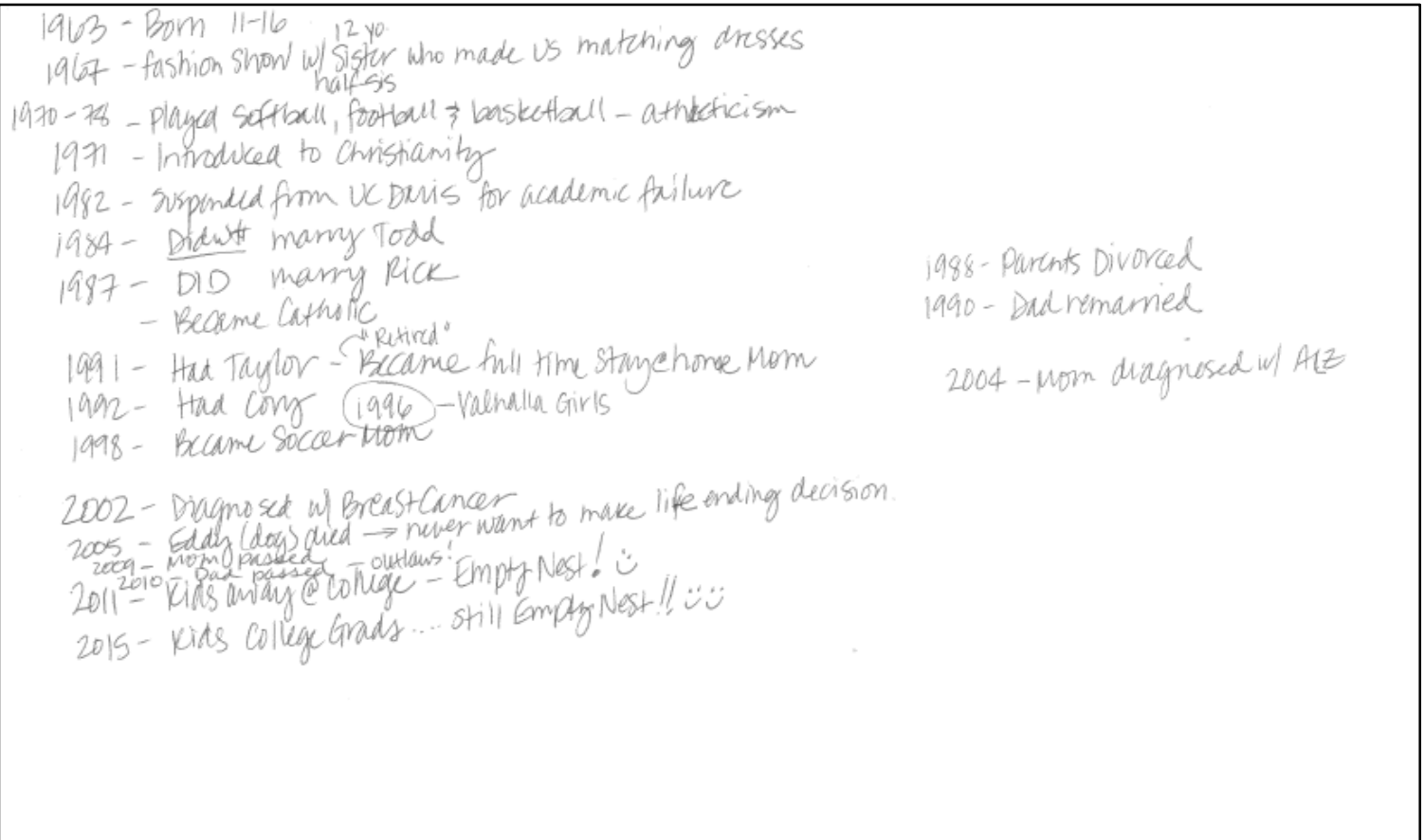

Figure 41. Trixie's Timeline (Trixie, 2016) 


\section{Appendix B}

\section{Photovoice Sessions Outline}




\section{Appendix B}

Photovoice Sessions Outline

First photovoice session. During the first session, the participants will be introduced to the potential contribution of storytelling and the photovoice process that will be used to promote storytelling in the group. During this first session, there will be an opportunity to practice storytelling within the group, as well as an opportunity to construct a collage that will be used to highlight the link between stories and visuals. Each of the women will be encouraged to share her individual stories and collages with the group. Once the individuals have shared, the group will be asked to reflect on and discuss the following questions:

5. What did you hear when you listened to the stories? Saw the collages?

6. How did you feel?

7. Were there any common themes? Different themes?

8. What resonated with you?

Oher questions may arise during the discussion.

After these exercises of sharing stories and making collages, as well as the ensuing discussion, the group will be asked to discuss what it is like to be a middle-aged woman. Group members will be encouraged to provide different answers to this question. After all participants have responded at least once, the responses, which will have been charted, will be subsumed under more overarching themes that members of the group will identify after reading through the charted responses. Based on the photovoice literature, it is likely some of the following concepts as identity, power, agency, and 
voice (Carlson, Engebretson \& Chamberlain, 2006; Freire, 1973, 2000; Wang \& Burris, 1997). These themes will be unpacked throughout the photovoice process.

Next, participants will learn how to take photos using their smartphones to tell the story of what it is like to be a middle-aged woman in today's society. The women will be asked to take photos over the next week. They will be asked to email their top three to five photos with an accompanying five-sentence story (either fiction or non-fiction), which speaks to the photo and being a middle-aged woman.

In order to get some immediate feedback regarding the first session, a sheet of paper with three questions will be distributed at the end of the session to each of the women for them to write their answers. The three questions include: (1) What worked during the session? (2) What did not work? and (3) What, if anything, are you taking away from the session? The participants will be asked to share their responses, and the written accounts will be collected. I will take notes throughout the session, and write reflective entries in my journal regarding the session. After the session I will take additional notes while reviewing the video of the session.

Second photovoice session. Before the second session, I will make $8 \times 10$ enlargements of the favorite photographs with the accompanying stories. Each of the participants will present her selected photos and stories. Afterward, the photos and stories will be displayed around the room so the women can walk around and spend more time viewing the images and stories. After the presentations, the group will be asked the following questions:

7. What did you hear when listening to the stories and seeing the photos regarding what it is like to be a middle-aged women? 
8. What were the common narratives, or themes, across the presentations, if any, you saw or heard?

9. How are the stories related, understood, misunderstood?

10. What were the unique stories, if any, being told?

11. What could be some counternarratives to the photos and stories being told?

12. How do these stories relate and interact with other stories, especially contradictory stories which have been indoctrinated into the consciousness of the participating women?

After the discussion, a sheet of paper with three questions will once again be distributed to each of the women to write their responses. The three questions include: what worked, what did not, and what will be taken away from the session. The participants will be asked to share their responses. I will take notes throughout the session, and write reflective entries in my journal regarding the session.

Finally, the group will review and discuss the themes and stories which were shared in the session, and to within the next week take photographs in their own private spaces and frequented public spaces which reflect the stories and themes which resonate with them as middle-aged women. Before the third session, they will be asked to email me their favorite three to five photos they took in their respective private and frequented public spaces, and the accompanying stories.

Third photovoice session. I will print and bring the three to five 8-by-10-inch enlargements, and the stories, which will be identified by each of the women from the second session. The same process will be followed as outlined in the second session, including asking the six questions mentioned above. 
Once the questions and discussion have been completed, all of the photos and stories from the first and second sessions will be displayed for the group. Each participant will be asked to choose her own favorite two to four enlarged photographs with the accompanying five sentence story. Then, these photographs and stories will be displayed around the room and used for group dialogue around those common themes and issues which resonate with the group (e.g., voice, identity, leadership, agency, etc.).

The photographs and stories are intended to engage the group in critical reflection and dialogue/discussion directed to understand whether or not there was a change in individual and/or group thinking about what is like to be a middle-aged woman in contemporary society. Following the critical dialogue, I will facilitate a group discussion about what the group's future looks like (i.e., whether there is interest in the group continuing, sharing the photographs and stories, publishing the research, etc.).

At the end of the third session, a sheet of paper with the same three questions from the previous two sessions will be distributed to each of the women to write their responses. The three questions include: what worked, what did not, and what will be taken away from the session. The participants will be asked to share their responses. I will take notes throughout the session, and write a reflective piece in my journal regarding the session. 


\section{Appendix C}

Demographic Data Form 


\section{Appendix C}

\section{Demographic Data Form}

1. What is your birthdate?

2. Please specify your ethnicity.
a. White
b. Hispanic or Latino
c. Black or African American
d. Native American or American Indian
e. Asian / Pacific Islander
f. Other (Please specify):

3. Which of the following do you consider yourself?
a. Christian
b. Muslim
c. Jewish
d. Roman Catholic
e. Latter Day Saints or Mormon
f. Buddhist
g. Hindu
h. Agnostic (You are not sure there is a god.)
i. Atheist (You believe there is no god.)
j. Spiritual, but not committed to a particular faith
k. Don't give religious things much thought
1. Other

4. What is the highest degree or level of school you have completed? If currently enrolled, highest degree received.
a. High school graduate, diploma or the equivalent (for example: GED)
b. Some college credit, no degree
c. Trade/technical/vocational training
d. Associate degree
e. Bachelor's degree
f. Master's degree
g. Professional degree
h. Doctorate degree

5. Are you currently...?
a. Employed for wages. Occupation?
b. Self-employed
c. Out of work and looking for work
d. Out of work but not currently looking for work 

e. A homemaker
f. A student
g. Military
h. Retired
i. Unable to work

6. What is your total household income before taxes in the past 12 months?
a. Less than $\$ 25,000$
b. $\$ 25,000$ to $\$ 34,999$
c. $\$ 35,000$ to $\$ 49,999$
d. $\$ 50,000$ to $\$ 74,999$
e. $\$ 75,000$ to $\$ 99,999$
f. $\$ 100,000$ to $\$ 149,999$
g. $\$ 150,000$ or more

7. Do you consider yourself to be:
a. Heterosexual or straight;
b. Gay or lesbian; or
c. Bisexual?

8. What is your marital status?
a. Single, never married
b. Married or domestic partnership
c. Widowed
d. Divorced
e. Separated

9. If you have children, please complete.

\begin{tabular}{|c|c|c|c|}
\hline Child & $\begin{array}{c}\text { M } \\
(\text { Male } / \text { F(Female })\end{array}$ & Birthdate & In home? Y or N \\
\hline 1 & & & \\
\hline $\mathbf{2}$ & & & \\
\hline $\mathbf{3}$ & & & \\
\hline $\mathbf{4}$ & & & \\
\hline
\end{tabular}

10. Any other persons living in house (e.g., roommate, parent, sibling, etc.)? Please indicate.

What are your thoughts and feelings, if any, about being a middle-aged woman? 


\section{Appendix D}

Questions Following Each Photovoice Session 


\section{Appendix D}

Questions Following Each Photovoice Session

1. What worked during the session?

2. What did not work?

3. What, if anything, are you taking away from the session? 
Appendix E

Post-Intervention Interview Questions 


\section{Appendix E}

\section{Post-Intervention Interview Questions}

1. Now that you have had time to reflect on the experience, tell me what kinds of things (e.g., stories, images, the process, etc.) stayed with you as a result of participating in this project?

2. What did you learn about yourself? What did you learn from the other women about being a middle-aged women you did not know before this process?

3. What surprised you?

4. What do you think happened to you and the other women as a result of being part of the group?

5. What happened, if anything, in terms of your ability to tell your story and find your voice?

6. How, if at all, did your thinking change as a result of participating in photovoice sessions? 
Appendix F

Facilitation Plan/Agenda 
Appendix F

Facilitation Plan/Agenda

\begin{tabular}{|c|c|c|c|}
\hline Time & Activity & Materials/Instructions & $\begin{array}{c}\text { Person } \\
\text { Responsible }\end{array}$ \\
\hline \multicolumn{4}{|l|}{ SESSION 1} \\
\hline $5-5: 05 p$ & $\begin{array}{l}\text { Welcome/thank you } \\
\text { Purpose of research } \\
\text { Distribute consent forms }\end{array}$ & $\begin{array}{l}\text { Review consent form (i.e., } \\
\text { confidentiality, anonymity, } \\
\text { etc.) } \\
\text { Collect signed consent } \\
\text { forms }\end{array}$ & Michelle \\
\hline $5: 05-5: 15 p$ & Check-in & $\begin{array}{l}\text { Names } \\
\text { Why did you volunteer for } \\
\text { this project? }\end{array}$ & Avonlie \\
\hline $5: 15-5: 45 p$ & $\begin{array}{l}\text { Photovoice } \\
\text { introduction/overview } \\
\text { of process including the } \\
\text { power of visuals and } \\
\text { stories, and how to tell a } \\
\text { story using a photo. }\end{array}$ & $\begin{array}{l}\text { WHAT IS NEEDED FOR } \\
\text { THE INSTRUCTION? }\end{array}$ & Hilary \\
\hline $5: 45-6: 00 p$ & Making collages & $\begin{array}{l}\text { As a way of practicing } \\
\text { photovoice and } \\
\text { introducing ourselves to } \\
\text { the group, we will be } \\
\text { doing collages, and telling } \\
\text { short stories based on the } \\
\text { photovoice instruction } \\
\text { above. } \\
\text {-Five minutes to find } 4-5 \\
\text { images which resonate } \\
\text { with you and help to tell } \\
\text { your story. } \\
\text {-Five to } 10 \text { minutes to put } \\
\text { collage together. }\end{array}$ & Avonlie \\
\hline $6: 00-6: 15 p$ & Sharing collages/stories & Facilitate sharing & Hilary \\
\hline $6: 15-6: 35 p$ & $\begin{array}{l}\text { Ask evaluation } \\
\text { questions }\end{array}$ & $\begin{array}{l}\text {-What did you hear } \\
\text { when you listened to } \\
\text { the stories? Saw the } \\
\text { collages? } \\
\text {-How did you feel? } \\
\text {-Were there any } \\
\text { common themes? - } \\
\text { Different themes? }\end{array}$ & Hilary \\
\hline
\end{tabular}




\begin{tabular}{|c|c|c|c|}
\hline & & $\begin{array}{l}\text { What resonated with } \\
\text { you? }\end{array}$ & \\
\hline $6: 35-6: 45 p$ & $\begin{array}{l}\text { Instruction on how to } \\
\text { take photos of what it's } \\
\text { like to be a middle-aged } \\
\text { women in today's } \\
\text { society on smartphones, } \\
\text { and answer any } \\
\text { questions about how to } \\
\text { take compelling photos } \\
\text { and that tell a story }\end{array}$ & & Hilary \\
\hline $6: 45-6: 50 p$ & $\begin{array}{l}\text { Photovoice process } \\
\text { Preparation for next } \\
\text { week. }\end{array}$ & $\begin{array}{l}\text { Over the next week, } \\
\text { participants take photos } \\
\text { using their smartphones } \\
\text { per instructions above. By } \\
\text { Friday (6/10), they send } \\
\text { Michelle their two favorite } \\
\text { photos to be enlarged. } \\
\text { Please send all the photos } \\
\text { you took to Michelle. } \\
\text { They aren't meant to share } \\
\text { but to be used as data. Be } \\
\text { prepared to tell stories } \\
\text { about your two favorite } \\
\text { photos. } \\
\text { Michelle will contact you } \\
\text { during the week to follow } \\
\text { up. }\end{array}$ & Michelle \\
\hline $6: 50-6: 55 p$ & Discussion & $\begin{array}{l}\text { Distribute three questions: } \\
\text {-what worked during the } \\
\text { session } \\
\text {-what did not work? } \\
\text {-what, if anything, did you } \\
\text { take away from the } \\
\text { session? }\end{array}$ & Avonlie \\
\hline $6: 55-7 p$ & Check out & $\begin{array}{l}\text { Any questions? } \\
\text { One word check out }\end{array}$ & Avonlie \\
\hline \multicolumn{4}{|l|}{ SESSION 2} \\
\hline $3-3: 10 p$ & $\begin{array}{l}\text { Welcome back } \\
\text { Check-in }\end{array}$ & $\begin{array}{l}\text { One round of saying } \\
\text { something to get you } \\
\text { present in the room, and } \\
\text { then any thoughts about } \\
\text { your experience over the } \\
\text { last week }\end{array}$ & Avonlie \\
\hline $3: 10-3: 15 p$ & Distribute two photos to & & Avonlie \\
\hline
\end{tabular}




\begin{tabular}{|c|c|c|c|}
\hline & each participant & & \\
\hline $3: 15-3: 50 \mathrm{p}$ & $\begin{array}{l}\text { Present all images on } \\
\text { the table for display, and } \\
\text { then for each of the } \\
\text { participants }\end{array}$ & Facilitate the presentation & Hilary \\
\hline $3: 50-4: 30 p$ & Ask follow up questions & $\begin{array}{l}\text {-What did you hear } \\
\text { when listening to the } \\
\text { stories and seeing the } \\
\text { photos regarding what } \\
\text { it is like to be a } \\
\text { middle-aged women? } \\
\text {-What were the } \\
\text { common narratives, or } \\
\text { themes, across the } \\
\text { presentations, if any, } \\
\text { you saw or heard? } \\
\text {-How are the stories } \\
\text { related, understood, } \\
\text { misunderstood? } \\
\text {-What were the unique } \\
\text { stories, if any, being } \\
\text { told? } \\
\text {-What could be some } \\
\text { counter narratives to } \\
\text { the photos and stories } \\
\text { being told? } \\
\text {-How do these stories } \\
\text { relate and interact with } \\
\text { other stories, especially } \\
\text { contradictory stories } \\
\text { which have been } \\
\text { indoctrinated into the } \\
\text { consciousness of the } \\
\text { participating women? }\end{array}$ & Hilary \\
\hline $4: 30-4: 45 p$ & $\begin{array}{l}\text { Next photovoice } \\
\text { assignment }\end{array}$ & $\begin{array}{l}\text { Taking photos in the } \\
\text { women's personal and } \\
\text { frequented public spaces } \\
\text { which reflect the stories } \\
\text { and themes which resonate } \\
\text { with them as middle-aged } \\
\text { women }\end{array}$ & Hilary \\
\hline $4: 45-4: 50 p$ & $\begin{array}{l}\text { Photovoice process } \\
\text { Preparation for next } \\
\text { week }\end{array}$ & $\begin{array}{l}\text { Over the next week, } \\
\text { participants take photos } \\
\text { using their smartphones } \\
\text { per instructions above. By }\end{array}$ & Michelle \\
\hline
\end{tabular}




\begin{tabular}{|c|c|c|c|}
\hline & & $\begin{array}{l}\text { Friday }(6 / 17) \text {, they send } \\
\text { Michelle their two favorite } \\
\text { photos to be enlarged. } \\
\text { Please send all the photos } \\
\text { you took to Michelle. } \\
\text { They aren't meant to share } \\
\text { but to be used as data. Be } \\
\text { prepared to tell stories } \\
\text { about your two favorite } \\
\text { photos. } \\
\text { Michelle will contact you } \\
\text { during the week to follow } \\
\text { up. }\end{array}$ & \\
\hline $4: 50-4: 55 p$ & Discussion & $\begin{array}{l}\text { Distribute three questions: } \\
\text {-what worked during the } \\
\text { session } \\
\text {-what did not work? } \\
\text {-what, if anything, did you } \\
\text { take away from the } \\
\text { session? }\end{array}$ & Avonlie \\
\hline $4: 55-5 p$ & Check out & $\begin{array}{l}\text { Any questions? } \\
\text { One word check out }\end{array}$ & Avonlie \\
\hline \multicolumn{4}{|l|}{ SESSION 3} \\
\hline $6-6: 10 p$ & $\begin{array}{l}\text { Welcome back } \\
\text { Check-in }\end{array}$ & $\begin{array}{l}\text { One round of saying } \\
\text { something to get you } \\
\text { present in the room, and } \\
\text { then any thoughts about } \\
\text { your experience over the } \\
\text { last week }\end{array}$ & Avonlie \\
\hline $6: 10-6: 15 p$ & $\begin{array}{l}\text { Distribute two photos to } \\
\text { each participant }\end{array}$ & & Avonlie \\
\hline $6: 15-6: 50 p$ & $\begin{array}{l}\text { Present all images on } \\
\text { the table for display, and } \\
\text { then for each of the } \\
\text { participants }\end{array}$ & Facilitate the presentation & Hilary \\
\hline 6:50-7:50p & Ask follow up questions & $\begin{array}{l}\text {-What did you hear } \\
\text { when listening to the } \\
\text { stories and seeing the } \\
\text { photos regarding what } \\
\text { it is like to be a } \\
\text { middle-aged women? } \\
\text {-What were the } \\
\text { common narratives, or } \\
\text { themes, across the } \\
\text { presentations, if any, } \\
\text { you saw or heard? }\end{array}$ & Hilary \\
\hline
\end{tabular}




\begin{tabular}{|c|c|c|c|}
\hline & & $\begin{array}{l}\text {-How are the stories } \\
\text { related, understood, } \\
\text { misunderstood? } \\
\text {-What were the unique } \\
\text { stories, if any, being } \\
\text { told? } \\
\text {-What could be some } \\
\text { counternarratives to the } \\
\text { photos and stories } \\
\text { being told? } \\
\text {-How do these stories } \\
\text { relate and interact with } \\
\text { other stories, especially } \\
\text { contradictory stories } \\
\text { which have been } \\
\text { indoctrinated into the } \\
\text { consciousness of the } \\
\text { participating women? }\end{array}$ & \\
\hline $7: 50-7: 55 p$ & Discussion & $\begin{array}{l}\text { Distribute three questions: } \\
\text {-what worked during the } \\
\text { session } \\
\text {-what did not work? } \\
\text {-what, if anything, did you } \\
\text { take away from the } \\
\text { session? }\end{array}$ & Avonlie \\
\hline $7: 55-8 p$ & $\begin{array}{l}\text { Check out } \\
\text { Thank you }\end{array}$ & $\begin{array}{l}\text { Any questions? } \\
\text { One round of saying } \\
\text { something }\end{array}$ & $\begin{array}{l}\text { Avonlie } \\
\text { Michelle }\end{array}$ \\
\hline
\end{tabular}




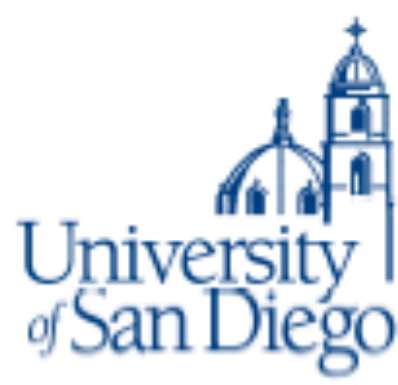

\section{Institutional Review Board Project Action Summary}

Action Date: May 9, 2016

Note: Approval exples one year after ths date.

Type: _ New Ful Revlew _ X_New Expedted Review Continuaton Revlew Exempt Review Modification

Action:

X_Approved

Approved Pending Modincation

Not Approved

Project Number. 2016-05-224

Researcher(s): Michele M. Zlve Grad SOLES

Dr. Robert Donmoyer Fac SOLES

Project Ttie: $\quad$ An Exploration of the Use of Photovolce to Faciltate Narrative Leadership in a Small Group of Middle-Aged Women

Note: We send IRB correspondence regarding student research to the faculty advitor, who bears the uttmate responsibuty for the conduct of the research. We request that the faculty advisor share this correspondence with the student researcher.

\section{Modincations Requlred or Ressons for Non-Approval}

None

The next deadine for submitting project proposals to the Provost's Ombe for full revlew Is N/A. You may submit a project proposal for expedited review at any tme.

Dr. Thomas R. Herrinton

Administrator, Insttutional Revlew Board

University of San Diego

herrintonigsandlego.edu

5998 Alcala Park

San Diego, Callornla 92110-2492 